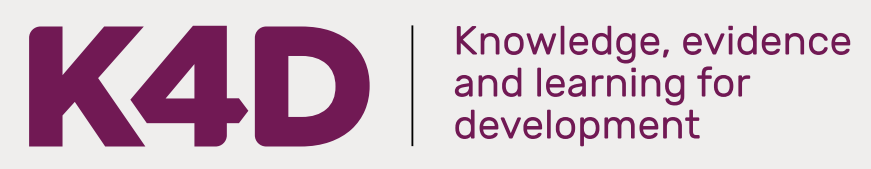

\title{
Education systems for girls' education in the Indo-Pacific region
}

Lorenzo Newman, Alice Pelosi, Giovanni Zino and Silvia Crespi

Education Development Trust and Learn More

Dr Rebecca Gordon

University of Birmingham

September 2021 


\section{About this report}

The K4D Emerging Issues report series highlights research and emerging evidence to policymakers to help inform policies that are more resilient to the future. K4D staff researchers work with thematic experts and the UK Government's Foreign, Commonwealth \& Development Office (FCDO) to identify where new or emerging research can inform and influence policy.

This report is based on 10 days of desk-based research, carried out during July 2021.

$\mathrm{K} 4 \mathrm{D}$ services are provided by a consortium of leading organisations working in international development, led by the Institute of Development Studies (IDS), with the Education Development Trust, Itad, University of Leeds Nuffield Centre for International Health and Development, Liverpool School of Tropical Medicine (LSTM), University of Birmingham International Development Department (IDD), and the University of Manchester Humanitarian and Conflict Response Institute (HCRI).

For any enquiries, please contact helpdesk@k4d.info.

\section{Acknowledgements}

We would like to thank lan MacAuslan, Kate Sims, and Pauline Rose, who provided advice and guidance on the development of this report, and Rebecca Gordon who served as an external expert reviewer.

Finally, we would like to thank Barbara Cheney, who copy-edited this report.

\section{Suggested citation}

Newman, L., Pelosi., A, Zino, G., Crespi, S., \& Gordon, R. (2021). Education systems for girls' education in the Indo-Pacific region. K4D Emerging Issues Report 45. Brighton, UK: Institute of Development Studies. DOI: $10.19088 / K 4 D .2021 .114$

\section{Copyright}

This report was prepared for the UK Government's Foreign, Commonwealth \& Development Office (FCDO) and its partners in support of pro-poor programmes. Except where otherwise stated, it is licensed for noncommercial purposes under the terms of the Open Government Licence v3.0. K4D cannot be held responsible for errors or any consequences arising from the use of information contained in this report. Any views and opinions expressed do not necessarily reflect those of FCDO, K4D, or any other contributing organisation.

(c) Crown copyright 2021.

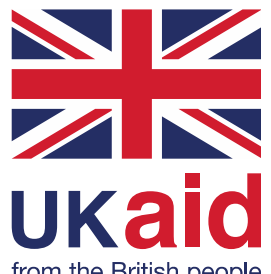




\section{Contents}

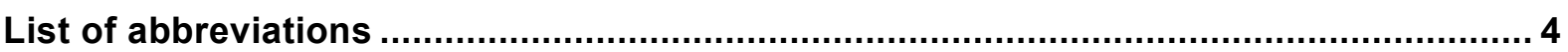

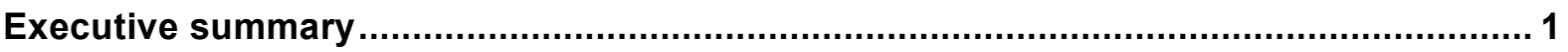

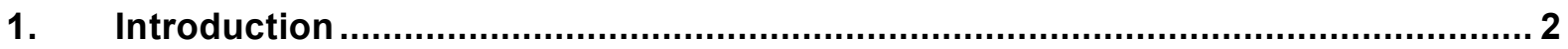

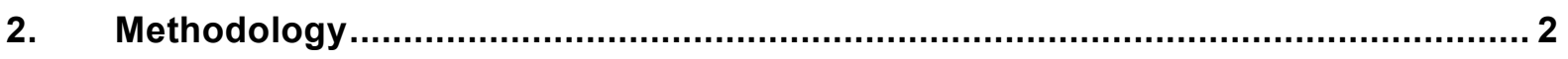

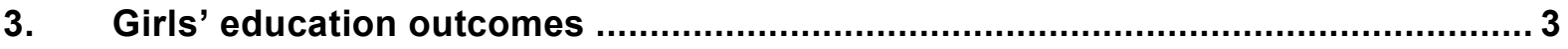

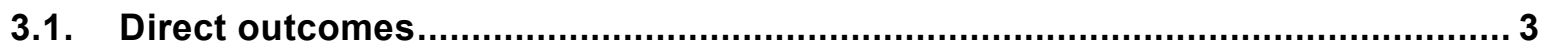

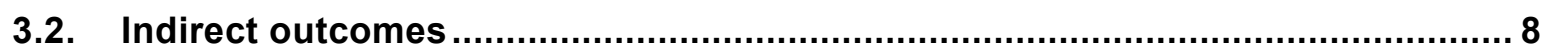

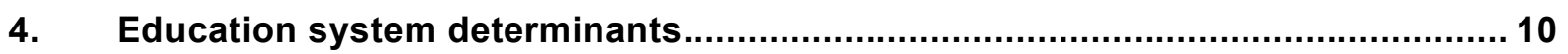

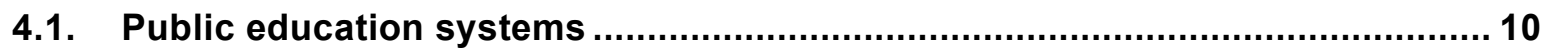

4.2. WASH systems and menstrual hygiene management ................................ 12

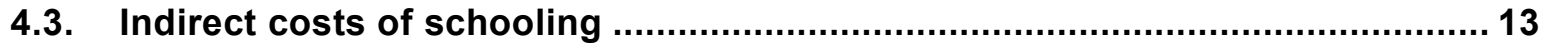

4.4. School-related gender-based violence (SRGBV) .......................................... 14

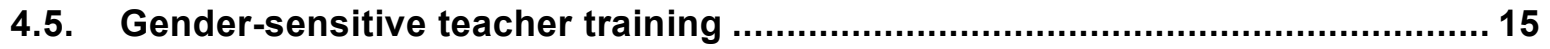

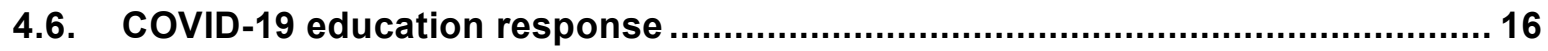

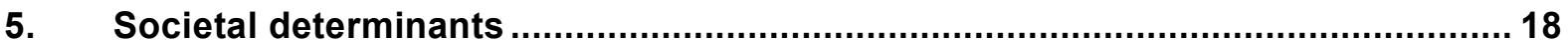

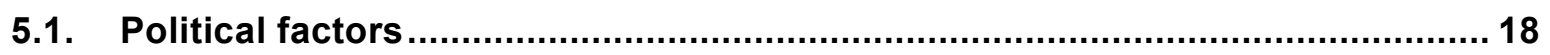

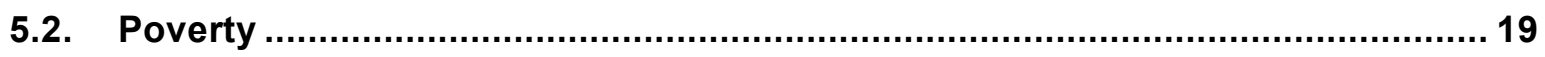

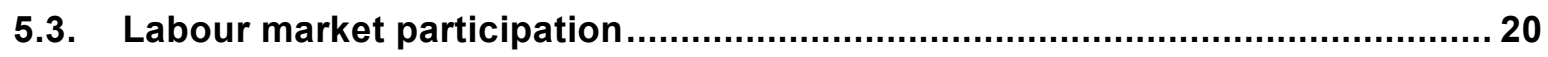

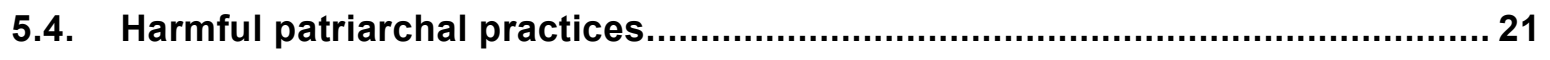

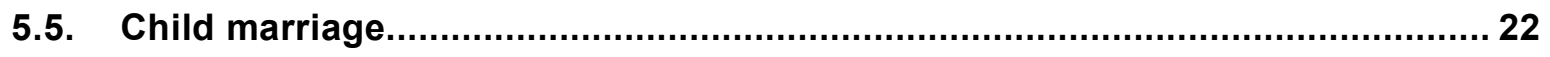

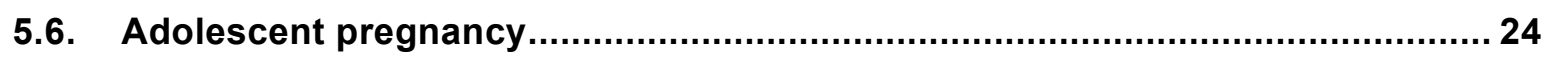

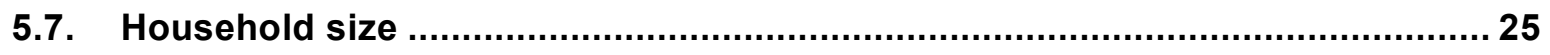

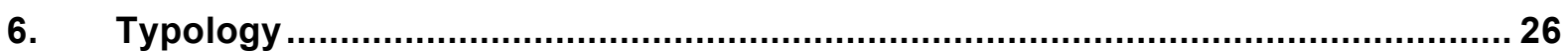

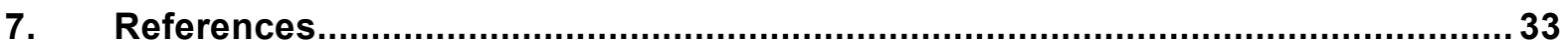

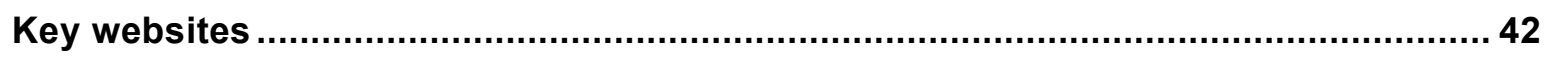

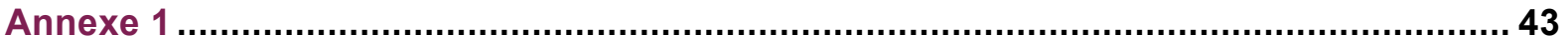

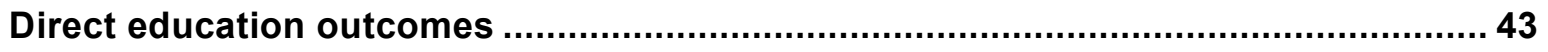

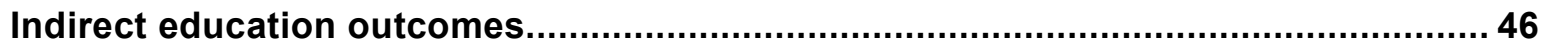

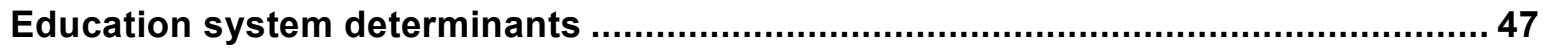

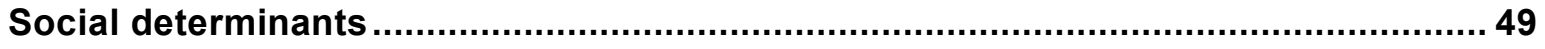

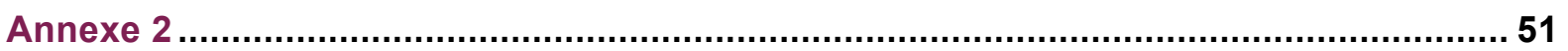

Government policies and plans relating to gender equality in education .................51 


\section{List of abbreviations}

$\begin{array}{ll}\text { ASEAN } & \text { Association of Southeast Asian Nations } \\ \text { FCDO } & \text { Foreign, Commonwealth and Development Office } \\ \text { FGM } & \text { female genital mutilation } \\ \text { GBV } & \text { gender-based violence } \\ \text { GRP } & \text { gender-responsive pedagogy } \\ \text { HLO } & \text { Harmonised Learning Outcomes } \\ \text { ODA } & \text { overseas development aid } \\ \text { PDR } & \text { People's Democratic Republic } \\ \text { RISE } & \text { Research on Improving Systems of Education } \\ \text { SRGBV } & \text { school-related gender-based violence } \\ \text { WASH } & \text { water, sanitation, and hygiene }\end{array}$




\section{Executive summary}

Despite substantial progress over the last two decades, girls in many parts of the world experience worse educational outcomes than boys, particularly at the secondary and tertiary levels. The COVID-19 pandemic appears to have exacerbated this learning gap in many regions, making research on the relationship between girls' education outcomes and education systems increasingly urgent.

This rapid review explores the determinants of girls' education outcomes in a specific group of Indo-Pacific countries. ${ }^{1}$ It examines the education system determinants of these outcomes such as government investment, teacher training, water, sanitation, and hygiene (WASH) infrastructure in schools, school-related gender-based violence, and indirect costs of education, drawing from pre-COVID-19 data. It also investigates societal determinants such as political factors, poverty rates, labour market participation trends, and child marriage rates. By attempting to explain differences in learning outcomes for girls, it also achieves a typology of countries in the region and suggests ideas for further research and FCDO programming.

Malaysia, Thailand, Fiji, and the Philippines have made rapid strides in girls' educational outcomes. However, these countries suffer from bottlenecks preventing young women from accessing tertiary education. This is possibly due to remaining patriarchal practices including child marriage in rural areas and gendered discrimination in the labour market affecting educational aspirations.

South Asian countries feature evidence of above-average education outcomes across most dimensions. However, below-average female literacy, a tertiary bottleneck, and labour market disparities persist, suggesting ample scope for programming and advocacy work. Causes include persistent poverty, chronic education system inefficiencies, school-related gender-based violence, lack of WASH infrastructure, the prevalence of child marriage, high indirect costs of education, and the associated societal burdens these factors place on girls.

Timor-Leste, Myanmar, Papua New Guinea, Lao PDR, and Cambodia feature a unique set of challenges. These geopolitically isolated South-East Asian countries show evidence of poor education outcomes for girls at both primary and secondary levels. Data suggest this is a result of lack of government investment, enduring rural poverty, and harmful patriarchal practices. Afghanistan and Pakistan present similar challenges on a much greater scale.

By contrast, Singapore, Japan, and increasingly also Viet Nam and China, are leaders across all measures of education outcomes, despite the persistence of patriarchal social norms. Pockets of extreme poverty in China influence poor learning outcomes for girls but these are harder to account for in a comparative analysis.

Drawing on the RISE framework of determinants and proximate determinants within education and political economy systems, this report presents key factors and considerations that determine learning outcomes across all levels of education systems. It will consider how to best

\footnotetext{
${ }^{1}$ For the purposes of this analysis, the countries included in the "Indo-Pacific region" are Afghanistan, Bangladesh, Bhutan, Cambodia, China, Fiji, India, Indonesia, Japan, Lao PDR, Malaysia, the Maldives, Myanmar, Nepal, Pakistan, Papua New Guinea, Philippines, Singapore, Sri Lanka, Taiwan, Thailand, Timor-Leste, and Viet Nam.
} 
contribute to girls' education in the region and engage with the education systems, including in countries where there has been little or no overseas development aid expenditure to date.

\section{Introduction}

Despite substantial progress over the last two decades, in many countries girls still have lower levels of educational attainment than boys, especially at the secondary and tertiary level. Together with occupational segregation and social norms that prevent women from taking full advantage of labour market opportunities, this leads to large gaps in earnings between men and women (World Bank, 2020). In addition, low educational attainment for girls has potential negative impacts on a wide range of other development outcomes not only for the girls themselves, but also for surrounding children, families, communities, and societies (Wodon, Montenegro, Nguyen, \& Onagoruwa, 2018).

The COVID-19 pandemic is aggravating chronic challenges facing girls' education. Across East Asia and the Pacific, the number of girls out of school is expected to increase by nearly $10 \%$, with at least 1.2 million additional girls at risk of dropping out of school. According to the joint initiative among Girls' Education Challenge and UNICEF Gender and Education Sections "Leave No Girl Behind" (Attfield, Henderson, \& Abdurazzakova 2021), trends in South Asia are similar; in Nepal, due to school closures, the percentage of girls not re-engaging in education after lockdowns could reach as high as $50 \%$. However, due to data constraints, the statistics presented in this report do not explicitly account for the pandemic, except for evidence shared in a section dedicated to the topic.

This report provides an overview of education outcomes for girls in the Indo-Pacific region. ${ }^{2}$ It explores determinants within education systems and society which explain girls' education outcomes, including in comparison to boys' outcomes. Section 2 presents the methodology for this report.

Section 3 reports on the education outcomes in the region, distinguishing between girls' learning outcomes most directly linked to primary and secondary education systems and indirect outcomes seen in tertiary education and employment. Measures investigated mainly include both absolute and relative measures of girls' enrolment and learning outcomes.

Section 4 assesses the education system determinants of these outcomes. It focuses on governments' overall commitment to education, the role of water, sanitation, and hygiene (WASH) in schools, indirect costs of learning, gender-sensitive teacher training, and the effects of the COVID-19 pandemic on learning outcomes.

Section 5 evaluates the social, economic, and cultural determinants of these education outcomes, focusing on political factors at the national level, and on societal dynamics such as school-related gender-based violence (SRGBV), child marriage, household size, adolescent pregnancy rates, female labour market participation rates, and poverty.

This research culminates in Section 6, which presents a typology of countries drawing on the literature around learning outcomes and the regional literature, and attempts to explain these

\footnotetext{
${ }^{2}$ For the purposes of this analysis, the countries included in the "Indo-Pacific region" are Afghanistan, Bangladesh, Bhutan, Cambodia, China, Fiji, India, Indonesia, Japan, Lao PDR, Malaysia, the Maldives, Myanmar, Nepal, Pakistan, Papua New Guinea, Philippines, Singapore, Sri Lanka, Taiwan, Thailand, Timor-Leste, and Viet Nam.
} 
outcomes. The data analysis and statistics that informed this report can be found in the Annexes and are also available as a navigable MS Excel tool.

\section{Methodology}

This research investigates the determinants of girls' education outcomes in the Indo-Pacific region by reviewing existing quantitative and qualitative evidence. It does not seek to comprehensively explain these trends, but to provide fresh insight by establishing a country typology based on girls' education outcomes. We employ mostly quantitative data to compare education outcomes and education system determinants. As quantitative data are less readily available to compare societal determinants, the report utilises child marriage rates as a proxy of harmful patriarchal practices and SRGBV, finding a strong correlation with poor education outcomes for girls at every level. Due to the paucity of publicly available longitudinal data, this report does not examine girls' educational outcomes over time; future research should prioritise investigating how these trends have and will evolve over time, potentially utilising learning profiles (Silberstein, 2021). Additionally, all data are pre-pandemic except for evidence presented in Section 4.6 on the impact on COVID-19.

The brief for this research called for an analysis of girls' education outcomes overall. Following an early review of secondary sources, we chose to distinguish between direct education outcomes such as primary and secondary learning outcomes and indirect education outcomes including tertiary completion and labour market success. This allowed us to build a typology of countries distinguishing between contexts in which direct education outcomes are of most concern and those where indirect education outcomes are the most pressing issue.

We also revised our use of the Research on Improving Systems of Education (RISE) framework. Normally this approach calls for a systemic analysis of education pathways and trends, typically distinguishing between proximate and indirect determinants of education outcomes. In this research, we identified strong feedback loops between education system determinants that made it harder and potentially overly simplistic to draw this distinction. Furthermore, the principal-agent issues for which the RISE approach is typically deployed are harder to explore in this research, which relies on a limited set of secondary sources and cannot tackle the question of policy versus implementation in great depth over such a large sample of vastly different countries.

Therefore, we employ a distinction between education and societal determinants, the interplay of which ultimately affects girls' education outcomes at school and beyond. Figure 1 summarises this conceptual model. This choice was particularly useful as these two categories of determinants clearly affect direct education outcomes and indirect education outcomes in different ways, as summarised in Section 6 on the typology. 
Figure 1. Analytical model for analysing the determinants of girls' education outcomes

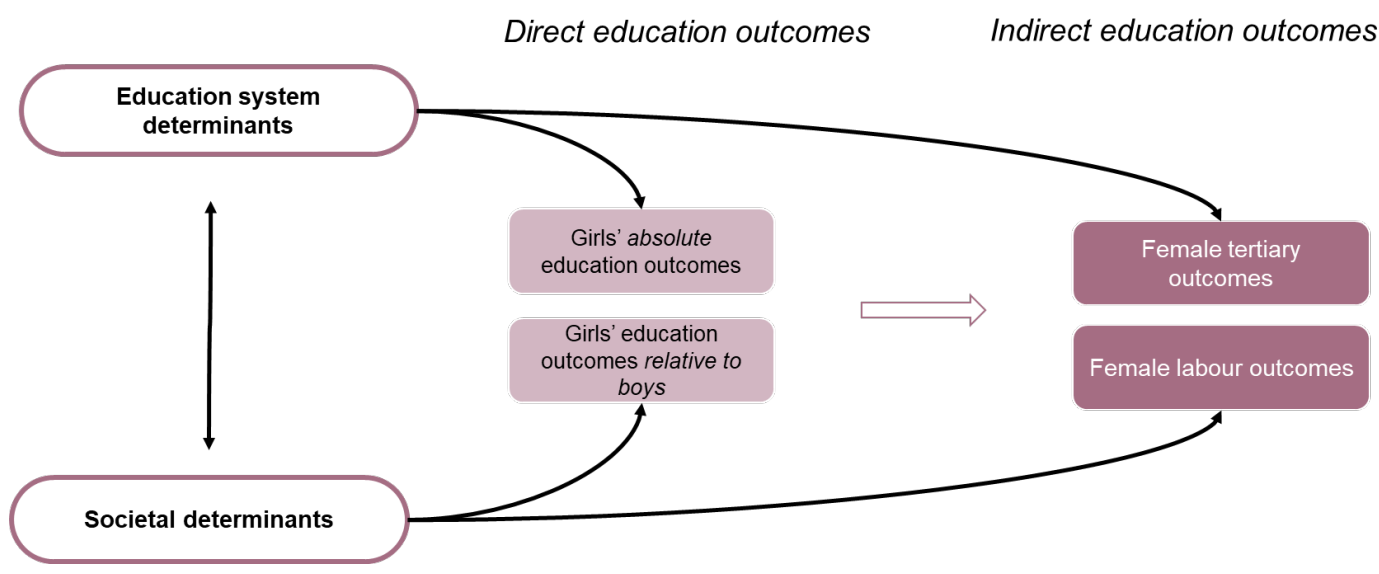

Source: Authors' own.

\section{Girls' education outcomes}

\subsection{Direct outcomes}

In this report, we utilise three indicators of girls' direct education outcomes: school completion rates, female literacy rates, and learning outcomes.

\section{Girls' absolute education outcomes}

Primary school completion rates are high across the region, totalling over $90 \%$ for girls in all countries except for Papua New Guinea and Pakistan. ${ }^{3}$ However, secondary level completion rates are less than $50 \%$ in Afghanistan and Pakistan in particular, and range between $68 \%$ and $54 \%$ in Papua New Guinea, Cambodia, Myanmar, and Lao PDR. Once more, this correlates strongly with other negative education outcomes such as girls' literacy. Completion rate data track out-of-school girls almost perfectly.

Female literacy rates show signs of great progress, except for Afghanistan with only $30 \%$ of literate girls being over 15 years old. Only Bangladesh, Bhutan, Cambodia, Lao PDR, Nepal, India, Timor-Leste, Pakistan, Myanmar, and Papua New Guinea - all countries with lower learning outcomes for girls - have female literacy rates below $80 \%$. However, rates are $90 \%$ or more in all but three of these countries if we restrict our sample to women aged 24 or less, suggesting that the conditions for continued progress are in place. Timor-Leste, Myanmar, and Papua New Guinea have lower female literacy rates, indicating that literacy improvements should be prioritised as a policy and possibly programmatic priority in these contexts.

Girls' learning outcomes, both in terms of expected and learning-adjusted years of schooling, ${ }^{4}$ are lowest in the Indo-Pacific's smaller and more geopolitically isolated countries: Afghanistan, Bhutan, Cambodia, Lao PDR, Myanmar, Pakistan, and Papua New Guinea (see Figure 2). These countries also have the highest percentage of girls dropping out of

\footnotetext{
${ }^{3}$ Here and elsewhere, we exclude countries from our analysis if data are from 2011 or earlier.

${ }^{4}$ These and other indicators highlighted in bold are shown in the summary statistics tables (Direct education outcomes) in Annexe 1 and in the attached MS Excel tool.
} 
secondary education, except for Bhutan and Timor-Leste where there have been significant improvements in school retention in recent years despite struggles across other dimensions of their education systems. Female literacy rates are also lowest in this group of countries, suggesting that outcomes across these dimensions of educational outcomes are strongly interlinked.

Figure 2: Learning-adjusted years of schooling for girls (2020)

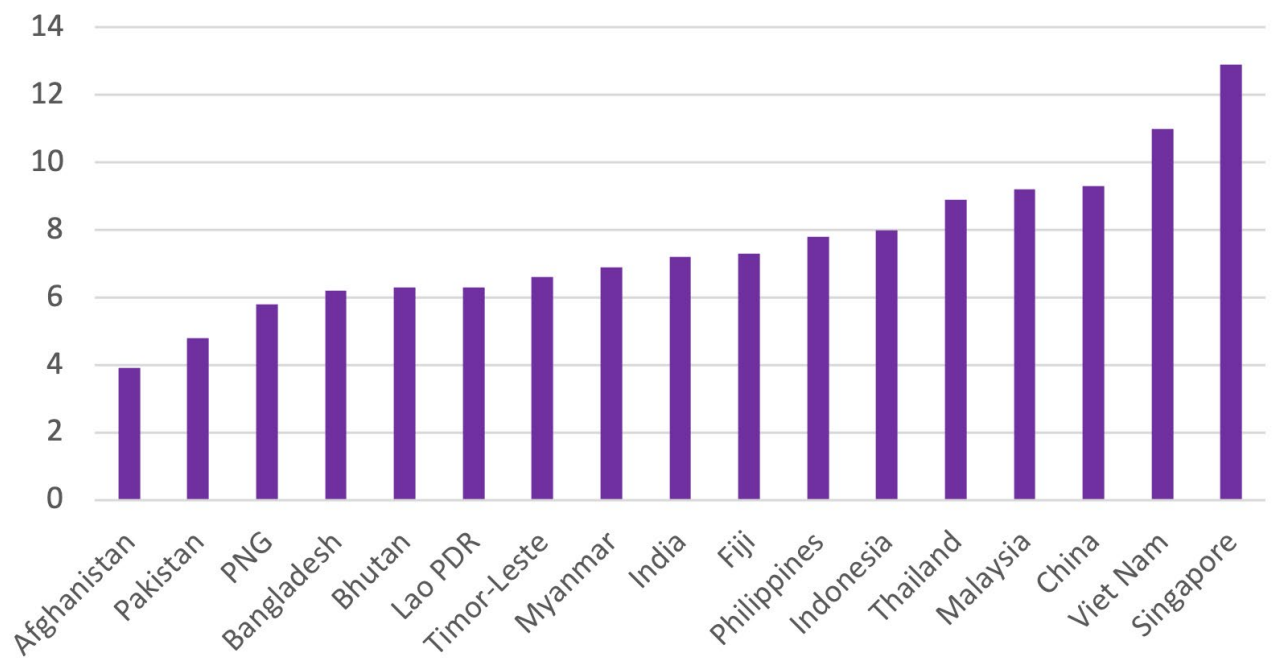

Source: World Bank (n.d.,b).

Similar trends are noted when comparing girls' Harmonised Learning Outcomes (HLO) in the region where data were available. As demonstrated by Figure 3, girls' HLO scores for reading at primary level are lowest in Pakistan, Afghanistan, Papua New Guinea, Bangladesh, Lao PDR, and Timor-Leste. These countries also have a higher percentage of out-of-school children in the region. School completion rates, however, appear not be greatly correlated with lower HLO scores.

Figure 3: Girls' Harmonised Learning Outcome scores for reading by country

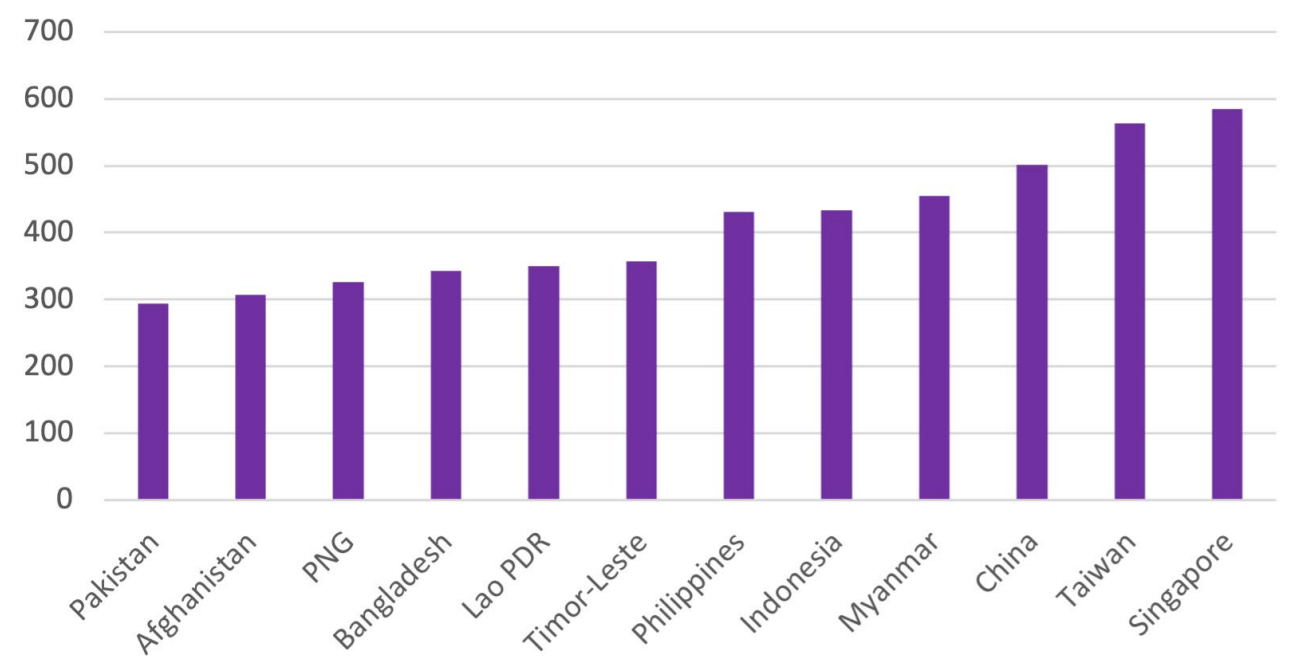

Source: World Bank Harmonized Learning Outcomes (HLO) Database (Angrist et al., 2021b). 
Countries in the region with higher HLO scores for girls' reading at the primary level include China, Japan, and Singapore. Viet Nam also scores highly for girls' reading at the secondary level. Among these countries, those participating in the PISA ${ }^{5}$ test 2018 were among the highest scorers in reading and had among the highest high school completion rate too, both at primary and secondary level. Countries where girls have higher HLO scores also have tertiary enrolment rates for girls between $58 \%$ to $95 \%$.

\section{Girls' relative education outcomes}

However, girls' learning outcomes in absolute terms are only partially informative, whilst comparing learning outcomes between girls and boys can reveal useful information on girls' relative education outcomes. This so-called "gender gap" also varies more significantly than absolute measures depending on the indicator employed.

Low rates of girls' school completion in absolute terms - particularly at the secondary level remain one of the most concerning issues in the region; however, they are high when measured relative to boys. Only in Afghanistan, the Maldives, Pakistan, Papua New Guinea, and Lao PDR are boys' completion rates significantly higher than those of girls. In Timor-Leste, Cambodia, the Philippines, Bangladesh, and Bhutan, girls are on average ten percentage points, or more, likely to complete secondary school. However, girls' relative school completion does not correlate in any obvious way with a country's income level as measured by gross domestic product (GDP) per capita or geographic location, suggesting the influence of both local contextual factors and national political factors. Many of these countries have also experienced a strong push to prioritise girls' school enrolment and completion, but further analysis to explore whether this has occurred at the expense of learning outcomes would be beneficial.

In terms of learning outcomes, by many metrics, girls achieve higher learning outcomes than boys in the region. Through exploring differentials in learning-adjusted years of schooling (see Figure 4), girls outperform boys in all countries for which there are data except for Afghanistan, Pakistan, and Papua New Guinea. This achievement gap is greatest in Bangladesh, Indonesia, Thailand, Malaysia, the Philippines, Timor-Leste, Viet Nam, and Fiji, all countries where girls perform best in absolute terms too.

Figure 4: Learning-adjusted years of schooling by gender (2020)

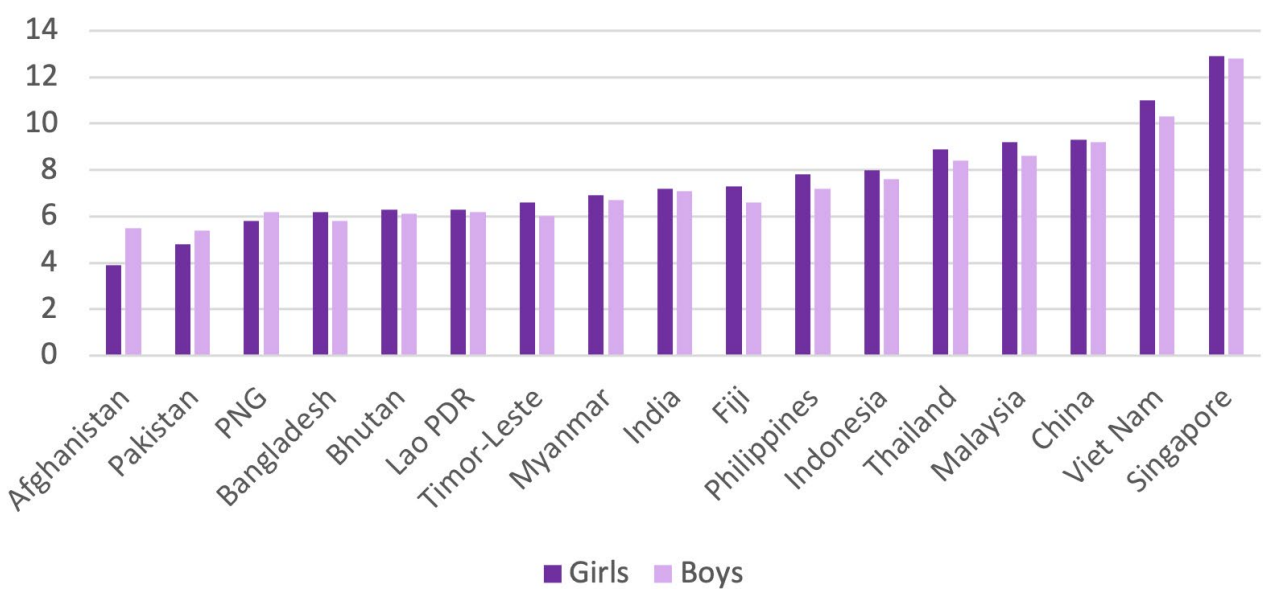

Source: World Bank (n.d., a).

\footnotetext{
5 The Programme for International Assessment (PISA) is an international assessment that measures 15year-old students' reading, mathematics, and science literacy every three years. https://www.oecd.org/pisa/
} 
Using the HLO database enables comparisons of learning progress across the world and by gender. As demonstrated in Figure 5, girls' HLO scores for reading at the primary level are also generally higher than for boys in the region, except for in Afghanistan, with girls' overperformance in Timor-Leste and the Philippines being especially large.

Figure 5: Harmonised Learning Outcomes for reading by gender

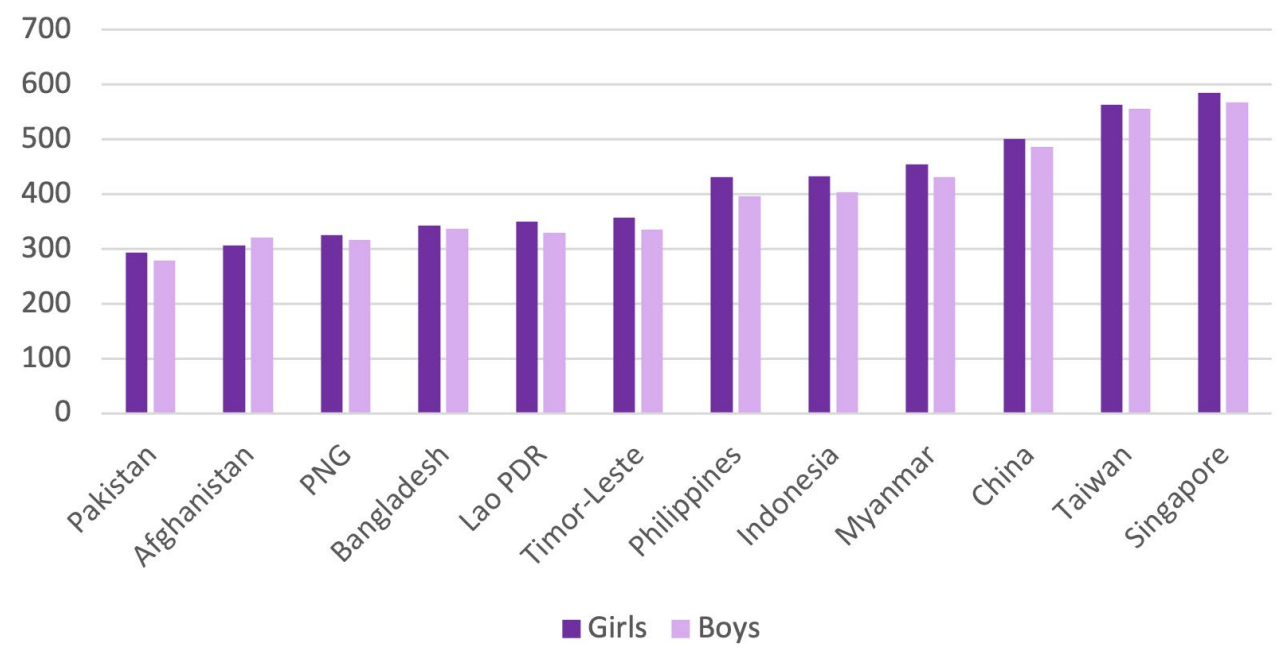

Source: World Bank Harmonized Learning Outcomes (HLO) Database (Angrist et al., 2021b).

Differentials in PISA scores, though available in only a few of the countries analysed, help paint a more nuanced picture of education outcomes overall. As Figure 6 demonstrates, girls outperform boys in reading assessments for countries with data.

Figure 6: PISA reading scores by gender (2018)

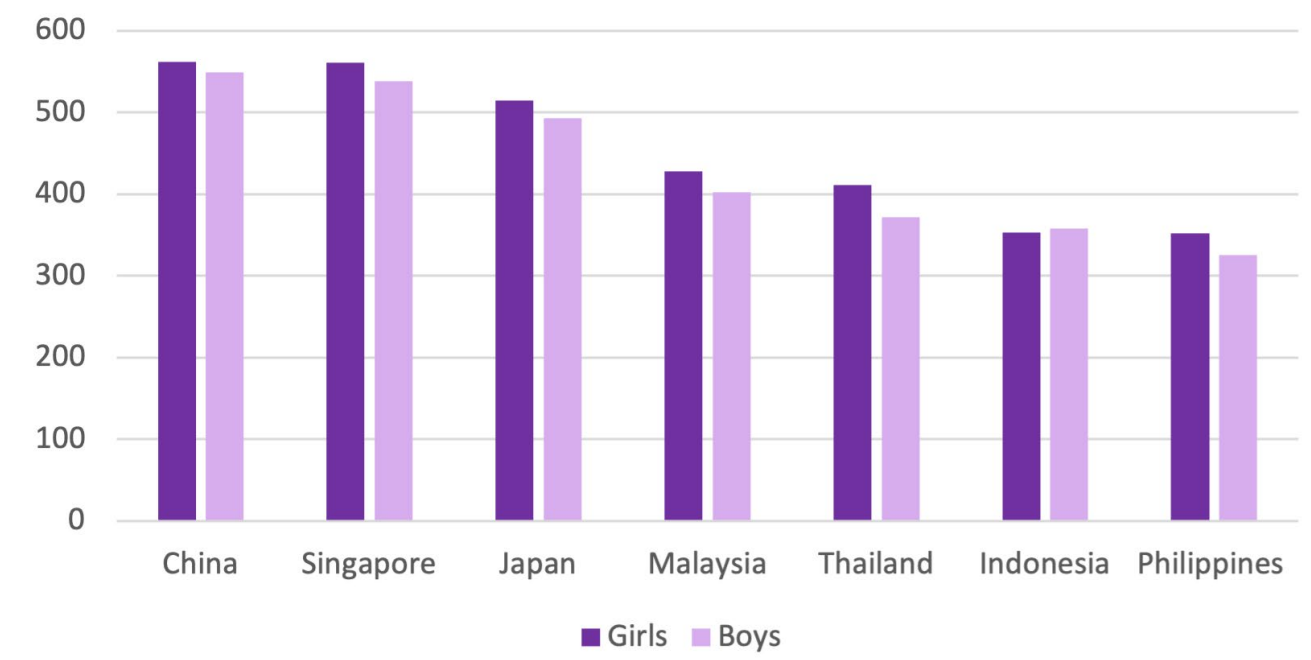

Source: OECD (2019).

However, boys outperform girls in maths and science in high-income countries including China, Singapore, and Japan, despite performing worse in reading assessments. Girls score higher than boys in all subjects in Indonesia, the Philippines, Malaysia, Sri Lanka, and Thailand. These are mostly countries where girls' learning outcomes, at least in terms of learning-adjusted years of schooling - a synthetic indicator that includes achievement - is 
on par with boys or higher, indicating that girls' learning outcomes can correlate with school completion.

Overall, this analysis demonstrates that countries with the most positive education outcomes for girls across all indicators are more likely to be high- and upper-middle-income countries in the Indo-Pacific: Japan, China, Singapore, Viet Nam, the Philippines, Thailand, Malaysia, and Indonesia, as well as Sri Lanka and the Maldives. However, this analysis is limited by a lack of up-to-date data in several countries, particularly Nepal and Bangladesh. Citizen-led assessments in both these countries, and in Pakistan and India, also provide an important indication of girls' education outcomes compared to boys. For example, the most recent Annual Status of Education Report (ASER) in India ${ }^{6}$ demonstrates that the proportion of out-of-school children is the same for girls and boys at the primary level, and the overall proportion of children out of school has increased since 2018. The ASER Centre has also been at the forefront of demonstrating the disparities between girls' and boys' learning outcomes in rural areas, which is not always captured by national-level assessments such as PISA. Thus, where available, citizen-led assessments have the potential to provide more in-depth insight into the disparities in girls' learning outcomes in comparison to boys in these contexts.

${ }^{6}$ https://www. asercentre.org/ 


\subsection{Indirect outcomes}

Girls' relative learning outcomes at the primary and secondary level often fail to translate to continued growth in tertiary education or in employment

\section{Tertiary education}

Across the region, young women are more likely to enrol in tertiary education than men (see Figure 7). This is particularly true in high-income countries such as Japan and Singapore, and in Malaysia, Thailand, and the Philippines, and smaller South Asian countries such as the Maldives and Sri Lanka. In Japan, Singapore, the Maldives, China, Thailand, Malaysia, and the Philippines, tertiary enrolment rates are significantly higher for women (above $40 \%$ ) than men (above 17\%).

Figure 7: Gross enrolment ratio, tertiary, gender parity index (gender parity is defined as between 0.97 and 1.30)

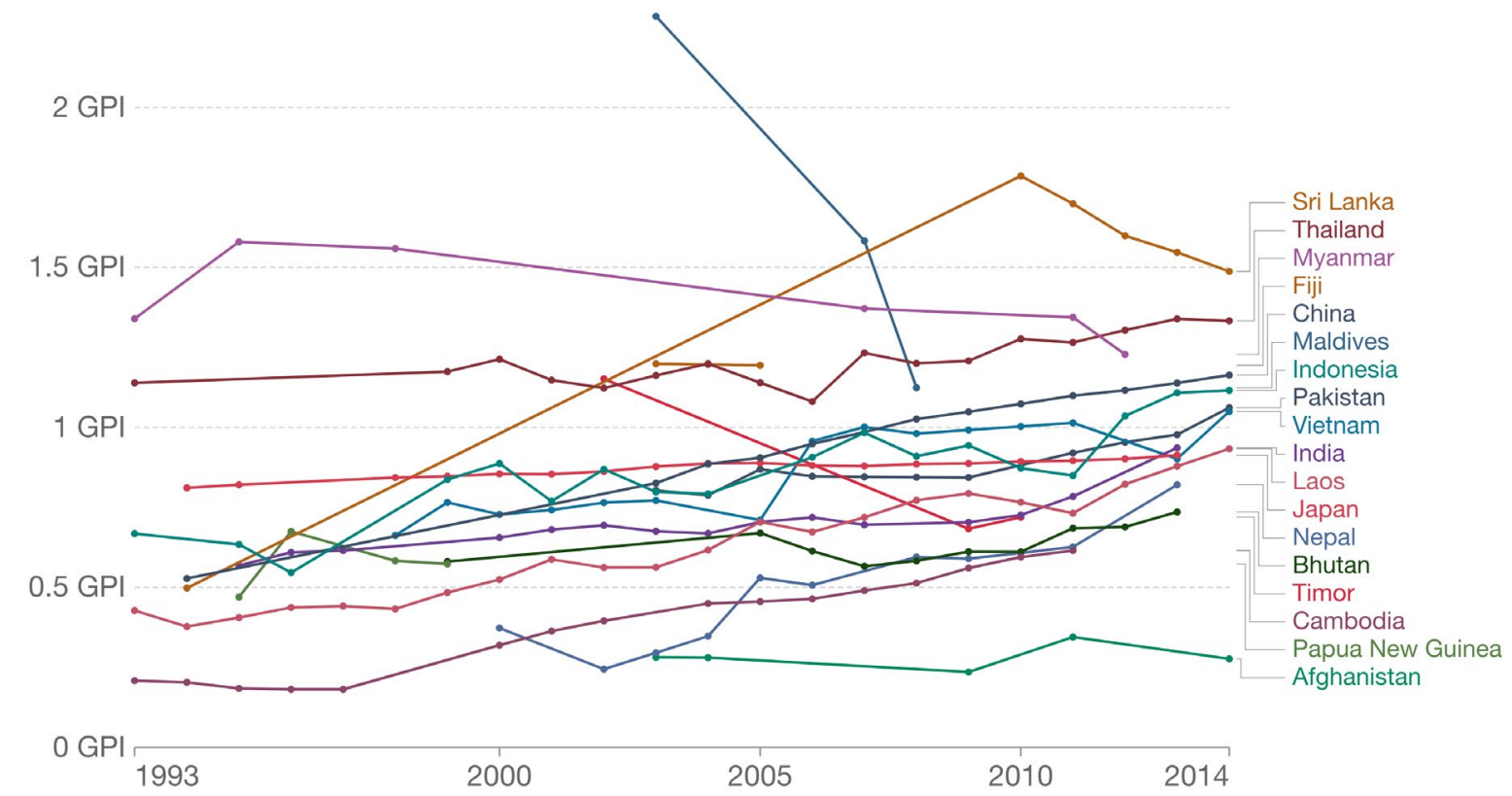

Source: Our World in Data CC BY (Roser \& Ortiz-Ospina, 2013).

In the rest of South Asia and in South-East Asian countries such as Lao PDR and Cambodia, girls' and boys' enrolment rates are broadly similar. However, in Bangladesh and Afghanistan, young women's enrolment at the tertiary level is significantly lower.

Completion trends tell a different story, suggesting that the greatest obstacles to girls' education outcomes in many contexts often manifest themselves during their university years. Women's educational attainment in tertiary education varies a lot across the region. In Singapore, Japan, the Philippines, Sri Lanka, and Malaysia, girls' completion rates range between $20 \%$ and 44\%. However, in Fiji, Bhutan, Timor-Leste, Lao PDR, Nepal, Cambodia, and Papua New Guinea, completion can be as low as $2.5 \%$. Other countries lie somewhere in between, but for all countries these differ from men's completion rates. This drop-off is even greater in the smaller, lower-income, and more geographically isolated countries where female enrolment is below $20 \%$. 
Tertiary education completion figures are even more concerning when we examine differentials between young women and men. The Philippines, Malaysia, and Thailand are the only countries for which recent data are available where women are significantly more likely to complete university than men. Women are five percentage points, or less, likely than men to complete university in all South Asian countries apart from in Sri Lanka and the Maldives.

\section{Employment}

In many contexts having a degree does not guarantee future employment, especially for young women. Afghanistan, Bhutan, India, and Bangladesh have the highest rates of unemployed women with advanced education, ranging between $31 \%$ and $21 \%$. Japan, Singapore, the Philippines, and Thailand have the highest female educational attainment rates in tertiary education and therefore are likely have low rates of unemployment for women with higher education, averaging $7 \%$ or less.

Comparisons with men's employment outcomes are stark. In India, Bangladesh, Sri Lanka, and Nepal, between $12 \%$ and $29 \%$ of unemployed women hold advanced education in comparison to $4 \%$ to $13 \%$ of men. Great differentials between the percentages of unemployed men with advanced education in these countries suggest significant gender discrimination during the hiring stages.

More generally, labour market participation rates vary widely across the region, particularly for women aged 15-24. In Bhutan, the Philippines, Bangladesh, Fiji, Sri Lanka, and India, rates fluctuate between $10 \%$ and $32 \%$. Rates are between $41 \%$ and $78 \%$ in Japan, China, and Singapore as well as Nepal - where male emigration to India has led to higher female employment - Cambodia, Lao PDR, and Viet Nam. Correlations with income per capita and other variables are not apparent, suggesting that highly contextual cultural and education system-related determinants are involved. 


\section{Education system determinants}

As we have seen, one of the most intractable problems in many parts of the Indo-Pacific region is the reversal of fortunes experienced by girls between secondary school, which they may complete, and tertiary education and the labour market, where they are less likely than men to succeed (ILO, 2018). However, it is worth asking why girls outperform boys so frequently in the first place. In other contexts, girls' higher educational attainment is often attributed to a mix of cognitive, cultural, and institutional differences. Therefore, girls' relatively strong academic achievement may partly be interpreted as a sign of normality, or convergence with global trends.

\subsection{Public education systems}

Some researchers have argued that governments which invest the most in education are more likely to see better educational outcomes for girls. However, spending on education varies dramatically across the region (see Figure 8 ).

Figure 8: Government expenditure on education (\% of GDP), 1971 to 2017

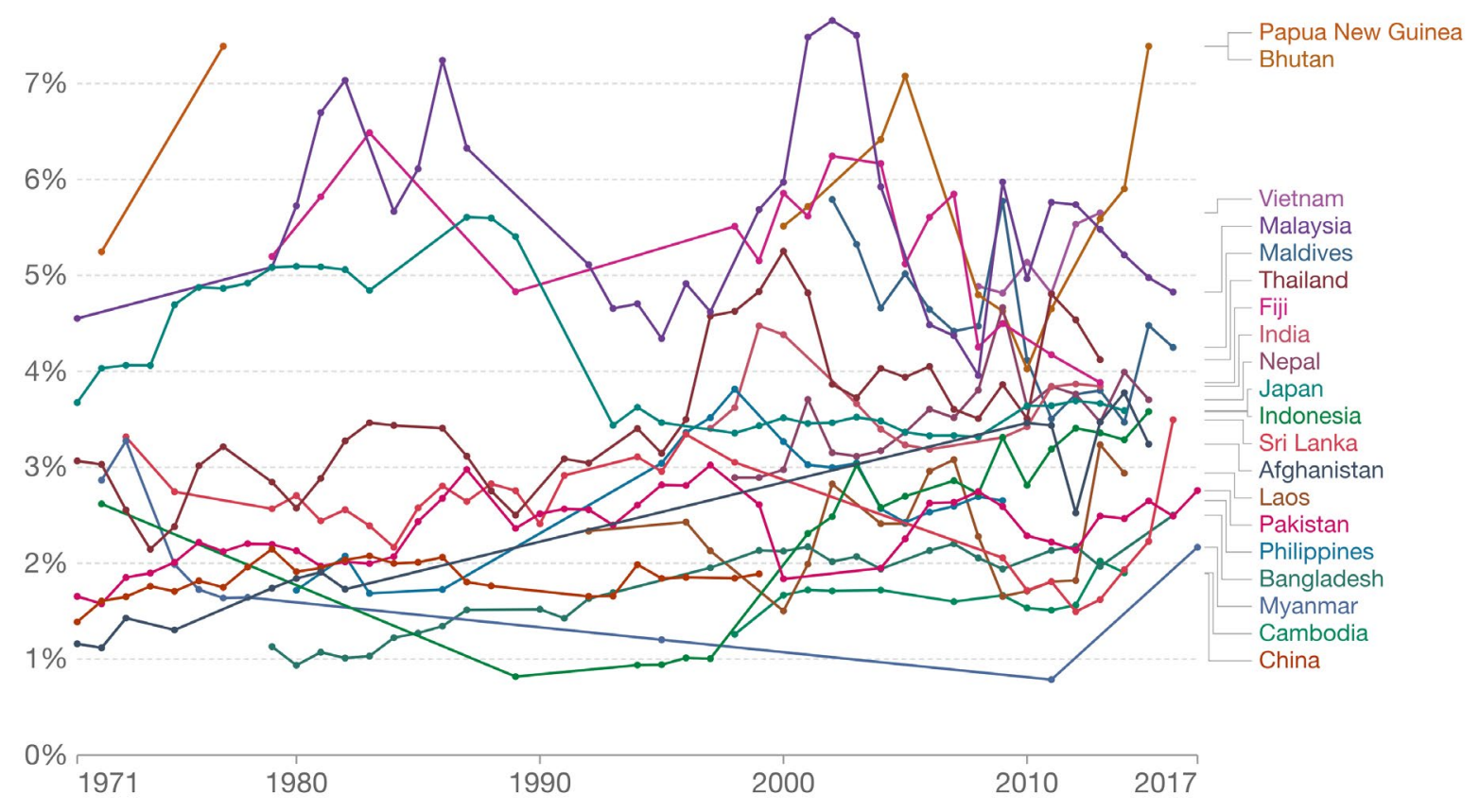

Source: Our World in Data CC BY (Ortiz-Ospina, \& Roser, 2016).

In some countries, figures for government expenditure in education are surprisingly poorly correlated with girls' relative and absolute education outcomes. On the one hand, these figures show how gender and social norms are still sources of educational inequality. On the other hand, they demonstrate that increasing government expenditures are not sufficient to achieve gender equity (Emara \& Hegazy, 2017). Absolute expenditure figures also defy straightforward categorisations of countries' income or pace of growth and development. Timor-Leste, Bhutan, Nepal, Viet Nam, and Afghanistan's governments each invest between $4.1 \%$ and $6.9 \%$ of their global GDP on education. Meanwhile, Bangladesh, Myanmar, Papua New Guinea, and Sri Lanka's governments invest less than $2.1 \%$ of their GDP. 
Government expenditure also varies across the region on a per student basis (see Figure 9). Japan, Malaysia, and Sri Lanka spend the most across both primary and secondary levels, between $22 \%$ up to $24 \%$ of GDP per capita per student. There is also variation within countries; for example, Bhutan spends $34 \%$ at the secondary level but only $13 \%$ at the primary level. Among the countries which allocate fewer resources are: Cambodia with $7 \%$ of GDP per capita per student at the primary level, Fiji with $6 \%$ both at primary and secondary level as well as Timor-Leste at $8 \%$. Other countries generally invest between $10 \%$ and $20 \%$.

Figure 9: Government per primary school student vs. GDP per capita

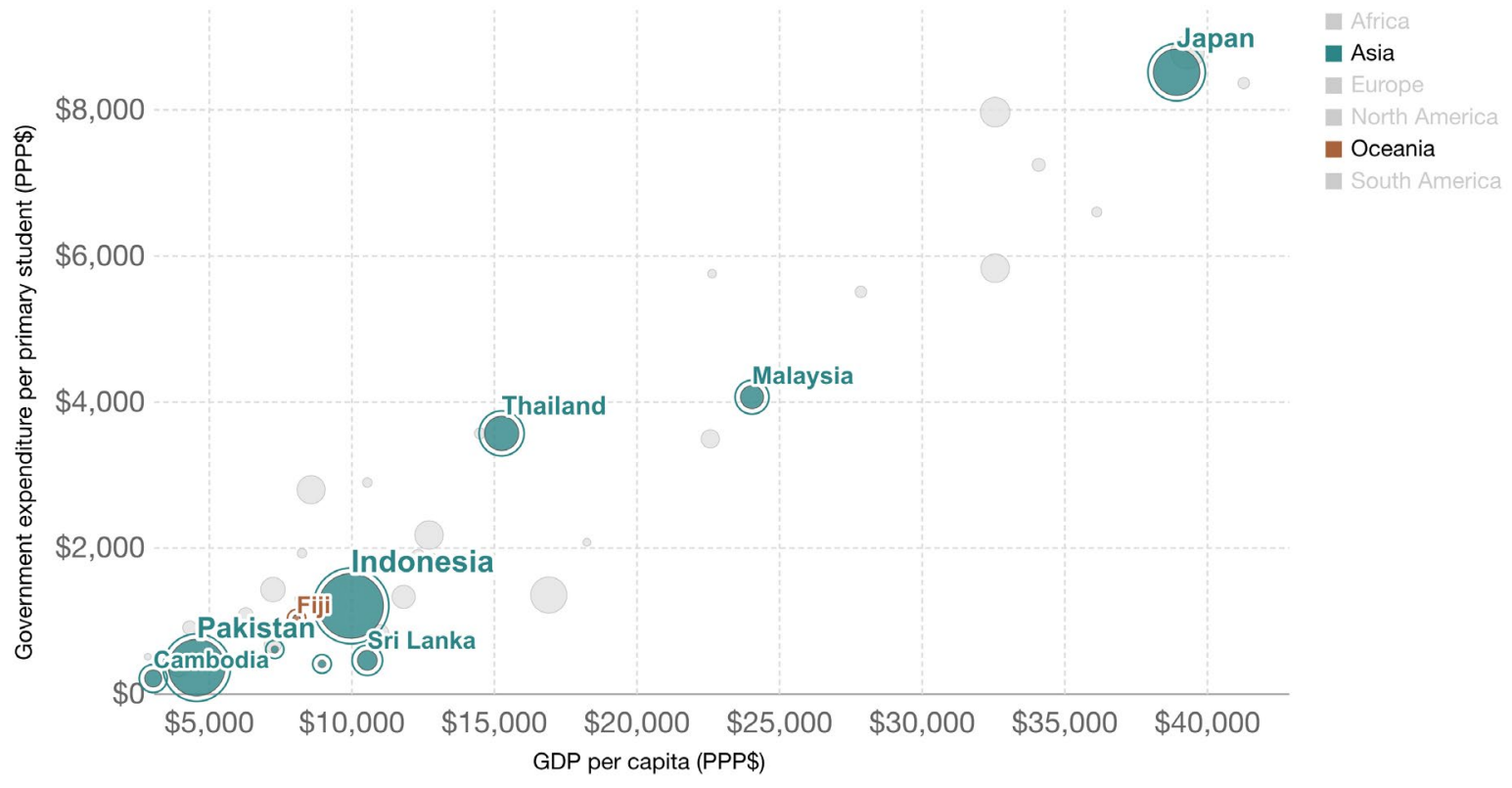

Source: Our World in Data CC BY (Roser \& Ortiz-Ospina, 2016).

Expenditure per student can correlate with learning outcomes, at least for outliers. Japan, Malaysia, and Sri Lanka have high HLO and PISA scores, as well as high learning-adjusted years of schooling, high completion rates, and low levels of out-of-school children. Cambodia, Fiji, and Timor-Leste score low on HLO and other metrics and have low education investment per student. In the middle of the pack, however, countries average similar figures in terms of expenditure per student while ranging widely in terms of learning outcome indicators, suggesting that ultimately quality of investment trumps quantity.

There are rising rates of enrolment in private educational institutions in South Asia in particular (see Figure 10). For example, in India there are rising levels of private school enrolment, particularly in rural areas, with $20 \%$ of boys and $16 \%$ of girls enrolled in private schools (Chudgar \& Creed, 2014). Private tuition has also increased and in some Indian states, over $50 \%$ of students reported receiving out-of-school private tuition (ASER Pakistan, 2013). This has important implications for education quality, but also for girls' education in contexts where spending on education is gendered (Datta \& Kingdon, 2019). 


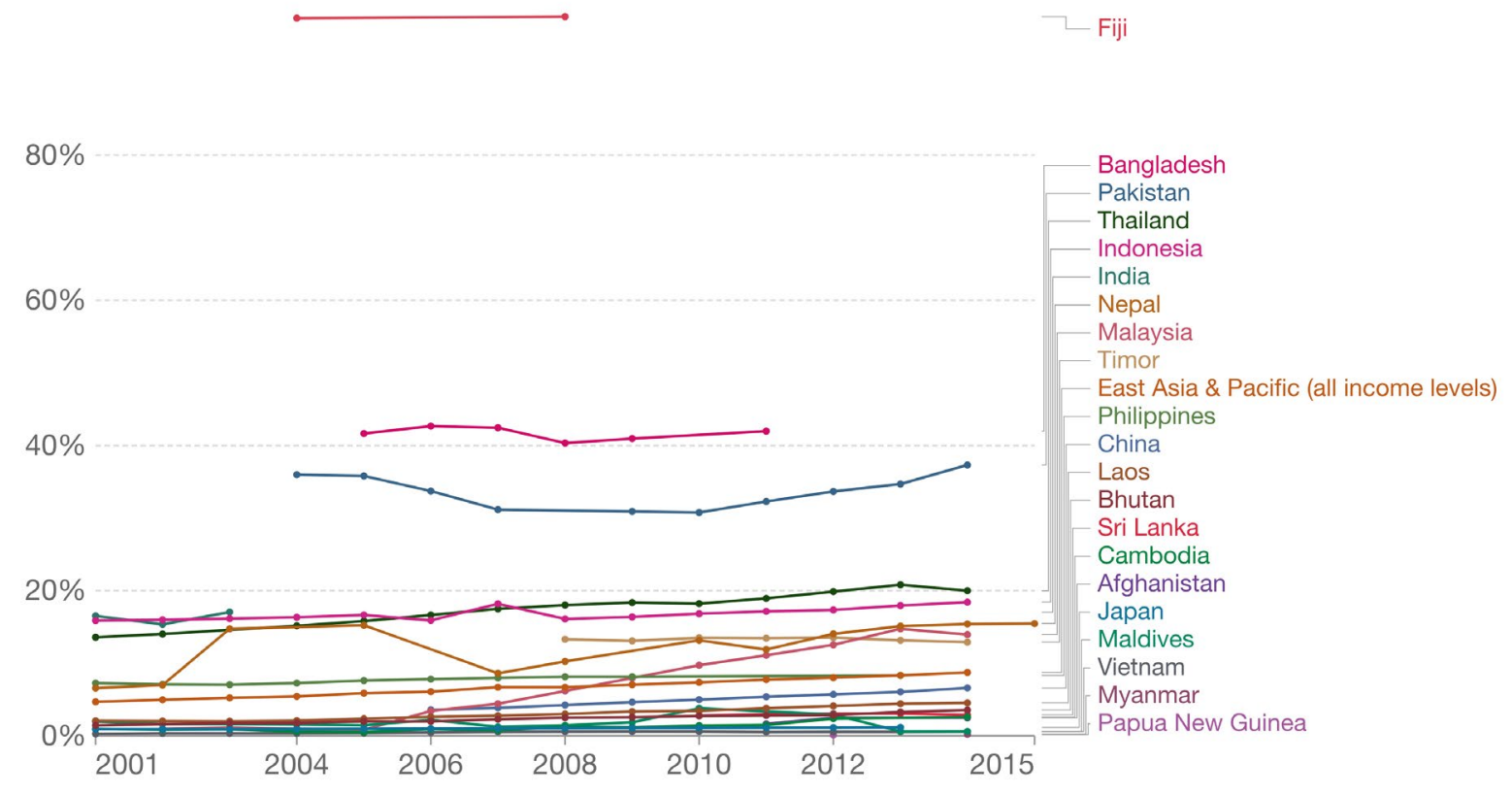

Source: Our World in Data CC BY (Roser \& Ortiz-Ospina, 2013).

Teacher-pupil ratios are generally a strong determinant of educational achievement and attainment (Jurus \& Musine, 2012). Countries with over 25 pupils per teacher at the secondary school level in our sample are Bangladesh, Papua New Guinea, Cambodia, India, Viet Nam, Nepal, Timor-Leste, Myanmar, and Thailand, a list that includes all the worst performers in terms of girls' education outcomes, but also countries that have achieved success, at least in terms of attainment. Crucially, these are not necessarily the same countries with the highest teacher-pupil ratios at the primary level, a list that includes the Philippines, Fiji, and Myanmar.

Female literacy rates are not just educational outcomes but should be seen as a determinant, given the importance of female role models in improving girls' education outcomes, as female role models can demonstrate how to overcome educational barriers, and education completion (Herrmann et al., 2016).

Overall girls' learning outcomes - both relative and absolute, and especially in secondary education and beyond - seem less closely correlated with quantifiable education system determinants, or at least those most associated with the performance of education systems. These are likely more easily associated with specific practices and policy choices explored in the following sections.

\subsection{WASH systems and menstrual hygiene management}

Overall, poor WASH management systems in the Indo-Pacific region have been found to disproportionately affect girls' regular attendance in school, causing absenteeism, poor academic performance, and in some cases, school dropout (UNICEF EAPRO, 2021). Lack of separate toilets, washing areas, and sanitary products tend to discourage girls from attending school, particularly when they are menstruating. Additionally, menstruation is often stigmatised in many parts of the region, causing girls to feel embarrassed to participate fully in school (Mohamed et al., 2018). Schools often also lack running water, increasing the 
possibility of contracting diseases. Girls with special needs and disabilities are disproportionately affected by poor WASH management systems in this regard too.

Inadequate WASH infrastructure in schools seems to be most common in South Asia and low-income South-East Asian countries such as Lao PDR, Cambodia, Timor-Leste, and Papua New Guinea. (UNICEF, 2017a; GPE, 2020). For example, in Bangladesh, despite significant government commitment, $12 \%$ of the schools do not have any kind of handwashing locations within the school compound, and $15 \%$ do not have handwashing locations with access to running water; $25 \%$ of female students do not go to school during menstruation, $33 \%$ of female students reported disruption in school performance due to menstruation, and only $10 \%$ use disposable pads, whereas $86 \%$ use old cloth (WaterAid, 2018). Unless improvements are made to WASH facilities and menstrual hygiene management resources, girls' ability to thrive in education systems will remain constrained.

Inadequate menstrual hygiene management remains a barrier to girls' education across the region. In the Maldives, an education sector analysis recently highlighted the lack of targeted menstrual hygiene management policies (GPE \& Ministry of Education, 2019). In Bhutan, lack of facilities is a key factor in girls' absenteeism in schools across the country. Despite the introduction of sex education in the curriculum, Bhutan still needs to improve knowledge around menstrual health, hygiene, and how to manage them in schools (UNICEF, 2017a).

Countries that have increased investment in quality education and managed to direct funds and donor support towards WASH management systems - particularly in East Asia, South-East Asia, and Fiji, have shown the most gains (UNICEF, 2018a). Fiji has incorporated menstrual hygiene management as part of the national curriculum (UNICEF, 2017b). Most schools in Fiji reported to have access to running and clean water, sanitation, and handwashing facilities, separated between boys and girls. These interventions have led to improvements in girls' education outcomes, increasing both access, retention, and completion of primary and, in part, secondary education attendance (ibid.).

\subsection{Indirect costs of schooling}

Most countries in the Indo-Pacific region offer free and compulsory primary and secondary education. ${ }^{7}$ Free and compulsory education is offered by Bangladesh, Malaysia, Myanmar, and Singapore up to 5th/6th grade; Afghanistan, China, India, Indonesia, Japan, Lao PDR, the Maldives, Thailand, and Timor-Leste up to 7th/9th grade; and Nepal, Pakistan, the Philippines, Sri Lanka, and Viet Nam up to 10th/13th grade.

However, indirect costs of schooling disproportionately affect girls' access, attendance, and learning outcomes across the region (OECD Development Centre, 2016). Students are often required to pay for books, stationery, uniforms, pens, textbooks, and transportation fees, which can be particularly challenging in predominantly rural contexts in South Asia and SouthEast Asia. In extremely poor contexts, indirect costs of schooling are also related to missing income generated by girls' labour opportunities and contribution to household work, causing families to invest in boys' education rather than girls' (Herbert, 2018).

\footnotetext{
${ }^{7}$ World Bank Education Data: https://data.worldbank.org/indicator/SE.COM.DURS?locations=BD-BT-KH-FJ-IN-ID-LA-
} MY-MV-MM-NP-PG-PH-LK-TH-TL-VN-AF-PK-CN-JP-SG 
In Myanmar, despite strong growth in the girls' completion rate in secondary education, ${ }^{8}$ indirect costs of schooling are still an important determinant of access and retention. Many female primary school students are reported to be overaged, mainly due to the impossibility of reconciling study and household work, or to lack of electricity at home to study in the evening (ADB et al., 2016). Likewise, low school completion rates in Nepal are largely due to the persistence of indirect costs to schooling. Though primary education is free and compulsory, families pay around $56 \%$ of the total cost of education once informal fees and charges for learning materials and uniforms are accounted for. These may account for more than one-third of the primary education costs (Oxfam International \& HAMI, 2019).

Though some East Asian countries have shown greater gains, more progress is needed here too. Viet Nam has strongly prioritised policies and interventions towards gender equality in education (UNDP, 2016); for instance, by developing programmes that offer tuition fee support or tuition exemption for children, in particular girls and those from remote areas. Despite these gains, a recent Oxfam country report (Oxfam International \& HAMI, 2019) on out-of-school children finds that poor, quasi-poor, and disadvantaged households, and especially migrant children, are still strongly affected by the indirect costs of schooling, such as uniforms, travel to school, and student activities (UNICEF, 2018b).

In particular, indirect costs affect families living in remote and rural areas, who struggle most to send their daughters to school (Price, 2020). Parents are often not able to pay for transportation fees and children may have to walk for hours to reach the nearest school. Fear of violence, sexual assault, and harassment on the way to school make many parents concerned for their daughters' safety. As a result, parents often decide not to enrol their daughters at all, regardless of their age or years of schooling, causing increasing dropout rates across the region (ibid.). This is particularly true at the secondary level as there are generally fewer schools and distances to be travelled are generally longer.

\subsection{School-related gender-based violence (SRGBV)}

School-related gender-based violence (SRGBV) is a human rights violation perpetrated through corporal punishment, physical and psychological violence and abuse, bullying, cyberbullying, and sexual violence and abuse (UNESCO, 2014). While boys are more at risk of harsh corporal punishment and physical abuse, girls are typically more exposed to sexual abuse and psychological forms of violence (UNICEF ROSA, 2016). SRGBV leads to lower educational enrolment, achievement, and attainment (Afkar, Yarrow, Surbakti, \& Cooper, 2020). This is particularly true for girls, who are the most affected by sexual harassment and violence. The threat of SRGBV is also the motivation for many families who refrain from enrolling their daughters (UNESCO, 2014).

SRGBV is prevalent in most Indo-Pacific countries. Comparative statistics on SRGBV are not readily available, but the qualitative evidence reviewed finds it to be prevalent to various extents in all countries examined in this research except for Japan and Singapore. For example, in India, a national survey of 5,987 girls aged 5-18 years found that at least $50 \%$ of them had experienced one or more forms of physical or sexual violence and emotional violence at school. Perpetrators include students and teachers, both male and female. In the Maldives, an unpublished national study revealed that one in seven children - twice as many girls as boys - in secondary school had been sexually abused (UNICEF ROSA, 2016). The prevalence

${ }^{8}$ World Bank Education Data: https://data.worldbank.org/country/myanmar 
of SRGBV potentially explains a significant portion of girls' poorer education outcomes, particularly lower completion rates.

SRGBV is most widespread in the region's poorest countries. In Timor-Leste, $60 \%$ of girls surveyed reported being subject to violent discipline in the last 12 months. Many described a general feeling of insecurity at school. Here, 9.7\% of girls reported experiencing sexual violence at school, which includes sexual comments made by teachers, sexual touching by teachers, and sexual harassment by other students (UNICEF, 2016). In Papua New Guinea, girls have been found to be deterred from participating actively in class for fear of attracting unwanted attention from teachers. In addition, children may avoid school or underperform in the class due to psychological and/or physical trauma due to sexual assault (UNESCO, 2014). Indeed, SRGBV interacts with poverty; for example, in Sri Lanka, a study conducted among 23 female victims of abuse in a residential school found that their vulnerability to sexual abuse was correlated with low socioeconomic status (Afkar et al., 2020).

However, progress has been seen, particularly in South-East Asia. In Indonesia's Sampang District, physical protection measures have been instated by regional government, particularly for girls enrolled in junior secondary school, including supervision both at school and on the girls' way home (ibid.).

\subsection{Gender-sensitive teacher training}

Teachers' attitudes and instructional practices are among the strongest influencers of students' motivation and educational achievement. A programmatic priority in many regions, particularly among donors, is to train teachers to promote girls' and boys' education equally, overcoming their own gender stereotypes and learning about gender differences in education and efficient teaching methods to foster all students' potential (Kollmayer et al., 2020).

However, in the Indo-Pacific region, there is a lack of general teacher education and training programmes dealing with gender stereotypes (ibid.). This results in schools reproducing, reinforcing, and maintaining gendered practices. If teachers are not trained or do not feel comfortable in responding to SRGBV and other issues faced by girls in school, negative stereotypes about girls and women may be reinforced. Across the region, genderresponsive pedagogy (GRP) is not included in teaching practices, lesson plans, and education curricula (Dorji, 2020).

Some countries have made efforts to implement gender-sensitive teacher training, but progress requires patience. Despite efforts to promote gender-inclusive policies and education plans in Bhutan, research suggests that GRP is not included in teachers' daily lesson plans and inclusion of GRP in the classroom is minimal (ibid.). Part of this is due to broader, more systemic issues such as overcrowded classrooms resulting from teachers preferring to teach in urban schools (Ministry of Education [Bhutan], 2014).

In Indonesia, the Ministry of Education's initiatives on gender mainstreaming and GRP appear to have had a positive impact. School heads and teachers who went through gender-sensitive teacher training report having disseminated what they learned to their peers, with the greatest systemic benefits occurring as they cascade their learnings to their colleagues (BAPPENAS, 2013). 


\subsection{COVID-19 education response}

As a direct result of the COVID-19 pandemic, hard-won gains in gender parity and school enrolment have been lost and are likely to have a long-term negative impact on girls' education outcomes in the region (UNICEF, 2020a). COVID-19 could result in a loss of between 0.3 and 0.9 years of schooling adjusted for quality, lowering the effective years of students' basic education from 7.9 years to between 7.0 and 7.6 years. Additionally, around 7 million students from primary and secondary education could drop out due to the income shock of the pandemic alone (Azevedo et al., 2020). Historical evidence globally shows that COVID19 will put girls at risk of falling behind, leaving them especially vulnerable and unable to return to the classroom after schools reopened (ibid.). COVID-19 will likely increase the number of girls out-of-school and exacerbate the learning crisis for girls in school (UNICEF, 2020b). Where schools have remained closed for long periods of time, such as in Myanmar, Nepal, the Philippines, and Cambodia, the impact of COVID-19 on learning will be worse than in other countries where schools remained mostly open, such as Lao PDR, Timor-Leste, Viet Nam, and Thailand.

As a result of COVID-19, learning has moved outside schools and into the children's homes. Many of the negative effects of the pandemic therefore depend largely on the accessibility, availability, and quality of distance learning. However, many countries in this region have among the world's greatest gender divides in terms of devices ownership (UNICEF, 2020a). A recent UNICEF review has found that in Indonesia, $68 \%$ of school-age girls are studying only two hours or less a day when they are at home and $30 \%$ of them do not receive any support from the school in terms of learning materials. Connectivity is a major challenge, though it seems to affect boys and girls almost equally (UNICEF, 2020b).

Mental health issues are also a concern. A recent UNICEF review found that prolonged quarantine measures have increased girls' psychosocial stress and increased mental health issues, affecting girls' ability to learn (ibid.). In a survey carried out in the Philippines, only $14 \%$ of girls reported any feelings of calm during the pandemic. A large-scale study in China has found that $46 \%$ of female students showed symptoms of depression and $38 \%$ reported anxiety. In a Viet Nam survey, $60 \%$ of respondents felt worried and distressed during the pandemic. A UNICEF Thailand survey found $75 \%$ of female respondents reporting mental health issues (e.g. stress, lack of motivation, boredom, frustration) due to lockdowns. All studies found girls to have been more vulnerable to mental health concerns than boys during the pandemic (ibid.).

The combination of being out of school and the loss of family livelihoods caused by the pandemic may leave girls especially vulnerable and exacerbate exclusion and inequality, particularly in the lower-middle-income countries of this region (Azevedo et al., 2020). COVID-19 has had dire socioeconomic consequences in most regions, causing poor families to no longer send their daughters to school so they can work or help with household chores (UNICEF, 2020b). While before the pandemic, girls and boys from the richest households in Lao PDR and the Philippines were almost equally likely to complete their education from primary to upper secondary, increasingly families are choosing to prioritise boys' learning. Furthermore, girls from poor households are facing barriers to accessing distance learning during school closures. Surveys conducted by UNICEF in Indonesia and Malaysia found that more than $30 \%$ of female students could not properly use the internet or attend online classes (ibid.).

Furthermore, lockdown measures have increased the risk of SRGBV, child marriage, and early pregnancy, which in turn negatively affect girls' ability to learn and access 
education (ibid.). Save the Children estimates that 118,000 girls are at risk of adolescent pregnancy across the East Asia and the Pacific region within the next year as a direct effect of the COVID-19 pandemic (ibid.). In a recent UNICEF survey in Papua New Guinea, $45 \%$ of respondents reported an increase in physical violence against women and children during the lockdown. In Viet Nam, shelters for women and girl victims of domestic violence have received double the usual number of beneficiaries since the adoption of COVID-related measures. Fiji's Minister for Women reported that the national domestic violence helpline received five times the usual number of calls during the peak of the pandemic. In Malaysia, the national hotline for violence against children reported a $12 \%$ increase in calls during the first lockdown. In Thailand, the number of calls and messages received by the UNICEF-supported Childline increased ninefold in the early months of the pandemic (ibid.). Distance learning also involves spending more time online, which has left girls vulnerable to online sexual exploitation (ibid.). The Philippines' Department of Justice registered a fourfold increase in online sexual exploitation and abuse reports during the 2020 community quarantine period compared to 2019.

Finally, the number of girls at risk of child marriage has increased significantly in many IndoPacific countries during the pandemic (ibid.). Save the Children estimates that 61,000 girls are at risk of forced marriage across East Asia and the Pacific within the next year as a direct effect of the pandemic (UNICEF, 2020c). In India and Indonesia, many who have lost their jobs and life savings during the pandemic are marrying off their daughters at an early age to reduce the financial burden (Krishnan, 2021). In 2020, Indonesia saw child marriage applications reach a historical high of 33,000 (Huynh, 2020). 


\section{Societal determinants}

Girls' education outcomes in the Indo-Pacific region vary due to intersecting factors including national political, poverty, geography, religion, caste, and patriarchal values. Combined, they mutually reinforce each other and account for many of the differences between boys' and girls' learning journeys.

\subsection{Political factors}

Relationships and forms of power beyond the education system play a crucial part in reproducing gender inequalities and in creating and replicating barriers to girls' education. Experts have argued that variations in how countries adopt and implement education reforms necessary to promote learning relate to differences in their political economies (Hickey \& Hossain, 2019). Limited political action on girls' education and limited legal frameworks to protect their rights are likely to hold back progress on girls' education, and governments' wider appetite for education reform and support for gender equality can be either a key enabler or a barrier to improvements for girls' learning outcomes (Rose, Sabates, Alcott, \& Ilie, 2017). There are a number of political factors which have specifically influenced girls' education in the Indo-Pacific region.

Equating gender parity to gender equality has reduced the much-needed focus on girls' education in some areas. In Fiji, for example, its Education for All (EFA) National Review 2015 explicitly states that "areas such as gender parity and equality are seen to be non-issues for Fiji. Within the Fiji education system, boys and girls have equal opportunities to all levels and forms of education. The goal on Gender parity and equality therefore was placed on low priority in the Action Plan" (Ministry of Education, National Heritage, Culture \& Arts, 2015: 6). This de-prioritisation of girls' education initiatives at the political level poses significant risks for girls' education and empowerment.

A lack of legal commitments in the Indo-Pacific region may inhibit girls from accessing their right to education. In 2017, The Right to Education Initiative developed a six-tier classification on whether states have ratified relevant human rights treaties guaranteeing the rights of women and girls to education including:

- 1979 Convention on the Elimination of all Forms of Discrimination against Women (CEDAW): Article 10 of this Convention sets out the established norms on what governments' obligations are in relation to equality in the access to and quality of education, reduction of female dropout rates, and programmes for women and girls who have left school.

- 1960 Convention against Discrimination in Education (CADE): CADE outlaws discrimination, including between genders, in access to and quality of education.

- 1966 International Covenant on Economic, Social and Cultural Rights (ICESCR): Article 13 of this Covenant lays out what governments must do to counteract any discrimination from taking place, including the need for disaggregated data to identify discrimination where it takes place.

Tier One - reflecting a country's highest commitment - is where governments have fully ratified CEDAW (with no reservations to articles pertaining to gender equality), CADE, and the ICESCR. Annexe 2 presents the conventions that each country has signed, but it is worth noting that only five out of the 23 countries in the Indo-Pacific region covered in this report are 
in Tier One, reflecting a country's highest commitment to international conventions underpinning gender equality in education.

Government commitment to gender equality in education can also be assessed through their policies and plans, which are mostly comprehensive across the region (see Annexe 2). For example, gender parity is integrated throughout Lao PDR's Education Sector Development Plan. However, as noted in Section 1, girls' education in Lao PDR faces significant challenges, demonstrating that even when governments have made commitments to girls' education, there are not always adequate plans or budget for implementation. There may also be a lack of power within governments for those responsible for gender, which impedes progress for girls' education.

Weak accountability relationships between citizens, government, and education providers are important determinants which have meant that citizens have limited power to challenge a lack of progress on girls' education. Political reform has often been inhibited by the inability of governments to promote accountability across key stakeholders and unsuccessful attempts to garner stakeholders' commitment to designing and implementing appropriate programmes to support girls' education. For example, in Bangladesh, it has previously been reported that because of the highly bureaucratic and top-down internal administration and management practices, the education authority is not held accountable to stakeholders - including parents, community, and students - for the decisions it makes. The provision of a stakeholders' forum through the National Council for Primary and Mass Education and the Project Coordinating Committee is supposed to ensure that stakeholders' voices are heard in the decision-making processes, but in practice the forum has been found to be ineffective (Chitrakar, 2009).

\subsection{Poverty}

Poverty is one of the most important factors for determining whether a girl can access and complete her education. Poor households lack resources to pay for schooling and associated costs (e.g. for textbooks, uniforms, school supplies, and transportation). Poor households with multiple children may choose to invest in boys' education rather than that of girls, while also relying on girls to help with household chores and care for younger siblings and other family members. Studies consistently show that girls who face multiple disadvantages - such as having low family income, living in remote or underserved locations, having a disability, or belonging to a minority ethno-linguistic group - are farthest behind in terms of access to and completion of education and learning outcomes (World Bank, 2021). Indeed, GDP per capita correlates strongly with the education outcome metrics considered in this research.

Though most countries in the region have made great progress in terms of poverty alleviation, the loss of income as a result of the pandemic risks reversing this. The World Bank forecasts that the number of people living in poverty in South-East Asia and the Pacific ${ }^{9}$ is likely to rise for the first time in 20 years and as many as 38 million (World Bank, 2018) people in the region will fall below the poverty line. The region's adolescent girls will be one of the groups that will be the hardest hit as families make decisions about them - whether they stay in school, marry, take on low-paid work to support their families, or care for siblings or elderly relatives (Plan International Australia, 2021). 
Poverty is generally most prevalent in rural settings. The combination of being poor, a woman, and living in a rural area forms the most common barrier to secondary education. A survey of 21 countries in Asia and the Pacific by UNESCAP (2019) shows that in 10 out of 21 countries, poorer women with rural backgrounds have lower attainment rates. In Lao PDR, these women represent $18 \%$ of the population and their secondary education attainment rate is only $1 \%$. In other words, the likelihood that a poor, rural Laotian woman completes secondary education is close to zero. The determining circumstances do not change drastically when it comes to higher education. In Bhutan, Cambodia, and Timor-Leste, the higher education attainment rate for women from rural poorer (bottom 40) households is essentially zero. Conversely, countries analysed with the highest percentages of urban populations - Singapore, Japan, Malaysia, Thailand, Sri Lanka, and Fiji - are also among those with the highest education outcomes.

\subsection{Labour market participation}

We have examined labour market participation chiefly as an indirect education outcome and touched upon it as an education system determinant, but it is also important to consider its role as a societal determinant.

Despite strong gains across the region, gender gaps in participation in the labour market in the Indo-Pacific region are expected to worsen or remain unchanged until 2021 due to the pandemic (ILO, 2017). Many women are likely to continue to experience lowquality work in the Indo-Pacific region (low status, insecure, part-time, informal, and with exploitative labour conditions).

Labour market participation statistics in the region can also distract from the types of work offered to women. In 2017, $81 \%$ of paid domestic workers in the Asia-Pacific region were women (ILO, 2013 in Hill, Baird, \& Ford, 2017). Women in the Asia-Pacific region are still taking on most paid and unpaid domestic and care responsibilities, doing, on average, more than twice the unpaid care work of men (Herbert, 2018). Labour force participation rates vary according to women's class, ethnic, location, and religious profile, accentuating preexisting patterns of inequality in the region (Hill et. al., 2017; Herbert, 2018).

Overall, East Asia and the Pacific countries perform better in terms of female labour force participation rates, despite the highlighted differences in quality of jobs. Conversely, South Asia has the second-lowest rate of female labour force participation of all regions $(28.3 \%)$, with women being almost three times less likely to be employed in full-time jobs than men. Many of these jobs are characterised by informality, and the quality of jobs available to women remain low across the region. In India, female labour force participation dropped from 34.1\% in 1999-2000 to 10\% in 2019 (ILO modelled estimate; Najeeb, Morales, \& Lopez-Acevedo, 2020).

The high rate of female labour force participation in Nepal (78\% according to 2019 ILO modelled estimates) also needs to be interpreted with caution. Data suggest that girls leave school early to marry (UNICEF \& UNFPA, 2019) and undertake household management, agricultural work, and livestock care responsibilities, while working-age spouses migrate for work in India and neighbouring countries (Sijapati, Bhattarai, \& Pathak, 2015). This could also account for the low Nepali male labour force participation for the same age range, which does not reach $40 \%$.

Gender norms and stereotypes can play an important role in undermining progress in girls' learning outcomes and labour force participation, perhaps even more so than 
poverty. In Bangladesh, there is a strong correlation between the prevalence of child marriage, girls' school dropout rates, and low-quality employment for women. Fifty-nine per cent of married women wedded aged 18 or younger, the highest rate among South Asian countries (UNICEF, 2020c), with over $75 \%$ of women dropping out of school and $43 \%$ not continuing to work after marriage according to the National Demographic and Health survey. Consequently, only $49 \%$ of married women were employed at the time of the survey, and $16 \%$ of them did not receive payment for their work (NIPORT \& ICF, 2020).

In Lao PDR, school dropouts, which increase significantly from primary to upper secondary level, are especially frequent among married girls. According to the Lao Social Indicator Survey II (LSIS II), approximately a quarter of girls aged 15-19 are currently married (UNICEF Lao PDR, 2020). As a result, some $45.6 \%$ of women and girls who are employed are unpaid family workers. Management and professional occupations do have more women (57\% of positions) than men (43\%), but women's pay is lower. Overall, women's average monthly income is only $77 \%$ that of men, with significant gaps in some sectors where women's income can be as low as $56 \%$ of men's (ibid.).

In Indonesia, even though girls outperform boys in enrolment, completion, and achievement up until higher education, the labour market perpetuates strong gender discriminations. While Indonesia's male labour force participation rate is $83.2 \%$, for females the figure is $51 \%$. Even when women in Indonesia do work, they are paid less than their male counterparts (Afkar et al., 2020).

\subsection{Harmful patriarchal practices}

The persistence of patriarchal values and practices, exacerbated by poverty and other intersectional factors of discrimination such as disability, ethnicity, religion, and caste, often create the context for violence against girls and women. This in turn helps explain the high dropout rates of girls in secondary school throughout the region, despite generally higher enrolment rates than boys in both primary and secondary school, and high primary completion rates in most of the countries analysed.

Harmful sociocultural practices, such as female genital mutilation (FGM) can intersect, and cause, other barriers to girls' education. FGM is recognised internationally as a violation of the human rights of girls and women (WHO, 2020). Data on the prevalence of FGM in the Indo-Pacific region are scarce and hence not included in global reporting. Data collection efforts may be hampered in situations where authorities deny or ignore the existence of FGM or minimise the harmfulness of the practice. ${ }^{10}$ Although indirect data exist that testify how the harmful practice of FGM is spreading across the region, insufficient official national statistics

\footnotetext{
${ }^{10}$ In its reply to the list of issues posed by the CEDAW on the occasion of its 69th session, the Government of Malaysia stated that "the 86th Muzakarah (Conference) of the Fatwa Committee National Council of Islamic Religious Affairs Malaysia [...] discussed female genital mutilation. The Committee had decided that female circumcision is part of Islamic teachings and it should be observed by Muslims. [...] the Committee has decided that female circumcision is obligatory (wajib). [...] To ensure proper female circumcision procedure, the Ministry of Health (MoH) had conducted several task force meetings, of which members comprised of medical professionals, religious body and NGOs to discuss the best approach to fulfil religious obligations and the same time the practice that is to be practised does not amount to mutilation. The outcome was a publication of the 'Guideline on Female Circumcision Procedures for Muslim Women'. It stated that only accredited medical professionals will be medically privileged to perform the procedure. This procedure then has been monitored by $\mathrm{MoH}[\ldots]$ in 2015 83-85\% of the Muslim baby girls have been circumcised by medical professionals in private clinics without any complications [N.d.R.]".
} 
have been produced or made available to allow for a rigorous analysis of the impact of FGM on girls' learning outcomes in the region.

In India, Bangladesh, Malaysia, the Philippines, Singapore, Sri Lanka, Malaysia, Brunei, Singapore, Cambodia, Viet Nam, Lao PDR, the Philippines, and Thailand, small-scale primary research studies document the existence of FGM through direct interviews with survivors, community members, and religious leaders. ${ }^{11}$ Most of these studies have a small sample size (End FGM European Network, End FGM/C US Network, \& Equality Now, 2020; Dawson et al., 2020).

Only Indonesia (UNICEF Data and Analytics Section, 2019) and the Maldives (MOH \& ICF, 2018) have shared nationally representative prevalence data on FGM. In the Maldives, 13\% of women aged 15-49 have undergone some form of FGM, $83 \%$ of whom before turning five years old. The prevalence increases with age. In Indonesia, a staggering $49 \%$ of girls under 12 years old has suffered some form of FGM, regardless of provenance, education, or the family's income level (UNICEF Data and Analytics Section, 2019).

Other patriarchal practices can influence levels of child marriage and gender-based violence. In some parts of India, the gauna or "send-off" ceremony takes place as soon as the girl, who may have been promised in marriage even before she was born, reaches puberty (Center for Reproductive Rights, 2018). According to a global monitoring report on sexual exploitation and abuse of children (ECPAT International, 2017), in Lao PDR the practices of Tshoob nii ("bride theft" or effectively kidnapping a girl bride, even as young as 12 years old) and Tshoob zawj (forced marriages with payments offered to the child bride's family) reportedly still occur.

Harmful patriarchal practices occur even in countries with above-average education outcomes for girls. The use of bulubulu, a traditional form of apology to the father of the pregnant underaged girl by her male partner, is still reported in some communities in Fiji, and occasionally used also as a form of reconciliation measure to sexual abuse (ECPAT International, 2019). In the Maldives and Malaysia, studies suggest that the rise of conservative forms of Islam is influencing the roles of women and girls, and the views of families towards their daughters. Reducing the mobility of girls, pulling them out of school, or resorting to child marriage as a preventive and punitive measure against premarital sexual activity are reportedly more common (UNICEF \& UNFPA, 2019; SIS \& ARROW, 2018).

\subsection{Child marriage}

Unfortunately, there is no comparative quantitative data on the determinants described above. However, child marriage can be considered a good proxy indicator of many of the forms of harmful patriarchal norms outlined here, particularly gender-based violence due to its strong correlation with statutory rape, FGM, arranged and forced marriages, and other harmful practices.

Many factors interact to place a child at risk of marriage: social norms, customary or religious laws that condone the practice, an inadequate legislative framework, the state of a country's civil registration system and poverty (UNICEF Data, 2020). The timing of marriage and school

\footnotetext{
${ }^{11}$ FGM is considered by some to be a rite of passage in the Philippines, while in Southern Thailand it is associated with 'softening' the female character. Research from India, Indonesia, and Malaysia has found the practice is associated with cleanliness, reducing female sexual desire and maintaining purity, and purifying the body.
} 
leaving for girls is tied to norms surrounding gender and sexuality (UNICEF ROSA, 2019). Indeed in some contexts, child marriage is seen as a protection against sexual harassment, abuse at school, and premarital sex.

Though marriage before the age of 18 is a violation of human rights (ICRW, 2012), it is quite common in the Indo-Pacific region, predominantly affecting girls but also boys to a lesser extent. ${ }^{12}$ In India, $27 \%$ of women aged 20-24 were first married or in union before the age of 18 (UNICEF, 2019). Of the country's 223 million child brides, 102 million were married before turning 15 (ibid.). Bangladesh has the highest prevalence of child marriage $(51 \%)$ among South Asian countries and ranks among the ten countries in the world with the highest levels of child marriage, with 38 million child brides (UNICEF, 2020c). Nepal has the third highest rate of child marriage in Asia (40\%) and the 16th in the world for both girls and boys; and more than a third of women aged 20-24 report that they were married by the age of 18 , and just over one in ten by 15 (UNICEF ROSA, 2019). In Thailand, $20 \%$ of girls were married before their 18th birthday (National Statistical Office of Thailand, 2020).

In Viet Nam, customary law still enables young girls to be married off with the consent of their parents. Although it is illegal, the practice of hai pu (bride kidnapping), with girls being taken from their homes and forcibly married, is still widespread (UNICEF Viet Nam \& UNFPA Viet Nam, 2018). In Indonesia, where religious courts are more likely to grant marriage dispensation to allow child marriage rather than district courts (UNICEF, BPS, BAPPENAS, \& PUSKAPA, 2020), marriage is sometimes used to prevent or remedy the stigma associated with female sexual experience outside of marriage and adolescent pregnancy, including through sexual violence, even in high-income communities with high levels of education (Plan International, 2016).

All but two East Asia and the Pacific countries examined in the region have child marriage rates lower than $20 \% .{ }^{13} \mathrm{~A}$ significant exception is Lao PDR, which has the highest percentage of child marriage in East Asia and the Pacific (33\% of women aged 20-24 are married by the age of 18) (Lao Statistics Bureau, 2018). Likewise, in Papua New Guinea $27 \%$ of women were married or in union before the age of 18 (NSO [Papua New Guinea] \& ICF, 2019).

The effects of child marriage on girls' education can be glaring, particularly in preventing girls' educational opportunities. Child marriage is one of the main reasons for adolescent girls dropping out of school, with a large negative effect on educational attainment.

\footnotetext{
${ }^{12} \mathrm{Nepal}$ is one of only eight countries in the world where more than $10 \%$ of boys are married before the age of 18 (UNICEF ROSA \& UNFPA APRO, 2017). Eleven per cent of boys in Laos are married before their 18th birthday, which makes Laos the country with the eighth highest prevalence rate of child marriage for boys (Lao Statistics Bureau, 2018). In Cambodia, $4 \%$ of boys are married before their 18th birthday (National Institute of Statistics, Directorate General for Health, \& ICF, 2015); $5 \%$ of boys in Myanmar are married before the age of 18 (MoHS \& ICF, 2017); $4 \%$ in Papua New Guinea (NSO \& ICF International, 2019); and $8 \%$ in Thailand (NSO \& UNICEF, 2016).

${ }^{13}$ In Timor-Leste, $19 \%$ of young women (20-24) are married before the age of 18 (Cummins, 2017). In the Philippines, one out of six (16.5\%) young women aged 20-24 married before they became 18 (PSA, 2018). Almost one in five girls in Cambodia (National Institute of Statistics et al., 2015) are married before their 18th birthday and $2 \%$ are married before the age of 15. In Indonesia, one in 10 women (12\%) aged 20-24 was married or in union before the age of 18 in 2015. Only $0.6 \%$ of women were married or in union before the age of 15 (UNICEF, 2017a). In Myanmar, 16\% of girls are married before the age of 18 and $2 \%$ are married before the age of 15 (MoHS \& ICF, 2017). Child marriage rates are difficult to accurately track in Myanmar due to complex customary practices among the country's 135 recognised ethnic groups. In Bhutan and Malaysia, precise figures are difficult to determine since many marriages are not officially registered and updated statistics are not available; NGO literature in Malaysia suggests that child marriage is not linked to poverty or education level but is deeply rooted in the conservative interpretation of Muslim religion. In Sri Lanka and the Maldives, the prevalence of child marriage is low $(10 \%$ and $4 \%$ respectively, according to data analysis by https://atlas.girlsnotbrides.org).
} 
Once an adolescent girl is married, it is highly unlikely that she will return to school (Wodon et al., 2017). In Bangladesh, a married girl is four times more likely to be out of school than an unmarried one (UNICEF, 2020c). Despite progress in secondary school enrolment for girls (from 39\% in 1998 to $67 \%$ in 2017), dropout rates for girls in 2017 were at a high of $42 \%$ at the secondary school level and completion rates were low, with grade 10 rates bottoming at only $10 \%$, and secondary-level completion rates a mere $59 \%$ (Sosale, Asaduzzaman, \& Ramachandran, 2019). In Indonesia, a married girl under 18 years is six times less likely to have completed senior secondary education than her unmarried peer ( $9 \%$ compared to $54 \%$ ) (UNICEF, 2017a). In Lao PDR, almost $60 \%$ of women aged 20-24 with no education were married before the age of 18 , compared to $16 \%$ who completed secondary education (Lao Statistics Bureau, 2018). In the Philippines, marriage was the reason for not being in school for $37.2 \%$ of all females aged $6-24$ not attending school; $44.9 \%$ of them belonged to the bottom $30 \%$ income stratum of the country (PSA, 2018).

Girls living in poor, rural households are almost twice as likely to marry before the age of 18 than girls in higher-income households (Wodon et al., 2017). In India and Nepal, there is a direct correlation between poverty quintile, residing in a rural area, and age of marriage. Here in the four poorest quintiles in rural areas more than $50 \%$ of girls are married, compared to the less than $35 \%$ in the richest quintiles of rural areas in both countries (UNICEF ROSA \& UNFPA APRO, 2017; UNICEF, 2019). In Indonesia, women in the lowest wealth quintile were four times more likely to have married before 18 years than women in the highest wealth quintile (UNICEF, 2017a). Fifty-six per cent of women in Lao PDR's poorest households married as children, of whom $39 \%$ live in rural areas. By comparison, only $13 \%$ of women living in the richest households married as children (Lao Statistics Bureau, 2018). The 2015-16 Thailand MICS has also found that $30 \%$ of women in the poorest households were married before the age of 18 , compared to $10 \%$ from the richest households.

Research has also demonstrated that external factors could increase the rates of child marriage. For example, in countries like Nepal (UNICEF ROSA \& UNFPA APRO, 2017), Sri Lanka (Plan International, 2013), and Bangladesh (Human Rights Watch, 2015), natural disasters have also contributed to a rise in the number of child marriages. As climate change will lead to increases in natural disasters, child marriage may become increasingly prevalent.

\subsection{Adolescent pregnancy}

Many girls living low-income marginalised communities of the Indo-Pacific region face considerable pressure to marry early, thus increasing their likelihood of adolescent pregnancy. These pregnancies increase in contexts where girls are denied the right to make decisions about their sexual and reproductive health and wellbeing. There are many risks connected to adolescent pregnancy, particularly related to health. Adolescent pregnancy is the biggest killer of girls and women aged $15-19$ in the world. ${ }^{14}$

The rate of adolescent pregnancy has been growing in low- and middle-income countries in the East Asia-Pacific region over the past ten years. In the Philippines, the age of consent is 12 and the adolescent birth rate has risen to 62 per 1,000. Likewise, in Cambodia the rate has jumped from 46 to 52 out of 1,000 and in Fiji adolescent births have

\footnotetext{
${ }^{14}$ Plan International: https://plan-international.org/sexual-health/teenage-pregnancy
} 
risen to 45 per 1,000. In 2019 in Papua New Guinea, 54 of every 1,000 births were to adolescent girls.

Evidence shows that education is a key factor in avoiding both child marriage and teen pregnancy. For example, in Bangladesh, mothers and mothers-in-law who have accessed education were less likely to pressure their daughters to marry and have children (UNICEF ROSA, 2019). Indeed, Bangladesh has seen improvements with the rate of adolescent pregnancies, declining from $59 \%$ to $51 \%$; however, they remain very high at 82 births out of 1,000 (Doherty, 2018).

Adolescent pregnancy often leads to the interruption of education and limited opportunities for future employment, which perpetuates the cycle of poverty (Plan International, n.d.). In some contexts, girls are deliberately expelled from school because of pregnancy. These consequences are particularly evident in girls' learning outcomes in South Asia, particularly in India, Bangladesh, and Nepal. Research shows that $28.4 \%$ of dropouts in Nepal are due to adolescent pregnancies, which are a direct consequence of the high rate of early marriages (Shrestha, 2012). In India, nearly 10 million secondary school girls could drop out of school due to the COVID-19 pandemic, putting them at risk of early pregnancy (RTE Forum, 2021).

Girl's low educational attainment also contributes to the risk of adolescent pregnancy. Globally, girls who have received minimal education are five times more likely to become mothers than those with higher levels of education (Plan International, n.d.). In Bangladesh, girls who had no education were found to have 2.76 times higher odds of adolescent motherhood than their counterparts who had completed secondary school (Islam, Islam, Hasan, \& Hossain, 2017).

\subsection{Household size}

Family characteristics have been widely recognised as essential factors impacting children's education. Number of siblings is recognised as one of the most important predictors of determining a child's educational attainment and intellectual development (Feng, 2020).

Across the Indo-Pacific region, average household sizes vary greatly. Viet Nam, Indonesia, and Malaysia - the most dynamic and ever-evolving countries of this region - have on average 3.9 to 4.2 components per household. On the other hand, Papua New Guinea, Lao PDR, and Timor-Leste - countries facing some of the most intractable poverty trends - have 5 to 5.3 components per household on average. Likewise, Fiji and the Maldives have an average household size of 4.8 to 5.3. The impact of household structure on girls' education is well documented in many countries. In India, for instance, where families have on average 4.6 members, children from larger families have less education and poor health, because if parents are financially constrained, they may have to choose in which child to invest; in areas where son preference is prevalent, girls' education will likely be affected in larger families (Kugler \& Kumar, 2016). Indeed, in Indonesia, an additional sibling for an Indonesian girl means 0.112 years less of schooling (Feng, 2020). 


\section{Typology}

The research presented in this report demonstrates the wide range of interrelated factors affecting girls' education outcomes in a region containing over half the world's population. Precisely because educational and societal determinants are so dynamically interlinked, the country typology proposed here is based primarily on a classification into five types by education outcome: (1) Countries with strong education outcomes for girls at all levels; (2) Countries experiencing challenges with tertiary education; (3) Countries experiencing significant challenges related to learning outcomes and indirect education outcomes; (4) Countries experiencing challenges at every level; and (5) Countries experiencing barriers at every level, exacerbated by additional challenges. This section presents recurring determinants for each typology and suggests priorities for FCDO as it considers programming priorities.

\section{Type 1 - Countries with strong education outcomes for girls at all levels.}

Figure 11. Visual representation of determinants affecting girls' education outcomes in Type 1 countries

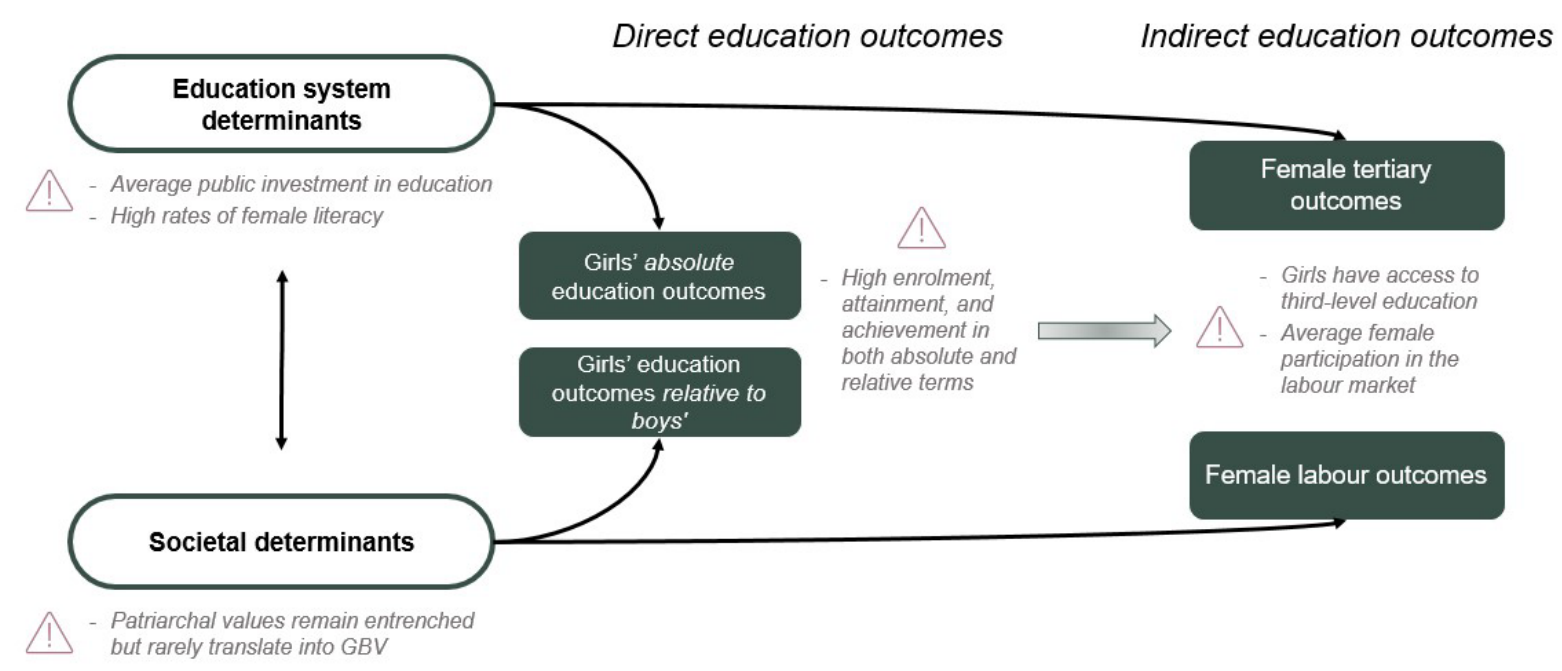

Source: Authors' own. 
Table 1. Characteristics of Type 1 countries

\begin{tabular}{ll} 
Countries & $\begin{array}{l}\text { Japan, Singapore, and most of China and Viet Nam. Other mid to high-income } \\
\text { East Asian economies like South Korea likely have similar characteristics. }\end{array}$ \\
\hline $\begin{array}{l}\text { Direct education } \\
\text { outcomes }\end{array}$ & $\begin{array}{l}\text { Girls do well in both absolute and relative terms across all enrolment and learning } \\
\text { outcome metrics. Girls score higher than boys on PISA reading assessments but lag } \\
\text { slightly behind in maths and science. (China's diversity means areas of extreme } \\
\text { educational inequity remain.) }\end{array}$ \\
$\begin{array}{l}\text { Indirect education } \\
\text { outcomes }\end{array}$ & $\begin{array}{l}\text { Young women have access to tertiary education and tend to complete it. They } \\
\text { participate in the labour market at average rates but rarely experience } \\
\text { unemployment when they have tertiary education. }\end{array}$ \\
$\begin{array}{l}\text { Education system } \\
\text { determinants }\end{array}$ & $\begin{array}{l}\text { Government investment in education is average but effective, as pupil-teacher ratios } \\
\text { are very low. Female literacy rates are high. SRGBV exists but is infrequent and } \\
\text { WASH facilities are generally adequate. }\end{array}$ \\
$\begin{array}{l}\text { Societal } \\
\text { determinants }\end{array}$ & $\begin{array}{l}\text { These countries are high-income. Though patriarchal values remain, traditional } \\
\text { gender norms and discriminatory practices rarely translate into child marriage and } \\
\text { other rights violations beyond rates seen in other high-income countries. }\end{array}$ \\
$\begin{array}{l}\text { FCDO } \\
\text { programming } \\
\text { implications }\end{array}$ & $\begin{array}{l}\text { Promote mutually beneficial knowledge exchange opportunities } \\
\text { - Explore joint aid ventures }\end{array}$ \\
\hline
\end{tabular}

Source: Authors' own.

\section{Type 2 - Countries experiencing challenges with tertiary education}

Type 2 countries have above-average education outcomes for girls but experience bottlenecks at the tertiary level and barriers remain at the secondary level for girls from the most disadvantaged and marginalised communities. Reasons may include adolescent pregnancy, child marriage rates, and other factors that remain unaddressed by school systems, especially in rural areas.

Figure 12. Visual representation of determinants affecting girls' education outcomes in Type 2 countries

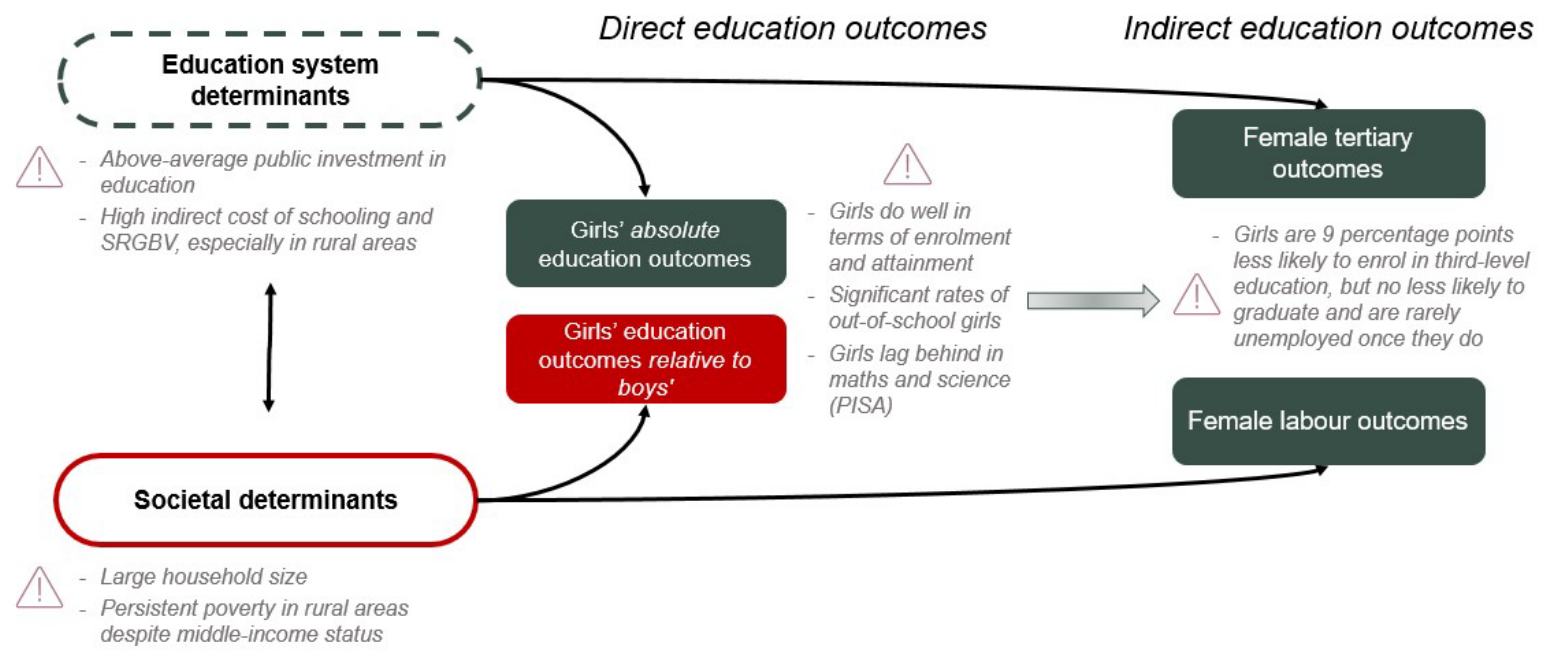

Source: Authors' own. 


\begin{tabular}{|c|c|}
\hline Countries & $\begin{array}{l}\text { Indonesia, Fiji, Thailand, the Philippines, the Maldives, and Malaysia. Other } \\
\text { high and upper-middle income South-East Asian, East Asian, and island } \\
\text { nations likely present similar characteristics. }\end{array}$ \\
\hline $\begin{array}{l}\text { Direct education } \\
\text { outcomes }\end{array}$ & $\begin{array}{l}\text { Girls do well in both absolute and relative terms across most enrolment and } \\
\text { attainment metrics. However, percentages of out-of-school girls remain significant - } \\
\text { over } 10 \% \text { in all countries except Thailand - though lower than those for boys. On } \\
\text { PISA scores, girls are mostly stronger readers than boys but lag slightly behind in } \\
\text { maths and science scores. }\end{array}$ \\
\hline $\begin{array}{l}\text { Indirect education } \\
\text { outcomes }\end{array}$ & $\begin{array}{l}\text { Young women are on average } 9 \% \text { less likely to enrol in tertiary education than men } \\
\text { (except for the Maldives), but no less likely to graduate and are rarely unemployed } \\
\text { once they do. }\end{array}$ \\
\hline $\begin{array}{l}\text { Education system } \\
\text { determinants }\end{array}$ & $\begin{array}{l}\text { Government expenditure is above average in all these countries except for the } \\
\text { Philippines, resulting in low pupil-teacher ratios everywhere except for the } \\
\text { Philippines and Fiji. Qualitative evidence of high indirect costs of schooling and } \\
\text { SRGBV suggest strong inequalities across the rural-urban divide, likely exacerbated } \\
\text { by the COVID-19 pandemic. }\end{array}$ \\
\hline $\begin{array}{l}\text { Societal } \\
\text { determinants }\end{array}$ & $\begin{array}{l}\text { Household size remains high and child marriage rates fluctuate between } 11 \% \text { and } \\
20 \% \text { in all countries for which there is data, except for the Maldives where it is } \\
\text { minimal. While these countries have transitioned rapidly to middle-income status, } \\
\text { significant areas are still in rural poverty, contexts where harmful patriarchal } \\
\text { practices are still common and possibly affect girls' attainment. }\end{array}$ \\
\hline \multirow{4}{*}{$\begin{array}{l}\text { FCDO } \\
\text { programming } \\
\text { implications }\end{array}$} & - $\quad$ Focus on rural areas \\
\hline & - Explore the nexus between child marriage and completion challenges \\
\hline & $\begin{array}{l}\text { - Strengthen WASH infrastructure and schemes to decrease indirect costs of } \\
\text { schooling }\end{array}$ \\
\hline & - $\quad$ Support tertiary education capacity-building efforts \\
\hline
\end{tabular}

Source: Authors' own.

\section{Type 3 - Countries experiencing significant challenges related to learning outcomes and indirect education outcomes}

Type 3 countries display above-average educational enrolment and learning outcomes for girls at the primary level but experience lower-than-average learning outcomes for girls at the secondary level, a strong tertiary bottleneck, and significant labour market disparities. Causes include chronic education system inefficiencies, high indirect costs, SRGBV, poor WASH facilities, and child marriage. 
Figure 13. Visual representation of determinants affecting girls' education outcomes in Type 3 countries

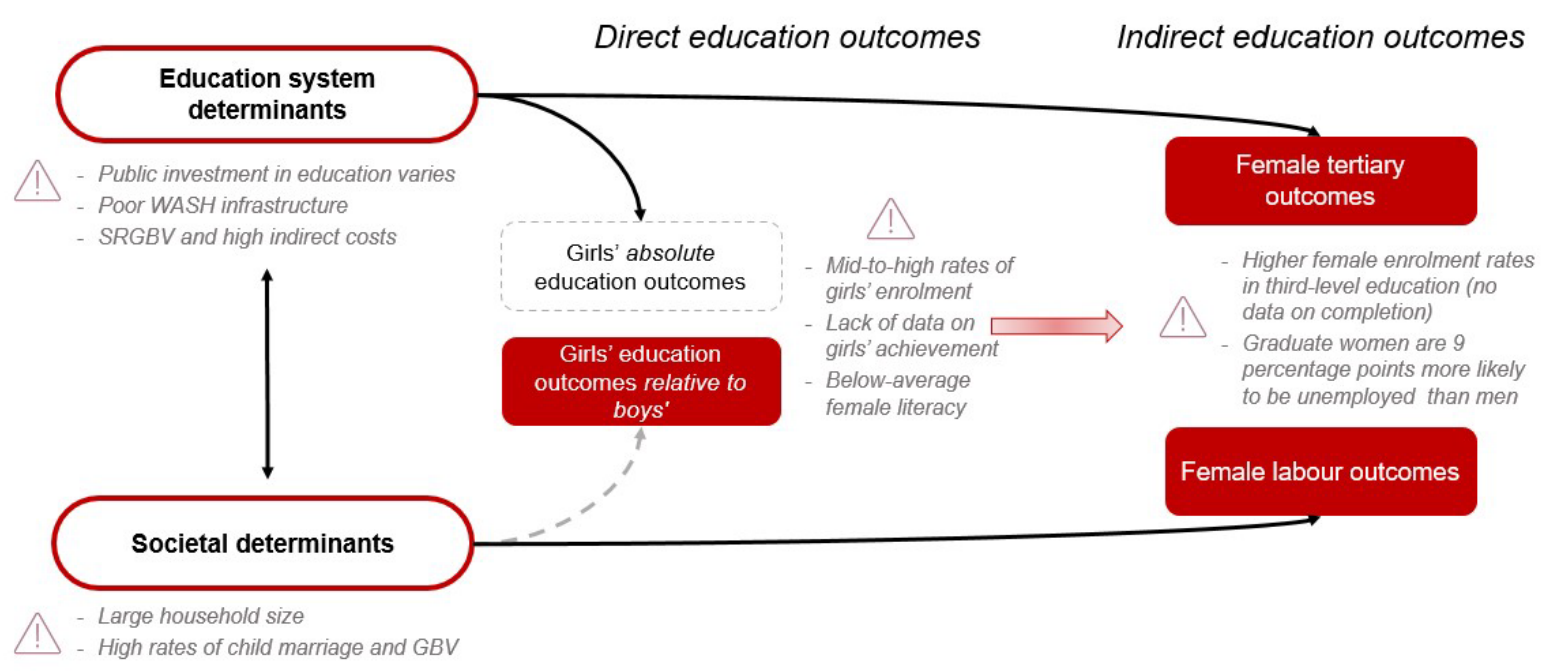

Source: Authors' own.

Table 3. Characteristics of Type 3 countries - countries experiencing challenges beyond basic education

Countries

Direct education outcomes

Indirect education outcomes

Education system determinants

Societal determinants

FCDO programming implications
India, Sri Lanka, Bangladesh, Nepal, and Bhutan, with significant differences within and between countries likely linked mostly to level of urbanisation.

Girls enrol in school at mid to high rates and are not significantly likelier to drop out at the secondary level except for in Bangladesh and Bhutan. Learning outcomes are varied, though literacy has improved.

Women generally enrol in university at higher rates than men but recent data on completion is lacking. Crucially, between $8 \%$ and $29 \%$ of unemployed women hold degrees, at a rate approximately nine percentage points greater than men.

Government expenditure fluctuates, resulting in high pupil-teacher ratios, lack of investment in teacher training, and - anecdotally - poor WASH infrastructure for schools. SRGBV is still common and indirect costs can be high.

Traditional gender roles are likely driving low female employment rates everywhere except Nepal. Household size strongly contributes to poor learning outcomes though adolescent pregnancy has declined to average rates everywhere except Bangladesh. Child marriage is high, with rates between $10 \%$ and $51 \%$. As in many recently middle-income countries, harmful patriarchal practices remain commonplace.

- Consider policy advocacy opportunities to push for education system reform, particularly aligning systems to focus on learning

- Explore further the determinants of successful tertiary education-to-work transitions for women

- Support capacity building for data collection on learning outcomes, potentially including PISA participation or citizen-led assessments

- Explore the role of child marriage and other harmful patriarchal practices in poor and rural contexts 


\section{Type 4 - Countries experiencing challenges at every level}

Type 4 countries have poor education outcomes, including low enrolment for girls at the primary and secondary levels, because of a lack of government investment in education, poor WASH facilities, SRGBV, enduring rural poverty, child marriage, and other trends.

Figure 14. Visual representation of determinants affecting girls' education outcomes in Type 4 countries

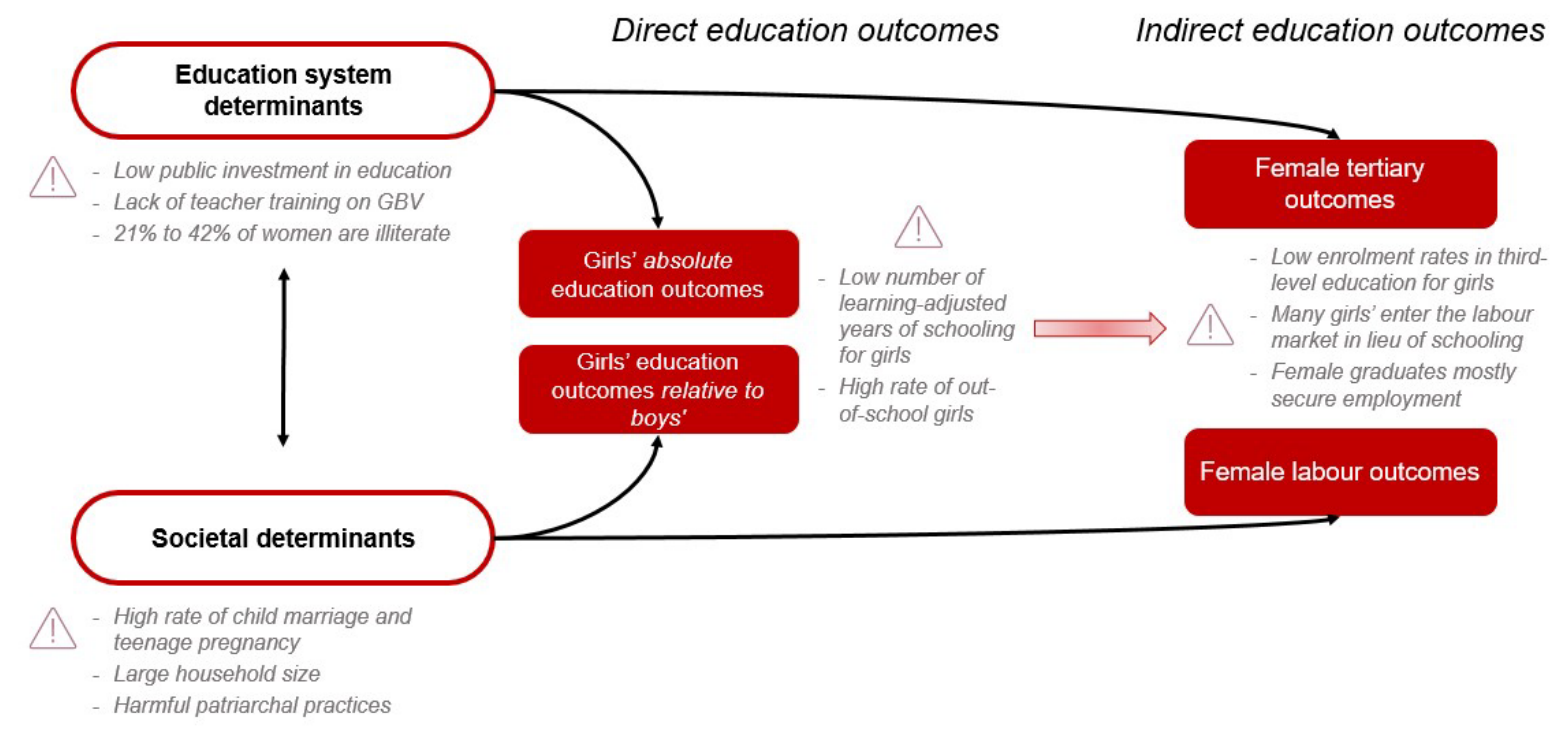

Source: Authors' own. 
Table 4. Characteristics of Type 4 countries

\begin{tabular}{|c|c|}
\hline Countries & Timor-Leste, Myanmar, Papua New Guinea, Lao PDR, and Cambodia \\
\hline $\begin{array}{l}\text { Direct education } \\
\text { outcomes }\end{array}$ & $\begin{array}{l}\text { Girls' learning-adjusted years of schooling are low overall and significantly lower than } \\
\text { expected years, a sign of low learning outcomes and corroborated by low HLO } \\
\text { scores. This links to high rates of out-of-school girls at the primary and secondary } \\
\text { level - even more so than boys in Papua New Guinea, an outlier among countries } \\
\text { analysed. }\end{array}$ \\
\hline $\begin{array}{l}\text { Indirect } \\
\text { education } \\
\text { outcomes }\end{array}$ & $\begin{array}{l}\text { Data on tertiary completion is almost non-existent, but enrolment is low, } \\
\text { without strong differences between genders. Women who complete tertiary } \\
\text { education are unlikely to be unemployed, however, suggesting access is a } \\
\text { greater concern. }\end{array}$ \\
\hline $\begin{array}{l}\text { Education system } \\
\text { determinants }\end{array}$ & $\begin{array}{l}\text { Except for Timor-Leste, government expenditure on education is low in these } \\
\text { countries, translating into high pupil-teacher ratios everywhere except Lao PDR. } \\
\text { Though data suggest over } 90 \% \text { of teachers have received basic training, it is not } \\
\text { clear whether gender sensitivity is a component. WASH infrastructure is poor and } \\
\text { SRGBV is common. }\end{array}$ \\
\hline $\begin{array}{l}\text { Societal } \\
\text { determinants }\end{array}$ & $\begin{array}{l}\text { Child marriage and adolescent pregnancy are still relatively common, } \\
\text { contributing to some of the largest family sizes in the region. Labour force } \\
\text { participation is average, ranging between } 36 \% \text { in Papua New Guinea and } 67 \% \\
\text { in Cambodia. Harmful patriarchal practices remain commonplace and may be } \\
\text { indicative of gendered norms that discourage girls' education. }\end{array}$ \\
\hline \multirow[t]{4}{*}{$\begin{array}{l}\text { FCDO } \\
\text { programming } \\
\text { implications }\end{array}$} & $\begin{array}{l}\text { - Consider policy advocacy opportunities to push for education system } \\
\text { reform, particularly increasing government investment in education and } \\
\text { aligning systems to focus on learning }\end{array}$ \\
\hline & $\begin{array}{l}\text { - Support teacher hiring and promote gender sensitivity as part of teacher } \\
\text { training }\end{array}$ \\
\hline & - Support the development of WASH infrastructure \\
\hline & - $\quad$ Broader interventions to eradicate child marriage and to address SRGBV \\
\hline
\end{tabular}

Source: Authors' own.

\section{Type 5 - Countries experiencing barriers at every level, exacerbated by additional challenges}

Type 5 countries have very low school enrolment, completion, and achievement both in absolute terms and relative to boys. Causes are similar to Type 4 countries but exacerbated by additional challenges such as conflict. 
Figure 15. Visual representation of determinants affecting girls' education outcomes in Type 5 countries

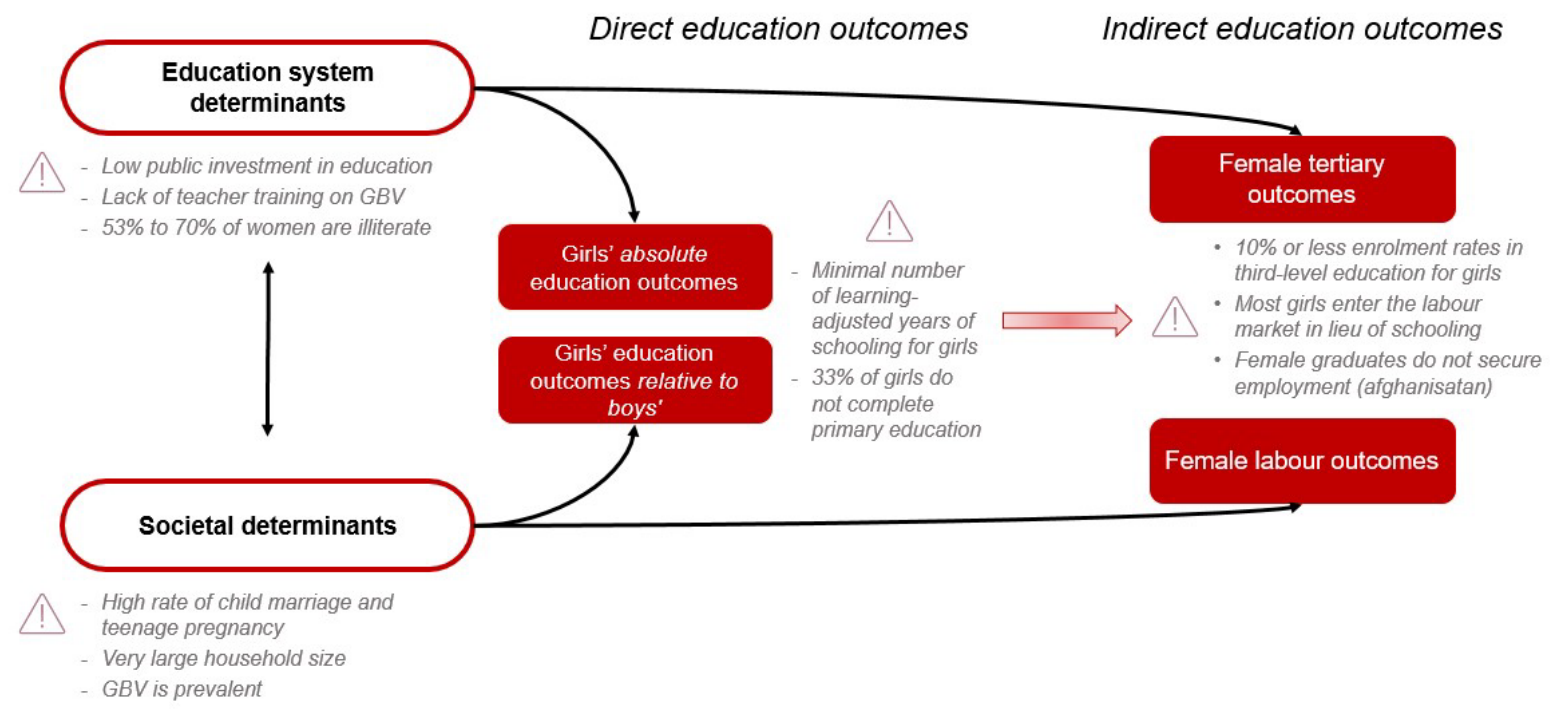

Source: Authors' own.

Table 5. Characteristics of Type 5 countries

\begin{tabular}{|c|c|}
\hline Countries & Afghanistan and Pakistan \\
\hline $\begin{array}{l}\text { Direct education } \\
\text { outcomes }\end{array}$ & $\begin{array}{l}\text { Enrolment and achievement metrics are the lowest in the region by all metrics, with } \\
\text { girls consistently doing worse than boys. } 33 \% \text { of girls do not complete primary } \\
\text { education, roughly the same as boys in Pakistan but far more than in Afghanistan. }\end{array}$ \\
\hline $\begin{array}{l}\text { Indirect education } \\
\text { outcomes }\end{array}$ & $\begin{array}{l}\text { Tertiary enrolment is minimal. Women's labour force participation is very low and } \\
\text { quality jobs are often only accessible to women with tertiary education. }\end{array}$ \\
\hline $\begin{array}{l}\text { Education system } \\
\text { determinants }\end{array}$ & $\begin{array}{l}\text { Government expenditure is average, but pupil-teacher ratios can be very high and } \\
\text { teacher training is not frequent, suggesting inadequate investment allocation. WASH } \\
\text { infrastructure is lacking and SRGBV is prevalent. Intergenerational illiteracy is } \\
\text { prevalent, with the majority of women not having been able to access education. }\end{array}$ \\
\hline $\begin{array}{l}\text { Societal } \\
\text { determinants }\end{array}$ & $\begin{array}{l}\text { Family size here ranges between } 6.6 \text { and } 8 \text {, the greatest in the region. GBV is a daily } \\
\text { occurrence in most contexts. Extreme poverty is prevalent in rural settings and highly } \\
\text { linked with patriarchal practices which influence the prioritisation of girls' education. } \\
\text { Most of all, both countries are beset by chronic conflict issues and political instability. }\end{array}$ \\
\hline \multirow{4}{*}{$\begin{array}{l}\text { FCDO } \\
\text { programming } \\
\text { implications }\end{array}$} & $\begin{array}{l}\text { - Advocate for girls' education as a policy priority, promoting women's rights } \\
\text { more broadly }\end{array}$ \\
\hline & $\begin{array}{l}\text { - Consider policy advocacy opportunities to push increased government } \\
\text { investment in education, particularly to address indirect costs of education, } \\
\text { and aligning systems to focus on learning }\end{array}$ \\
\hline & $\begin{array}{l}\text { - Support the development of WASH infrastructure and programmes to tackle } \\
\text { SRGBV }\end{array}$ \\
\hline & - $\quad$ Prioritise addressing high illiteracy levels \\
\hline
\end{tabular}




\section{References}

ADB, UNDP, UNFPA, \& United Nations Entity for Gender Equality and the Empowerment of Women. (2016). Gender equality and women's rights in Myanmar: A situation analysis. Mandaluyong City, Philippines: Asian Development Bank. Retrieved from: https://www.adb.org/sites/default/files/institutional-document/209596/gender-equalitywomens-rights-myanmar.pdf

Afkar, R., Yarrow, N., Surbakti, S., \& Cooper, R. (2020, June). Inclusion in Indonesia's education sector. A subnational review of gender gaps and children with disabilities (Policy Research Working Paper No. 9282). Washington, DC: The World Bank Group. Retrieved from: https://openknowledge.worldbank.org/bitstream/handle/10986/33943/Inclusion-inIndonesias-Education-Sector-A-Subnational-Review-of-Gender-Gaps-and-Childrenwith-Disabilities. pdf? sequence=1\&isAllowed=y

Angrist, N., Djankov, S., Goldberg, P. K., \& Patrinos, H. A. (2021a). Measuring human capital using global learning data. Nature, 592(7854), 403-408. Retrieved from: https://www.nature.com/articles/s41586-021-03323-7

Angrist, N., Djankov, S., Goldberg, P. K. \& Patrinos, H. A. (2021b). Measuring human capital using global learning data. Nature, 1-6. Retrieved from: https://datacatalog.worldbank.org/dataset/harmonized-learning-outcomes-hlodatabase

ASER Pakistan. (2014, January). Annual status of education report. ASER-Pakistan 2013. National. Lahore: South Asian Forum for Education Development (SAFED). Retrieved from:

http://aserpakistan.org/document/aser/2013/reports/national/ASER_National_Report_ 2013.pdf

Attfield, I., Henderson, C., \& Abdurazzakova, M. (2021, 24 May). COVID-19 and girls' learning continuity in South Asia: Misplaced anxiety or justified fear? Girls' Education Challenge Blog. Retrieved from: https://girlseducationchallenge.org/blogs/blogarticle/covid-19-and-girls-learning-continuity-in-south-asia-misplaced-anxiety-orjustified-fear/

Azevedo, J. P., Hasan, A., Goldemberg, D., Iqbal, S. A., \& Geven, K. (2020, June). Simulating the potential impacts of Covid-19 school closures on schooling and learning outcomes: A set of global estimates. World Bank Group. Retrieved from: https://thedocs.worldbank.org/en/doc/7980615924826827990090022020/original/covidandeducationJune17r6.pdf

BAPPENAS. (2013). Review of a decade of gender mainstreaming in education in Indonesia. Summary report. Jakarta: Ministry of National Development Planning \& National Development Planning Agency. Retrieved from: https://www.adb.org/sites/default/files/publication/176601/ino-gender-mainstreamingeducation-summary.pdf

Center for Reproductive Rights. (2018). Ending impunity for child marriage in India: Normative and implementation gaps. Retrieved from: 
https://reproductiverights.org/wp-content/uploads/2020/12/Ending-Impunity-for-ChildMarriage-India-WebUpdate-0218.pdf

Chitrakar, R. (2009). Overcoming barriers to girls' education in South Asia: Deepening the analysis. Kathmandu: UNICEF ROSA

Chudgar, A., \& Creed, B. (2014, February). How does demand for private schooling vary across locations with different private school supply? Analysis of data from rural India. College of Education Michigan State University. Retrieved from: https://ncspe.tc.columbia.edu/working-papers/OP222A.pdf

Cummins, D. (2017). Teenage pregnancy and early marriage in Timor-Leste. Research on the decision-making pathways of young women in the municipalities of Covalima, Aileu and Dili. Dili, Timor-Leste: UNFPA. Retrieved from: https://timorleste.unfpa.org/sites/default/files/pub-pdf/TPEM\%20REPORT _ENGLISH_LOW\%20DEF\%20-\%2048\%20pages.pdf

Datta, S., \& Kingdon, G. G. (2019, October). Gender bias in intra-household allocation of education in India: Has it fallen over time? (IZA Discussion Paper No. 12671). Bonn: IZA Institute of Labor Economics. http://ftp.iza.org/dp12671.pdf

Dawson, A., Rashid, A., Shuib, R., Wickramage, K., Budiharsana, M., Hidayana, I. M., \& Marranci, G. (2020). Addressing female genital mutilation in the Asia Pacific: The neglected sustainable development target. Australian and New Zealand Journal of Public Health, 44, 8-10. Retrieved from: https://doi.org/10.1111/1753-6405.12956

Doherty, B. (2018, 26 March). Rising adolescent pregnancy rates in east Asia Pacific spark health warning. The Guardian. Retrieved from: https://www.theguardian.com/society/2018/mar/27/rising-teenage-pregnancy-rates-ineast-asia-pacific-spark-health-warning

Dorji, T. (2020). Gender responsive pedagogy awareness and practices: A case study of a higher secondary school under Thimphu Thromde, Bhutan. International Journal of Linguistics and Translation Studies, 1, 100-111. 10.36892/ijlts.v1i2.21. Retrieved from: https://doi.org/10.36892/ijlls.v1i2.21

ECPAT International. (2017). Global monitoring status of action against sexual exploitation of children - Lao PDR. Retrieved from: https://www.ecpat.org/wpcontent/uploads/2017/05/A4A-Laos_2017_Final.pdf

ECPAT International. (2019). ECPAT country overview: Fiji. Bangkok: ECPAT International. Retrieved from: https://www.ecpat.org/wp-content/uploads/2019/05/ECPAT-CountryOverview-Report-Fiji-2019.pdf

Emara, N., \& Hegazy, A. (2017). Government spending on education and closing the gender gap: The case of developing economies. Retrieved from: https://mpra.ub.unimuenchen.de/94508/1/MPRA_paper_94508.pdf

End FGM European Network, End FGM/C US Network, \& Equality Now. (2020, March). Female genital multilation/cutting: A call for a global response. Retrieved from: https://www.endfgm.eu/editor/files/2020/03/FGM_Global_-_ONLINE_PDF_ VERSION_-_06_2.pdf 
Feng, N. (2020). The effect of sibling size on children's educational attainment: Evidence from Indonesia. ECNU Review of Education. Retrieved from: https://doi.org/10.1177/2096531120921703

Global Partnership for Education (GPE). (2020). Education sector analysis (ESA) for Bangladesh. Retrieved from:

https://www.globalpartnership.org/sites/default/files/document/file/2020-10Bangladesh-ESA.pdf

Global Partnership for Education (GPE) \& Ministry of Education. (2019). Education sector analysis. Maldives. Retrieved from: https://www.globalpartnership.org/sites/default/files/2019-05-maldives-educationsector-analysis.pdf

Herbert, S. (2018). The 'future of work' for women in the Indo-Pacific region (GSDRC Helpdesk Research Report). Birmingham, UK: GSDRC, University of Birmingham. Retrieved from: http://gsdrc.org/wp-content/uploads/2018/09/1434-The-future-ofwork-for-women-in-the-Indo-Pacific.pdf

Herrmann, S. D., Adelman, R. M., Bodford, J. E., Graudejus, O., Okun, M. A., \& Kwan, V. S. Y. (2016). The effects of a female role model on academic performance and persistence of women in STEM courses. Basic and Applied Social Psychology, 38(5), 258-268. Retrieved from: https://doi.org/10.1080/01973533.2016.1209757

Hickey, S., \& Hossain, N. (2019). The politics of education in developing countries: From schooling to learning. Oxford: Oxford University Press. Retrieved from: https://oxford.universitypressscholarship.com/view/10.1093/oso/9780198835684.001. 0001/oso-9780198835684

Hill, E., Baird, M., \& Ford, M. (2017). Work/care regimes in the Asia-Pacific: A feminist framework. In M. Baird, M. Ford, \& E. Hill (Eds.), Women, work and care in the AsiaPacific (Vol. 50). Taylor \& Francis. Retrieved from: https://www.routledge.com/Women-Work-and-Care-in-the-Asia-Pacific/BairdFordHill/p/book/9781138119048

Human Rights Watch. (2015). Marry before your house is swept away. Child marriage in Bangladesh. USA: Human Rights Watch. Retrieved from: https://www.hrw.org/sites/default/files/report_pdf/bangladesh0615_web.pdf

Huynh, R. (2020, 7 October). Child marriages on the rise in Indonesia amid Covid-19 outbreak. Modern Southeast Asia. Yale University. Retrieved from: https://seasia.yale.edu/news/child-marriages-rise-indonesia-amid-covid-19-outbreak

ICRW. (2012). Child marriage in Southern Asia. Policy options for action. Washington, DC: International Center for Research on Women. Retrieved from: https://www.icrw.org/wp-content/uploads/2016/10/CHILDMARRIAGE-F-13.pdf

ILO. (2017). World employment social outlook trends for women 2017. International Labour Organization. Retrieved from: https://www.ilo.org/global/research/globalreports/weso/trends-for-women2017/lang-- en/index.htm 
ILO (2018). World employment social outlook trends for women 2018. International Labour Organization. Retrieved from: https://www.ilo.org/wcmsp5/groups/public/---dgreports/--dcomm/---publ/documents/publication/wcms_619577.pdf

Islam, M. M., Islam, M. K., Hasan, M. S., \& Hossain, M. B. (2017). Adolescent motherhood in Bangladesh: Trends and determinants. PloS ONE, 12(11), e0188294. Retrieved from: https://doi.org/10.1371/journal.pone.0188294

Jurus, A., \& Musine, L. (2012). Quel impact de la taille des classes sur les performances scolaires? Regards Croisés Sur l'économie, 12(2), 81. Retrieved from: https://doi.org/10.3917/rce.012.0081

Kollmayer, M., Schultes, M.-T., Lüftenegger, M., Fistenwald, M., Spiel, C., \& Schober, B. (2020). REFLECT - A teacher training program to promote gender equality in schools. Frontiers in Education, 5. Retrieved from: https://doi.org/10.3389/feduc.2020.00136

Krishnan, M. (2021, 22 June). COVID: India sees a surge in underage marriages. Deutsche Welle. Retrieved from: https://www.dw.com/en/covid-india-sees-a-surge-in-underagemarriages/a-57992104

Kugler, A., \& Kumar, S. (2016, 20 March). The fewer the merrier: Family size and education in India. VOX, CEPR Policy Portal. Retrieved from: https://voxeu.org/article/familysize-and-education-india

Lao Statistics Bureau. (2018). Lao social indicator survey II 2017. Survey findings report. Vientiane, Lao PDR: Lao Statistics Bureau and UNICEF. Retrieved from: https://www.dhsprogram.com/pubs/pdf/FR356/FR356.pdf

Ministry of Education [Bhutan]. (2014). Bhutan education blueprint 2014-2021. Rethinking education. Thimphu: Ministry of Education Royal Government of Bhutan. Retrieved from:

https://www.globalpartnership.org/sites/default/files/bhutan_education_blueprint_2014 -2024.pdf

Ministry of Education, National Heritage, Culture \& Arts. (2015). Education for all 2015 national review report: Fiji. Retrieved from:

https://unesdoc.unesco.org/ark:/48223/pf0000231487/PDF/231487eng.pdf.multi

Ministry of Health (MOH) [Maldives] \& ICF. (2018). Maldives demographic and health survey 2016-17. Malé, Maldives, and Rockville, MA: MOH and ICF. Retrieved from: https://dhsprogram.com/pubs/pdf/FR349/FR349.pdf

Ministry of Health and Sports (MoHS) [Myanmar] \& ICF. (2017). Myanmar demographic and health survey 2015-16. Nay Pyi Taw, Myanmar, and Rockville, MA: Ministry of Health and Sports \& ICF. Retrieved from:

https://www.dhsprogram.com/pubs/pdf/FR324/FR324.pdf

Mohamed, Y., Durrant, K., Huggett, C., Davis, J., Macintyre, A., Menu, S., et al. (2018) A qualitative exploration of menstruation-related restrictive practices in Fiji, Solomon Islands and Papua New Guinea. PLoS ONE 13(12), e0208224. Retrieved from: https://doi.org/10.1371/journal.pone.0208224 
Najeeb, F., Morales, M., \& Lopez-Acevedo, G. (2020). Analyzing female employment trends in South Asia (Policy Research Working Paper No. 9157). Washington, DC. World Bank. Retrieved from: https://openknowledge.worldbank.org/handle/10986/33362

National Institute of Statistics, Directorate General for Health, \& ICF International. (2015). Cambodia demographic and health survey 2014. Phnom Penh, Cambodia, and Rockville, MA: National Institute of Statistics, Directorate General for Health, and ICF International. Retrieved from: https://dhsprogram.com/pubs/pdf/FR312/FR312.pdf

National Statistical Office (NSO) and UNICEF. (2016). Thailand multiple indicator cluster survey 2015-2016. Final report. Bangkok: NSO and UNICEF. Retrieved from: https://www.unicef.org/thailand/sites/unicef.org.thailand/files/201806/Thailand_MICS_Full_Report_EN_0.pdf

National Statistical Office of Thailand. (2020). Thailand multiple indicator cluster survey 2019. Survey findings report. Bangkok: National Statistical Office of Thailand. Retrieved from: https://mics-surveysprod.s3.amazonaws.com/MICS6/East\%20Asia\%20and\%20the\% 20Pacific/Thailand/2019/Survey\%20findings/Thailand\%202019\%20MICS\%20Survey $\% 20$ Findings\%20Report_English.pdf

NIPORT \& ICF. (2020). Bangladesh demographic and health survey 2017-18. Dhaka, Bangladesh, and Rockville, MA: National Institute of Population Research and Training and ICF. Retrieved from: https://dhsprogram.com/pubs/pdf/FR344/FR344.pdf

NSO [Papua New Guinea] \& ICF. (2019). Papua New Guinea demographic and health survey 2016-18. Port Moresby, Papua New Guinea, and Rockville, MA: National Statistical Office and ICF. Retrieved from: https://dhsprogram.com/pubs/pdf/FR364/FR364.pdf

OECD Development Centre. (2016). SIGI regional report for East Asia and the Pacific. Retrieved from: https://www.oecd.org/dev/developmentgender/Brochure_SIGI_EAP_web.pdf

OECD. (2019). PISA 2018 results (volume II): Where all students can succeed. Paris: OECD Publishing. Retrieved from: https://doi.org/10.1787/f56f8c26-en

Ortiz-Ospina, E., \& Roser, M. (2016). Government spending. OurWorldInData.org [Online resource]. https://ourworldindata.org/government-spending

Oxfam International \& Humanitarian Accountability Monitoring Initiative (HAMI). (2019). Fighting inequality in Nepal. The road to prosperity. Oxford: Oxfam GB for Oxfam International. Retrieved from:

https://oxfamilibrary.openrepository.com/bitstream/handle/10546/620607/bp-fightinginequality-nepal-110119-en.pdf?sequence=1

Plan International. (2013). Because I am a girl: The state of the world's girls 2013 - In double jeopardy: Adolescent girls and disasters. Retrieved from: https://planinternational.org/publications/state-worlds-girls-2013-adolescent-girls-anddisasters\#download-options 
Plan International. (2016). Getting the evidence: Asia Child Marriage Initiative. Retrieved from: https://plan-international.org/publications/getting-evidence-asia-child-marriageinitiative\#download-options

Plan International. (n.d.). Adolescent pregnancy. Plan International. Retrieved 27 July 2021 from: https://plan-international.org/sexual-health/teenage-pregnancy

Plan International Australia. (2021). Smart, successful, strong: The case for investing in adolescent girls' education in aid and COVID-19 response and recovery. Retrieved from: https://www.plan.org.au/publications/smart-successful-strong/

Price, R. (2020). Key barriers to girls' education in the ASEAN and Pacific region (K4D Helpdesk Report). Brighton, UK: Institute of Development Studies. Retrieved from: https://opendocs.ids.ac.uk/opendocs/handle/20.500.12413/15738

PSA. (2018). APIS 2017 - Annual poverty indicators survey: Final report. Quezon City, Philippines: Philippine Statistics Authority. Retrieved from: https://psa.gov.ph/sites/default/files/2017\%20APIS\%20FINAL\%20REPORT.pdf

Rose, P., Sabates, R., Alcott, B., \& Ilie, S. (2017). Overcoming inequalities within countries to achieve global convergence in learning (Background paper for The Learning Generation). The Education Commission. Retrieved from: https://palnetwork.org/wpcontent/uploads/2017/09/Overcoming-Inequalities-within-Countries.pdf

Roser, M., \& Ortiz-Ospina, E. (2013) Primary and secondary education. OurWorldInData.org [Online resource]. https://ourworldindata.org/primary-and-secondary-education

Roser, M., \& Ortiz-Ospina, E. (2016). Financing education. OurWorldlnData.org [Online resource]. https://ourworldindata.org/financing-education

RTE Forum. (2021). Policy brief on girls' education. New Delhi: RTE Forum. Retrieved from: https://www.careindia.org/wp-content/uploads/2021/05/Policy-Brief-GirlsEducation.pdf

Shrestha, A. (2012). Adolescent pregnancy in Nepal: Consequences, causes and policy recommendations. Retrieved from: https://www.bibalex.org/Search4Dev/files/428878/455706.pdf

Sijapati, B., Bhattarai, A., \& Pathak, D. (2015). Analysis of labour market and migration trends in Nepal. Kathmandu, Nepal: GIZ and International Labour Organization. Retrieved from: https://www.ilo.org/wcmsp5/groups/public/---asia/---ro-bangkok/---ilokathmandu/documents/publication/wcms_407963.pdf

Silberstein, J. (2021). Measuring, visualising, and simulating solutions to the learning crisis: New evidence from learning profiles in 18 countries. Research on Improving Systems of Education (RISE). Retrieved from: https://riseprogramme.org/sites/default/files/202106/Measuring_Visualising_Simulating_Solutions_Learning_Crisis_.pdf

Sisters in Islam (SIS) \& Asian-Pacific Resource and Research Centre for Women (ARROW). (2018). National report: Malaysia - Child marriage: Its relationship with religion, culture and patriarchy. Retrieved from: https://arrow.org.my/wpcontent/uploads/2018/03/National-Report-Child-Marriage.pdf 
Sosale, S., Asaduzzaman, T. M., \& Ramachandran, D. (2019, 24 June). Girls' education in Bangladesh: A promising journey. World Bank Blogs. Retrieved from: https://blogs.worldbank.org/endpovertyinsouthasia/girls-education-bangladeshpromising-journey

United Nations Development Programme (UNDP). (2016). Gender equality and women's empowerment strategy and action plan 2017-2021. Towards more efficient and effective responses to development challenges in Viet Nam. Retrieved from: https://www.undp.org/content/dam/Viet Nam/docs/Publications/gender\%20strategy_UNDP\%20VN.pdf

UNESCAP. (2019). Inequality of opportunity in Asia and the Pacific: Education (ESCAP Social Development Policy Papers No. 2018-01). Thailand. Retrieved from: https://www.unescap.org/sites/default/d8files/knowledge-products/Education_Report_ 20190129.pdf

UNESCO. (2014). School-related gender-based violence in the Asia-Pacific region. Bangkok: UNESCO Bangkok Office. Retrieved from:

https://healtheducationresources.unesco.org/library/documents/school-relatedgender-based-violence-asia-pacific-region

United Nations Girls' Education Initiative (UNGEI) \& Global Partnership for Education (GPE). (2017). Guidance for developing gender-responsive education sector plans. Retrieved from: www.edulinks.org/sites/default/files/media/file/ACFrOgBOa753QTH02Xc7zVq67zFZxAEh5nbo7hE 9R49r8_4ictLYppdWIQLwNSOgHZNL1aC2ojOnNFEc_2wzKokNzehJCjwtJHjbc8kAEdAS PnLtWVTrBv2S3ej-HE8_.pdf

UNICEF. (2016). Study on violence against children in and around educational settings: Timor-Leste. Retrieved from: https://www.unicef.org/timorleste/media/2671/file/Study_on_VAC_english_version_FI NAL.pdf.pdf

UNICEF. (2017a). Menstrual hygiene management: The challenges facing students and nuns in Bhutan. New York, NY: United Nations Children's Fund. Retrieved from: https://www.unicef.org/rosa/media/5431/file/WASH\%20Field\%20Note_Menstrual\%20 Hygiene \%20Management:\%20The $\% 20$ Challenge $\% 20$ facing $\% 20$ students $\% 20$ and $\% 20$ nuns\%20in\%20Bhutan.pdf

UNICEF. (2017b). Education UNICEF Country Programme 2019-2023. Bona Khoy: UNICEF Cambodia. Retrieved from:

https://www.unicef.org/cambodia/media/2386/file/CountryProgramme_Education.pdf\% 20.pdf

UNICEF. (2018a, 25 May). FAST FACTS: Nine things you didn't know about menstruation [Press release]. Retrieved from: https://www.unicef.org/press-releases/fast-facts-ninethings-you-didnt-know-about-menstruation\#_edn5

UNICEF. (2018b). Out-of-school children report 2016: Viet Nam Country Study. Retrieved from: https://www.unicef.org/Viet Nam/media/2481/file/Main\%20report\%20Out-ofschool-children-report-2016.pdf 
UNICEF. (2019). Ending child marriage: A profile of progress in India. Retrieved from: https://data.unicef.org/wp-content/uploads/2019/02/Child-Marriage_India_fordigital_0215.pdf

UNICEF. (2020a). Gender-responsive education in the context of COVID19. Framework and progressive standards for South Asia. Panjwani: UNICEF Regional Office for South Asia. Retrieved from: https://inee.org/system/files/resources/Genderresponsive\%20Education\%20in\%20the\%20Context\%200f\%20COVID-19.pdf

UNICEF. (2020b, October). Issue Brief: COVID-19 and girls' education in East Asia and Pacific (UNICEF Education COVID-19 Response). Retrieved from: https://reliefweb.int/sites/reliefweb.int/files/resources/201016_eapro_girls_education_ covid_final.pdf

UNICEF. (2020c). Ending child marriage: A profile of progress in Bangladesh. Retrieved from:

https://www.unicef.org/bangladesh/media/4526/file/Bangladesh\%20Child\%20Marriag e\%20report\%202020.pdf.pdf

UNICEF Data. (2020, April). Child marriage. UNICEF Data. Retrieved from: https://data.unicef.org/topic/child-protection/child-marriage/

UNICEF Data and Analytics Section, Division of Data, Research and Policy. (2019). Indonesia. Statistical profile on female genital mutilation. Retrieved from: https://data.unicef.org/resources/fgm-country-profiles/

UNICEF East Asia and Pacific Regional Office (EAPRO). (2021, March). Water, sanitation and hygiene in East Asia and the Pacific. Annual results report 2020. Retrieved from: https://www.unicef.org/eap/media/7926/file/Water,\%20Sanitation\%20and\%20Hygiene \%20Annual\%20Results\%20Report\%202020.pdf

UNICEF Lao PDR. (2020). The situation of children and women Lao People's Democratic Republic. Ventiane: UNICEF. https://www.unicef.org/laos/reports/situation-childrenand-women-laoprd

UNICEF ROSA. (2016). Violence against children in education settings in South Asia. A desk review April 2016. Lekhnath Marg: UNICEF Regional Office for South Asia. Retrieved from:

https://www.unicef.org/media/66581/file/Violence-against-children-in-educationsettings-in-SouthAsia.pdf

UNICEF ROSA. (2019). Child marriage, adolescent pregnancy and school dropout in South Asia. Nepal: UNICEF Regional Office for South Asia.

https://www.unicef.org/rosa/media/3096/file/UNICEF_ROSA_Child_marriage_adolesc ent_pregnancy_3May2019.pdf

UNICEF Regional Office for South Asia (ROSA) \& UNFPA Asia and the Pacific Regional Office (APRO). (2017). Ending child marriage in Nepal. Retrieved from: https://www.unicef.org/nepal/media/401/file/Ending\%20Child\%20Marriage\%20in\%20 Nepal.pdf 
UNICEF, Statistics Indonesia (BPS), National Development Planning Agency (BAPPENAS), \& Center on Child Protection and Wellbeing at Universitas Indonesia (PUSKAPA). (2020). Prevention of child marriage: Acceleration that cannot wait. Retrieved from: https://www.unicef.org/indonesia/sites/unicef.org.indonesia/files/2020-06/Preventionof-Child-Marriage-Report-2020.pdf

UNICEF Viet Nam \& UNFPA Viet Nam. (2018). Ending child marriage, empowering girls. A joint discussion brief from UNICEF and UNFPA in Viet Nam on child marriage in Viet Nam. Retrieved from: https://www.unicef.org/Viet Nam/media/2406/file/Ending\%20child\%20marriage,\%20empowering\%20girls\%20.pdf

UNICEF \& UNFPA. (2019). Child marriage in South Asia: An evidence review. Kathmandu: UNICEF. Retrieved from: https://www.unicef.org/rosa/media/4251/file/Child\%20Marriage\%20Evidence\%20Revi ew_Web.pdf

WaterAid. (2018). Bangladesh. Menstrual hygiene management in schools in South Asia (Country snapshot). Retrieved from: https://washmatters.wateraid.org/sites/g/files/jkxoof256/files/menstrual-hygienemanagement-snapshot---bangladesh.pdf

WHO. (2020, 3 February). Female genital mutilation. World Health Organization. Retrieved from: https://www.who.int/news-room/fact-sheets/detail/female-genital-mutilation

Wodon, Q., et al. (2017) Economic impacts of child marriage: Global synthesis report. Washington, DC: World Bank Group. Retrieved from: http://documents.worldbank.org/curated/en/530891498511398503/Economic-impactsof-child-marriage-global-synthesis-report

Wodon, Q., Montenegro, C., Nguyen, H., \& Onagoruwa, A. (2018). Missed opportunities: The high cost of not educating girls (The Cost of Not Educating Girls Notes Series). Washington, DC: World Bank. Retrieved from: https://openknowledge.worldbank.org/handle/10986/29956

World Bank. (2018). World development report 2018: Learning to realize education's promise. Washington, DC: World Bank. Retrieved from: https://www.worldbank.org/en/publication/wdr2018

The World Bank. (2020). Women, business, and the law 2020. Washington, DC: World Bank. Retrieved from:

https://openknowledge.worldbank.org/bitstream/handle/10986/32639/9781464815324 .pdf? sequence $=10$

World Bank. (2021, 8 March). Girls' education. World Bank understanding poverty. https://www.worldbank.org/en/topic/girlseducation

World Bank. (n.d.,a). DataBank: Human Capital Index. [Online resource]. https://databank.worldbank.org/reports. aspx?source=3698\&series=HD.HCI.LAYS.FE

World Bank. (n.d.,b). Learning-adjusted years of school. TCdata360. [Online resource]. https://tcdata360. worldbank.org/indicators/h00280750? country=BRA\&indicator $=40964$ \&viz=line_chart\&years $=2010,2020$ 
Key websites

- Demographic and Health Survey Programme: https://dhsprogram.com

- Girls Not Brides atlas: https://atlas.girlsnotbrides.org

- Global Partnership for Education (GPE): https://www.globalpartnership.org

- Plan International: https://plan-international.org/sexual-health/teenage-pregnancy

- Population Reference Bureau (PRB): https://interactives.prb.org/2020-wpds/

- RISE - Research on Improving Systems of Education: https://riseprogramme.org

- UNICEF MICS: https://mics.unicef.org

- World Bank in East Asia Pacific: https://www.worldbank.org/en/region/eap

- World Bank in South Asia: https://www.worldbank.org/en/region/sar

- World Bank Open Data: http://data.worldbank.org/ 


\section{Annexe 1}

\section{Direct education outcomes}

\begin{tabular}{|c|c|c|c|c|c|c|c|c|c|c|c|}
\hline \multirow{2}{*}{ Typology } & \multirow{2}{*}{ Country } & \multicolumn{3}{|l|}{$\begin{array}{l}\text { Expected } \\
(2020)\end{array}$} & \multicolumn{3}{|c|}{$\begin{array}{l}\text { Learning-adjusted } \\
\text { school (2020) }\end{array}$} & \multicolumn{4}{|c|}{$\begin{array}{l}\text { Harmonised } \quad \text { Learning } \\
\text { (reading, most recent year available) }\end{array}$} \\
\hline & & Girls & Boys & Differential & Girls & Boys & Differential & Female & Male & Differential & Year \\
\hline \multirow{4}{*}{1} & China & 13.2 & 13.1 & 0.14 & 9.3 & 9.2 & 0.1 & 502.6 & 486.4 & 16.2 & 2015 \\
\hline & Japan & NA & NA & NA & NA & NA & NA & 522.7 & 509.4 & 13.3 & 2015 \\
\hline & Singapore & 13.9 & 13.9 & -0.03 & 12.9 & 12.8 & 0.1 & 585.1 & 567.6 & 17.5 & 2016 \\
\hline & Viet Nam & 13.2 & 12.5 & 0.65 & 11.0 & 10.3 & 0.7 & 522.5 & 491.7 & 30.8 & 2012 \\
\hline \multirow{6}{*}{2} & Fiji & 11.4 & 11.2 & 0.16 & 7.3 & 6.6 & 0.7 & NA & NA & NA & NA \\
\hline & Indonesia & 12.5 & 12.3 & 0.23 & 8.0 & 7.6 & 0.4 & 409.1 & 385.6 & 23.5 & 2015 \\
\hline & Malaysia & 12.7 & 12.3 & 0.44 & 9.2 & 8.6 & 0.6 & 417.6 & 377.5 & 40.1 & 2012 \\
\hline & Maldives & NA & NA & NA & NA & NA & NA & NA & NA & NA & NA \\
\hline & Philippines & 13.2 & 12.8 & 0.45 & 7.8 & 7.2 & 0.6 & 430.8 & 397.1 & 33.7 & 2013 \\
\hline & Thailand & 12.7 & 12.8 & -0.07 & 8.9 & 8.4 & 0.5 & 422.6 & 391.6 & 31.0 & 2015 \\
\hline \multirow{5}{*}{3} & Bangladesh & 10.5 & 9.8 & 0.69 & 6.2 & 5.8 & 0.4 & 342.8 & 337.2 & 5.6 & 2016 \\
\hline & Bhutan & 10.7 & 9.8 & 0.93 & 6.3 & 6.1 & 0.2 & NA & NA & NA & NA \\
\hline & India & 11.2 & 11.0 & 0.16 & 7.2 & 7.1 & 0.1 & 349.8 & 316.7 & 33.1 & 2009 \\
\hline & Nepal & 12.2 & 12.3 & -0.09 & NA & NA & NA & NA & NA & NA & NA \\
\hline & Sri Lanka & 13.3 & 13.2 & 0.12 & NA & NA & NA & NA & NA & NA & NA \\
\hline \multirow{5}{*}{4} & Cambodia & 9.6 & 9.3 & 0.28 & NA & NA & NA & NA & NA & NA & NA \\
\hline & Lao PDR & 10.5 & 10.7 & -0.19 & 6.3 & 6.2 & 0.1 & 349.7 & 329.6 & 20.1 & 2012 \\
\hline & Myanmar & 10.0 & 9.9 & 0.06 & 6.9 & 6.7 & 0.2 & 454.7 & 430.8 & 23.9 & 2016 \\
\hline & PNG & 9.8 & 10.8 & -0.99 & 5.8 & 6.2 & -0.4 & 325.5 & 326.6 & -1.1 & 2013 \\
\hline & Timor-Leste & 10.9 & 10.3 & 0.61 & 6.6 & 6.0 & 0.6 & 357.3 & 335.1 & 22.2 & 2011 \\
\hline \multirow{3}{*}{5} & Afghanistan & 6.9 & 9.7 & -2.80 & 3.9 & 5.5 & -1.6 & 307.0 & 320.0 & -13.0 & 2016 \\
\hline & Pakistan & 10.0 & 10.0 & 0.00 & 4.8 & 5.4 & -0.6 & 294.1 & 278.8 & 15.3 & 2017 \\
\hline & & \multicolumn{3}{|c|}{$\begin{array}{l}\text { Human Capital Index in World Bank Database: } \\
\text { (1) https://databank.worldbank.org/reports.aspx?sourc } \\
\text { e=3698\&series=HD.HCl.EYRS.FE } \\
\text { (2) https://databank.worldabank.org/reports. aspx?sourc } \\
\mathrm{e}=3698 \text { s }\end{array}$} & \multicolumn{3}{|c|}{$\begin{array}{l}\text { Human Capital Index 2020: } \\
\text { https://www.worldbank.org/en/publication/human } \\
\text {-capital\#IIndex }\end{array}$} & \multicolumn{4}{|c|}{ Angrist, Djankov, Goldberg, \& Patrinos (2021a). } \\
\hline
\end{tabular}


PISA scores (2018)

Typology Country

\section{Reading}

Maths

Girls Boys

China

\begin{tabular}{ll|l|l} 
& 562 & 549 & 13 \\
Japan & 514 & 493 & 21
\end{tabular}

Singapore

Viet Nam

Fiji

Indonesia

Indonesia

Maldives

Philippines

Thailand

Bangladesh

Bhutan

India

Nepal

Sri Lanka

Cambodia

Lao PDR

Myanmar

PNG

Timor-Leste

\begin{tabular}{l|l} 
Afghanistan \\
Pakistan
\end{tabular}

\begin{tabular}{l|l} 
Afghanistan \\
Pakistan
\end{tabular}

Girls Boys Differential

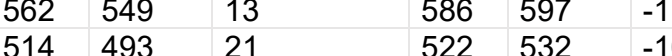

$561-538-23$

$\begin{array}{lll}561 & 538 & 23 \\ \text { NA } & \text { NA } & \text { NA }\end{array}$

NA NA NA

$\begin{array}{lll}353 & 358 & -5\end{array}$

\begin{tabular}{ll|l}
428 & 402 & 26
\end{tabular}

NA $N A \quad$ NA

\begin{tabular}{l|l|l}
411 & 372 & 39
\end{tabular}

$\begin{array}{lll}\text { NA } & \text { NA } & \text { NA } \\ \text { NA } & \text { NA } & \text { NA }\end{array}$

NA NA NA

NA NA NA

NA NA NA

NA NA NA

$\begin{array}{lll}\text { NA } & \text { NA } & \text { NA } \\ \text { NA } & \text { NA } & \text { NA }\end{array}$

NA NA NA

5

\begin{tabular}{l|l|l|l|l}
522 & 532 & -10 & 584 & 596 \\
\hline
\end{tabular}

$\begin{array}{lll}-11 & 528 & 531 \\ -4 & 549 & 553\end{array}$

NA NA NA

NA NA NA

$\begin{array}{lll}383 & 374 & 9\end{array}$

$\begin{array}{lll}443 & 437 & 6\end{array}$

NA NA NA

$\begin{array}{lll}358 & 346 & 12\end{array}$

$\begin{array}{lll}426 & 410 & 16\end{array}$

NA NA NA

NA NA NA

NA NA NA

$\begin{array}{lll}N A & N A & N A \\ N A & N A & N A\end{array}$

NA NA NA

$\begin{array}{lll}N A & N A & N A \\ N A & N A & N A\end{array}$

$\begin{array}{lll}N A & N A & N A \\ N A & N A & N A\end{array}$

NA NA NA

NA NA NA

NA NA NA

$N A$
$N A$
3
4
$N A$
359
4
$N A$
$N A$
$N A$
$N A$
$N A$
$N A$
$N A$
$N A$
$N A$
$N A$
$N A$

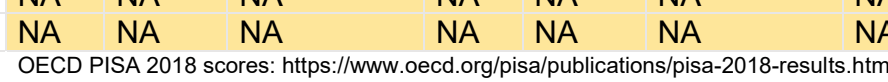

$\%$ of out-of-school children

Primary level

Secondary level

\begin{tabular}{|c|c|c|c|c|c|c|c|c|}
\hline \multirow[b]{2}{*}{ Differential } & \multicolumn{4}{|c|}{ Primary level } & \multicolumn{4}{|c|}{ Secondary level } \\
\hline & Girls & Boys & Differential & Year & Girls & Boys & Differential & Year \\
\hline-12 & $12 \%$ & $10 \%$ & $2 \%$ & 1997 & NA & NA & NA & NA \\
\hline-3 & NA & NA & NA & NA & NA & NA & NA & NA \\
\hline-4 & $0 \%$ & $0 \%$ & $0 \%$ & 2018 & $1 \%$ & $0 \%$ & $1 \%$ & 2018 \\
\hline NA & NA & NA & NA & NA & NA & NA & NA & NA \\
\hline NA & $1 \%$ & $1 \%$ & $0 \%$ & 2015 & $17 \%$ & $21 \%$ & $-4 \%$ & 2003 \\
\hline 6 & $8 \%$ & $3 \%$ & $5 \%$ & 2018 & $14 \%$ & $19 \%$ & $-5 \%$ & 2018 \\
\hline 7 & $0 \%$ & $0 \%$ & $0 \%$ & 2014 & $12 \%$ & $15 \%$ & $-3 \%$ & 2017 \\
\hline NA & $1 \%$ & $3 \%$ & $-2 \%$ & 2019 & $10 \%$ & $11 \%$ & $-1 \%$ & 2002 \\
\hline 4 & $4 \%$ & $4 \%$ & $0 \%$ & 2018 & $8 \%$ & $14 \%$ & $-6 \%$ & 2018 \\
\hline 20 & $2 \%$ & $1 \%$ & $1 \%$ & 2009 & $3 \%$ & $4 \%$ & $-1 \%$ & 2009 \\
\hline NA & $3 \%$ & $5 \%$ & $-2 \%$ & 2008 & $22 \%$ & $29 \%$ & $-7 \%$ & 2010 \\
\hline NA & $2 \%$ & $5 \%$ & $-3 \%$ & 2020 & $6 \%$ & $18 \%$ & $-12 \%$ & 2018 \\
\hline NA & $1 \%$ & $3 \%$ & $-2 \%$ & 2013 & $12 \%$ & $18 \%$ & $-6 \%$ & 2013 \\
\hline NA & $25 \%$ & $14 \%$ & $11 \%$ & 2004 & $1 \%$ & $4 \%$ & $-3 \%$ & 2019 \\
\hline NA & $3 \%$ & $2 \%$ & $1 \%$ & 2014 & $0 \%$ & $0 \%$ & $0 \%$ & 2018 \\
\hline NA & $9 \%$ & $9 \%$ & $0 \%$ & 2019 & $14 \%$ & $12 \%$ & $2 \%$ & 2015 \\
\hline NA & $9 \%$ & $8 \%$ & $1 \%$ & 2019 & $28 \%$ & $27 \%$ & $1 \%$ & 2019 \\
\hline NA & $12 \%$ & $10 \%$ & $2 \%$ & 2010 & $20 \%$ & $22 \%$ & $-2 \%$ & 2018 \\
\hline NA & $10 \%$ & $4 \%$ & $6 \%$ & 2016 & $19 \%$ & $10 \%$ & $9 \%$ & 2016 \\
\hline NA & $3 \%$ & $7 \%$ & $-4 \%$ & 2019 & $9 \%$ & $12 \%$ & $-3 \%$ & 2019 \\
\hline NA & NA & NA & NA & NA & NA & NA & NA & NA \\
\hline NA & NA & NA & NA & NA & NA & NA & NA & NA \\
\hline
\end{tabular}

Wha Statistics (uis.unesco.org) UNESCO Institule for Statistics (uis.unesco.org)

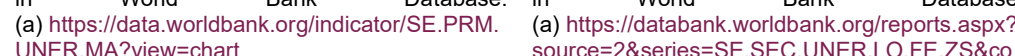
(b) https://data.worldbank.org/indicator/SE.PRM. unty

untry=
(b) https://data.worldbank.org/indicator/SE.SEC. UNER.LO.MA.ZS 
School completion rate $(\%)^{15}$

\begin{tabular}{|c|c|c|c|c|c|c|c|c|c|}
\hline \multirow[t]{2}{*}{ Typology } & \multirow[t]{2}{*}{ Country } & \multicolumn{4}{|c|}{ Primary } & \multicolumn{4}{|c|}{ Secondary } \\
\hline & & Girls & Boys & Differential & Year & Girls & Boys & Differential & Year \\
\hline \multirow{4}{*}{1} & China & $98 \%$ & $99 \%$ & $-1 \%$ & 2009 & $101 \%$ & $99 \%$ & $2 \%$ & 2011 \\
\hline & Japan & NA & NA & NA & NA & NA & NA & NA & NA \\
\hline & Singapore & $100 \%$ & $100 \%$ & $0 \%$ & 2018 & $99 \%$ & $100 \%$ & $-1 \%$ & 2018 \\
\hline & Viet Nam & $112 \%$ & $109 \%$ & $3 \%$ & 2018 & $101 \%$ & $95 \%$ & $6 \%$ & 2018 \\
\hline \multirow{6}{*}{2} & Fiji & $106 \%$ & $108 \%$ & $-2 \%$ & 2016 & $106 \%$ & $99 \%$ & $8 \%$ & 2016 \\
\hline & Indonesia & $102 \%$ & $103 \%$ & $-1 \%$ & 2018 & $93 \%$ & $87 \%$ & $5 \%$ & 2017 \\
\hline & Malaysia & $102 \%$ & $98 \%$ & $4 \%$ & 2017 & $88 \%$ & $82 \%$ & $5 \%$ & 2019 \\
\hline & Maldives & $93 \%$ & $90 \%$ & $3 \%$ & 2019 & $101 \%$ & $122 \%$ & $-21 \%$ & 2019 \\
\hline & Philippines & $113 \%$ & $117 \%$ & $-4 \%$ & 2018 & $87 \%$ & $74 \%$ & $13 \%$ & 2018 \\
\hline & Thailand & $94 \%$ & $94 \%$ & $0 \%$ & 2019 & $85 \%$ & $77 \%$ & $7 \%$ & 2018 \\
\hline \multirow{5}{*}{3} & Bangladesh & $72 \%$ & $64 \%$ & $8 \%$ & 2010 & $87 \%$ & $72 \%$ & $15 \%$ & 2016 \\
\hline & Bhutan & $104 \%$ & $96 \%$ & $8 \%$ & 2017 & $93 \%$ & $77 \%$ & $16 \%$ & 2020 \\
\hline & India & $93 \%$ & $90 \%$ & $3 \%$ & 2016 & $85 \%$ & $81 \%$ & $4 \%$ & 2019 \\
\hline & Nepal & $123 \%$ & $118 \%$ & $5 \%$ & 2019 & $102 \%$ & $97 \%$ & $4 \%$ & 2019 \\
\hline & Sri Lanka & $102 \%$ & $103 \%$ & $-1 \%$ & 2017 & $96 \%$ & $97 \%$ & $-1 \%$ & 2017 \\
\hline \multirow{5}{*}{4} & Cambodia & $95 \%$ & $88 \%$ & $7 \%$ & 2019 & $64 \%$ & $52 \%$ & $12 \%$ & 2019 \\
\hline & Lao PDR & $92 \%$ & $92 \%$ & $0 \%$ & 2019 & $64 \%$ & $67 \%$ & $-3 \%$ & 2019 \\
\hline & Myanmar & $95 \%$ & $96 \%$ & $-1 \%$ & 2018 & $68 \%$ & $62 \%$ & $6 \%$ & 2018 \\
\hline & PNG & $72 \%$ & $82 \%$ & $-10 \%$ & 2016 & $54 \%$ & $69 \%$ & $-15 \%$ & 2016 \\
\hline & Timor-Leste & $109 \%$ & $101 \%$ & $8 \%$ & 2019 & $96 \%$ & $86 \%$ & $10 \%$ & 2019 \\
\hline \multirow{3}{*}{5} & Afghanistan & $67 \%$ & $101 \%$ & $-34 \%$ & 2018 & $40 \%$ & $69 \%$ & $-29 \%$ & 2018 \\
\hline & Pakistan & $67 \%$ & $67 \%$ & $0 \%$ & 2019 & $46 \%$ & $52 \%$ & $-6 \%$ & 2019 \\
\hline & & \multicolumn{4}{|c|}{$\begin{array}{l}\text { World } \quad \text { Development } \quad \text { Indicators in } \quad \text { World } \\
\text { (a) https://databank.worldbank.org/reports.aspx?source=2\&series=SE.PRM.CMPT.MA.ZS\&countr } \\
\text { y= } \\
\text { (b) https://databank.worldbank.org/reports.aspx?source=2\&series=SE.PRM.CMPT.FE.ZS\&country } \\
=\end{array}$} & \multicolumn{4}{|c|}{$\begin{array}{l}\text { World Development Indicators in World Bank Database: } \\
\text { (a) https://databank.worldbank.org/reports.aspx?source=2\&series=SE.SEC.CMPT.LO.MA.ZS } \\
\text { \&country= } \\
\text { (b) https://databank.worldbank.org/reports.aspx?source=2\&series=SE.SEC.CMPT.LO.FE.ZS } \\
\text { \&country }=\end{array}$} \\
\hline
\end{tabular}

${ }^{15}$ World Bank Data: School completion ratio can exceed 100\% due to overaged and underaged children who enter primary school late/early and/or repeat grades. 


\section{Indirect education outcomes}

Educational attainment, short-cycle tertiary Unemployed population with advanced Tertiary education enrolment (\%, gross) $\begin{aligned} & \text { minimum completed, population aged 25+ } \\ & \text { (cumulative, \%) }\end{aligned}$

\begin{tabular}{|c|c|c|c|c|c|c|c|c|c|c|c|c|c|}
\hline \multirow[t]{2}{*}{ Typology } & \multirow[t]{2}{*}{ Country } & \multicolumn{4}{|c|}{ Tertiary education enrolment (\%, gross) } & \multicolumn{4}{|c|}{$\begin{array}{l}\text { minimum completed, population aged 25+ } \\
\text { (cumulative, \%) }\end{array}$} & \multicolumn{4}{|c|}{ education $(\%)$} \\
\hline & & Girls & Boys & Differential & Year & Female & Male & Differential & Year & Female & Male & Differential & Year \\
\hline \multirow{4}{*}{1} & China & $58 \%$ & $49 \%$ & $9 \%$ & 2019 & $8 \%$ & $10 \%$ & $-2 \%$ & 2020 & NA & NA & NA & NA \\
\hline & Japan & NA & NA & NA & NA & $32 \%$ & $37 \%$ & $-5 \%$ & 2010 & $2 \%$ & $2 \%$ & $0 \%$ & 2019 \\
\hline & Singapore & $95 \%$ & $83 \%$ & $12 \%$ & 2018 & $44 \%$ & $50 \%$ & $-6 \%$ & 2018 & $5 \%$ & $4 \%$ & $1 \%$ & 2017 \\
\hline & Viet Nam & $32 \%$ & $26 \%$ & $6 \%$ & 2016 & $6 \%$ & $8 \%$ & $-2 \%$ & 2009 & $6 \%$ & $3 \%$ & $3 \%$ & 2020 \\
\hline \multirow{6}{*}{2} & Fiji & $18 \%$ & $15 \%$ & $3 \%$ & 2005 & $5 \%$ & $5 \%$ & $0 \%$ & 2017 & $6 \%$ & $4 \%$ & $2 \%$ & 2016 \\
\hline & Indonesia & $39 \%$ & $34 \%$ & $5 \%$ & 2018 & $10 \%$ & $10 \%$ & $0 \%$ & 2018 & $5 \%$ & $4 \%$ & $1 \%$ & 2019 \\
\hline & Malaysia & $49 \%$ & $38 \%$ & $11 \%$ & 2019 & $20 \%$ & $17 \%$ & $3 \%$ & 2016 & $4 \%$ & $4 \%$ & $0 \%$ & 2016 \\
\hline & Maldives & $60 \%$ & $17 \%$ & $43 \%$ & 2017 & $1 \%$ & $2 \%$ & $-1 \%$ & 2006 & $4 \%$ & $2 \%$ & $2 \%$ & 2016 \\
\hline & Philippines & $40 \%$ & $31 \%$ & $9 \%$ & 2017 & $28 \%$ & $25 \%$ & $4 \%$ & 2013 & $7 \%$ & $9 \%$ & $-2 \%$ & 2016 \\
\hline & Thailand & $58 \%$ & $41 \%$ & $17 \%$ & 2016 & $20 \%$ & $18 \%$ & $2 \%$ & 2018 & $2 \%$ & $1 \%$ & $1 \%$ & 2019 \\
\hline \multirow{5}{*}{3} & Bangladesh & $20 \%$ & $28 \%$ & $-8 \%$ & 2019 & $7 \%$ & $13 \%$ & $-7 \%$ & 2019 & $21 \%$ & $8 \%$ & $13 \%$ & 2017 \\
\hline & Bhutan & $17 \%$ & $16 \%$ & $1 \%$ & 2020 & $7 \%$ & $13 \%$ & $-5 \%$ & 2017 & $29 \%$ & $13 \%$ & $16 \%$ & 2013 \\
\hline & India & $30 \%$ & $27 \%$ & $3 \%$ & 2019 & $7 \%$ & $13 \%$ & $-6 \%$ & 2011 & $23 \%$ & $13 \%$ & $10 \%$ & 2019 \\
\hline & Nepal & $14 \%$ & $13 \%$ & $1 \%$ & 2019 & $2 \%$ & $8 \%$ & $-6 \%$ & 2011 & $8 \%$ & $9 \%$ & $-1 \%$ & 2017 \\
\hline & Sri Lanka & $26 \%$ & $16 \%$ & $10 \%$ & 2019 & $15 \%$ & $13 \%$ & $2 \%$ & 2009 & $12 \%$ & $4 \%$ & $8 \%$ & 2018 \\
\hline \multirow{5}{*}{4} & Cambodia & $14 \%$ & $15 \%$ & $-1 \%$ & 2019 & $3 \%$ & $9 \%$ & $-7 \%$ & 2015 & $1 \%$ & $1 \%$ & $0 \%$ & 2014 \\
\hline & Lao PDR & $15 \%$ & $14 \%$ & $1 \%$ & 2019 & NA & NA & NA & NA & $7 \%$ & $7 \%$ & $0 \%$ & 2017 \\
\hline & Myanmar & $22 \%$ & $16 \%$ & $6 \%$ & 2018 & $2 \%$ & $3 \%$ & $-1 \%$ & 1983 & $1 \%$ & $1 \%$ & $0 \%$ & 2019 \\
\hline & PNG & $1 \%$ & $2 \%$ & $-1 \%$ & 1999 & NA & NA & NA & NA & $2 \%$ & $3 \%$ & $-1 \%$ & 2010 \\
\hline & Timor-Leste & $15 \%$ & $21 \%$ & $-6 \%$ & 2010 & NA & NA & NA & NA & $9 \%$ & $5 \%$ & $4 \%$ & 2016 \\
\hline \multirow{3}{*}{5} & Afghanistan & $5 \%$ & $14 \%$ & $-9 \%$ & 2018 & NA & NA & NA & NA & $31 \%$ & $12 \%$ & $19 \%$ & 2017 \\
\hline & Pakistan & $10 \%$ & $10 \%$ & $0 \%$ & 2018 & $11 \%$ & $11 \%$ & $0 \%$ & 2017 & $6 \%$ & $6 \%$ & $0 \%$ & 2018 \\
\hline & & \multicolumn{4}{|c|}{$\begin{array}{l}\text { World Development Indicators in World Bank Database: } \\
\text { (a) https://databank. Worldbank.org/reports.aspx?source=2 } \\
\text { \&series=SE.TER.ENRR.FE\&country= } \\
\text { (b) https://databank. Worldbank.org/reports.aspx?source=2 } \\
\text { \&series=SE.TER.ENRR.MA\&country= }\end{array}$} & \multicolumn{4}{|c|}{$\begin{array}{l}\text { World Development Indicators in World Bank Database: } \\
\text { (a) https://databank.worldbank.org/reports.aspx?source=2\&series=SE.TE } \\
\text { R.CUAT.ST.MA.ZS\&country= } \\
\text { (b) https://databank.worldbank.org/reports.aspx?source=2\&series=SE.TE } \\
\text { R.CUAT.ST.FE.ZS\&country= }\end{array}$} & \multicolumn{4}{|c|}{$\begin{array}{l}\text { World Development Indicators in World Bank Database } \\
\text { (a) https://databank.worldbank.org/reports.aspx?source=2\&series } \\
\text { =SL.UEM.ADVN.FE.ZS\&country= } \\
\text { (b) https://databank.worldbank.org/reports.aspx? } \text { ?source=2\&series } \\
\text { =SL.UEM.ADVN.MA.ZS\&country= }\end{array}$} \\
\hline
\end{tabular}




\section{Education system determinants}

Typology

1

2

3

4

5
Country

\begin{tabular}{|l|}
\hline China \\
\hline Japan \\
\hline Singapore \\
Viet Nam \\
\hline Fiji \\
\hline Indonesia \\
\hline Malaysia \\
\hline Maldives \\
\hline Philippines \\
\hline Thailand \\
\hline Bangladesh \\
\hline Bhutan \\
\hline India \\
\hline Nepal \\
\hline Sri Lanka \\
\hline Cambodia \\
\hline Lao PDR \\
\hline Myanmar \\
\hline PNG \\
\hline Timor-Leste \\
\hline Afghanistan \\
\hline Pakistan \\
\hline
\end{tabular}

Government expenditure on Government expenditure per student education (\% GDP)

(\% of GDP per capita)

\begin{tabular}{|c|c|c|c|c|c|c|c|c|}
\hline Data & Year & Primary & Secondary & Year & Primary & Year & Secondary & Year \\
\hline $3.5 \%$ & 2019 & NA & NA & NA & NA & NA & NA & NA \\
\hline $3.2 \%$ & 2017 & $24 \%$ & $24 \%$ & 2016 & NA & NA & NA & NA \\
\hline $2.9 \%$ & 2013 & NA & NA & NA & $98 \%$ & 2018 & $98 \%$ & 2018 \\
\hline $4.2 \%$ & 2019 & NA & NA & NA & NA & NA & NA & NA \\
\hline $3.9 \%$ & 2013 & $6 \%$ & $6 \%$ & 2011 & $100 \%$ & 2012 & $100 \%$ & 2012 \\
\hline $3.6 \%$ & 2015 & $11 \%$ & $11 \%$ & 2015 & NA & NA & NA & NA \\
\hline $4.2 \%$ & 2019 & $23 \%$ & $23 \%$ & 2018 & $97 \%$ & 2019 & $93 \%$ & 2018 \\
\hline $4.1 \%$ & 2016 & NA & NA & NA & $89 \%$ & 2019 & $94 \%$ & 2019 \\
\hline $3 \%$ & 2009 & $10 \%$ & $10 \%$ & 2000 & $100 \%$ & 2018 & $100 \%$ & 2018 \\
\hline $4.1 \%$ & 2013 & $18 \%$ & $18 \%$ & 2013 & $100 \%$ & 2019 & $100 \%$ & 2019 \\
\hline $1.3 \%$ & 2019 & NA & $10 \%$ & 2016 & $50 \%$ & 2017 & $61 \%$ & 2019 \\
\hline $6.9 \%$ & 2018 & $13 \%$ & $34 \%$ & 2014 & $100 \%$ & 2020 & $100 \%$ & 2018 \\
\hline $3.8 \%$ & 2013 & $17 \%$ & $17 \%$ & 2013 & $73 \%$ & 2019 & $76 \%$ & 2019 \\
\hline $5.1 \%$ & 2018 & $11 \%$ & $11 \%$ & 2015 & $97 \%$ & 2019 & $83 \%$ & 2019 \\
\hline $2.1 \%$ & 2018 & $22 \%$ & $22 \%$ & 2017 & $83 \%$ & 2018 & $79 \%$ & 2018 \\
\hline $2.2 \%$ & 2018 & $7 \%$ & NA & 2014 & $100 \%$ & 2019 & $99 \%$ & 2007 \\
\hline $2.9 \%$ & 2014 & $13 \%$ & $13 \%$ & 2014 & $97 \%$ & 2019 & $98 \%$ & 2019 \\
\hline $1.9 \%$ & 2019 & $10 \%$ & $10 \%$ & 2018 & $95 \%$ & 2018 & $89 \%$ & 2018 \\
\hline $1.9 \%$ & 2018 & NA & NA & NA & NA & NA & $100 \%$ & 2012 \\
\hline $6.8 \%$ & 2018 & $8 \%$ & $8 \%$ & 2014 & NA & NA & NA & NA \\
\hline $4.1 \%$ & 2017 & $10 \%$ & $11 \%$ & 2017 & NA & NA & NA & NA \\
\hline $2.9 \%$ & 2017 & $16 \%$ & $16 \%$ & 2015 & $77 \%$ & 2019 & NA & NA \\
\hline \multicolumn{2}{|c|}{$\begin{array}{l}\text { World Development Indicators in World Bank } \\
\text { Database: } \\
\text { https://databank.worldbank.org/reports.aspx?s } \\
\text { ource=2\&series=SE.XPD.TOTL.GD.ZS\&countr } \\
y=\end{array}$} & \multicolumn{3}{|c|}{$\begin{array}{l}\text { World Development Indicators in World Bank Data: } \\
\text { https://databank.worldbank.org/reports.aspx?source=2\& } \\
\text { series=SE.XPD.PRIM.PC.ZS }\end{array}$} & \multicolumn{4}{|c|}{$\begin{array}{l}\text { World Development Indicators in World Bank Data: } \\
\text { (a) https://databank.worldbank.org/reports.aspx?source=2\&series=SE.SE } \\
\text { C.TCAQ.ZS\&country= } \\
\text { (b) https://databank.worldbank.org/reports.aspx?source=2\&series=SE.PR } \\
\text { M.TCAQ.ZS\&country= }\end{array}$} \\
\hline
\end{tabular}


Typology

1

2

3

4

5
Country

China

Japan

Singapore

Viet Nam

Fiji

Indonesia

Malaysia

Maldives

Philippines

Thailand

Bangladesh

Bhutan

India

Nepal

Sri Lanka

Cambodia

Lao PDR

Myanmar

PNG

Timor-Leste

Afghanistan

Pakistan

\section{Pupil-teacher ratio}

\begin{tabular}{|l|l|}
\hline Primary & Year \\
16 & 2018 \\
\hline 16 & 2017 \\
15 & 2017 \\
20 & 2018 \\
\hline 28 & 2012 \\
\hline 17 & 2018 \\
\hline 12 & 2017 \\
\hline 10 & 2017 \\
\hline 29 & 2017 \\
\hline 17 & 2018 \\
\hline 30 & 2018 \\
\hline 35 & 2018 \\
\hline 33 & 2017 \\
\hline 20 & 2019 \\
\hline 22 & 2018 \\
\hline 42 & 2018 \\
\hline 22 & 2018 \\
\hline 24 & 2018 \\
\hline 36 & 2016 \\
\hline 27 & 2018 \\
\hline 49 & 2018 \\
\hline 20 & 2018 \\
\hline World & Development \\
\hline
\end{tabular}

\begin{tabular}{|l|l|}
\hline Secondary & Year \\
\hline 13 & 2018 \\
\hline 11 & 2017 \\
\hline 11 & 2017 \\
29 & 1998 \\
\hline 19 & 2012 \\
\hline 15 & 2018 \\
\hline 11 & 2018 \\
\hline 14 & 2003 \\
\hline 24 & 2017 \\
\hline 26 & 2018 \\
\hline 35 & 2018 \\
\hline 11 & 2018 \\
\hline 29 & 2018 \\
\hline 28 & 2019 \\
\hline 18 & 2018 \\
\hline 29 & 2007 \\
\hline 18 & 2018 \\
\hline 27 & 2018 \\
\hline 34 & 2016 \\
\hline 27 & 2018 \\
\hline NA & NA \\
\hline 20 & 2018 \\
\hline
\end{tabular}

Female literacy rate

Indicators in World Bank Data: World Development

\begin{tabular}{|l|l|l|l|}
\hline Age 15-24 & Age 15+ & Differential & year \\
\hline $100 \%$ & $95 \%$ & $5 \%$ & 2018 \\
\hline NA & NA & NA & NA \\
\hline $100 \%$ & $96 \%$ & $4 \%$ & 2018 \\
\hline $98 \%$ & $94 \%$ & $4 \%$ & 2018 \\
\hline $100 \%$ & $99 \%$ & $1 \%$ & 2017 \\
\hline $100 \%$ & $94 \%$ & $6 \%$ & 2018 \\
\hline $97 \%$ & $94 \%$ & $3 \%$ & 2018 \\
\hline $99 \%$ & $98 \%$ & $1 \%$ & 2016 \\
\hline $99 \%$ & $98 \%$ & $1 \%$ & 2015 \\
\hline $99 \%$ & $92 \%$ & $7 \%$ & 2018 \\
\hline $96 \%$ & $72 \%$ & $24 \%$ & 2019 \\
\hline $93 \%$ & $57 \%$ & $36 \%$ & 2017 \\
\hline $90 \%$ & $66 \%$ & $24 \%$ & 2018 \\
\hline $91 \%$ & $60 \%$ & $31 \%$ & 2018 \\
\hline $99 \%$ & $91 \%$ & $8 \%$ & 2018 \\
\hline $93 \%$ & $75 \%$ & $18 \%$ & 2015 \\
\hline $91 \%$ & $79 \%$ & $12 \%$ & 2015 \\
\hline $84 \%$ & $72 \%$ & $12 \%$ & 2017 \\
\hline $71 \%$ & $58 \%$ & $13 \%$ & 2010 \\
\hline $85 \%$ & $64 \%$ & $21 \%$ & 2018 \\
\hline $56 \%$ & $30 \%$ & $26 \%$ & 2018 \\
\hline $47 \%$ & $47 \%$ & $0 \%$ & 2017 \\
\hline World & Development $\%$ Indicators & in & World \\
\hline 6 Bank
\end{tabular}

TC.ZS\&country=

(b) https://databank. worldbank.org/reports.aspx?source=2\&series=SE.SEC.ENRL.T (b)

$y=$
(b) https
untry $=$ 


\section{Social determinants}

\begin{tabular}{|c|c|c|c|c|}
\hline Typology & Country & $\begin{array}{l}\text { Female working population } \\
\text { with advanced education (\%) }\end{array}$ & $\begin{array}{l}\text { GDP per capita in US dollars } \\
(2020)\end{array}$ & $\begin{array}{l}\text { Women who were first married by age } 18 \text { ( } \% \text { of women aged } \\
20-24)\end{array}$ \\
\hline \multirow{4}{*}{1} & China & NA & 10,500 & NA \\
\hline & Japan & 2019 & 40,113 & NA \\
\hline & Singapore & 2009 & 59,798 & 2020 \\
\hline & Viet Nam & 2020 & 2,786 & 2014 \\
\hline \multirow{6}{*}{2} & Fiji & 2016 & 4,882 & NA \\
\hline & Indonesia & 2019 & 3,870 & 2017 \\
\hline & Malaysia & 2016 & 10,402 & NA \\
\hline & Maldives & 2016 & 7,456 & 2017 \\
\hline & Philippines & 2016 & 3,299 & 2017 \\
\hline & Thailand & 2019 & 7,189 & 2019 \\
\hline \multirow{5}{*}{3} & Bangladesh & 2017 & 1,969 & 2019 \\
\hline & Bhutan & NA & 3,122 & 2010 \\
\hline & India & 2019 & 1,901 & 2016 \\
\hline & Nepal & 2017 & 1,155 & 2019 \\
\hline & Sri Lanka & 2018 & 3,682 & 2016 \\
\hline \multirow{5}{*}{4} & Cambodia & 2017 & 1,513 & 2014 \\
\hline & Lao PDR & 2017 & 2,630 & 2017 \\
\hline & Myanmar & 2019 & 1,400 & 2016 \\
\hline & PNG & 2010 & 2,637 & 2018 \\
\hline & Timor-Leste & 2016 & 1,381 & 2016 \\
\hline \multirow{3}{*}{5} & Afghanistan & 2017 & 508,8 & 2017 \\
\hline & Pakistan & $29 \% \quad 2018$ & 1,194 & $\begin{array}{ll}18 \% & 2018\end{array}$ \\
\hline & & $\begin{array}{l}\text { ILOSTAT Database in World Bank } \\
\text { Database: } \\
\text { https://data.worldbank.org/indicator/SL.TLF. } \\
\text { ADVN.FE.ZS }\end{array}$ & $\begin{array}{l}\text { World Bank national accounts data, and } \\
\text { OECD National Accounts data files in World } \\
\text { Bank Database: } \\
\text { https://data.worldbank.org/indicator/NY.GD } \\
\text { P.PCAP.CD }\end{array}$ & World Bank Data: https://data.worldbank.org/indicator/SP.M18.2024.FE.ZS \\
\hline
\end{tabular}


Typology

1

3

5
Country

\begin{tabular}{|l|l|}
\hline China & $42 \%$ \\
\hline Japan & $50 \%$ \\
\hline Singapore & $41 \%$ \\
\hline Viet Nam & $52 \%$ \\
\hline Fiji & $26 \%$ \\
\hline Indonesia & $40 \%$ \\
\hline Malaysia & $35 \%$ \\
\hline Maldives & $38 \%$ \\
\hline Philippines & $27 \%$ \\
\hline Thailand & $33 \%$ \\
\hline Bangladesh & $26 \%$ \\
\hline Bhutan & $32 \%$ \\
\hline India & $10 \%$ \\
\hline Nepal & $78 \%$ \\
\hline Sri Lanka & $20 \%$ \\
\hline Cambodia & $67 \%$ \\
\hline Lao PDR & $62 \%$ \\
\hline Myanmar & $40 \%$ \\
\hline PNG & $36 \%$ \\
\hline Timor-Leste & $38 \%$ \\
\hline Afghanistan & $21 \%$ \\
\hline Pakistan & $18 \%$ \\
\hline
\end{tabular}

Labour force participation Teenage mothers (\% of women aged 15-

rate for ages 15-24, female 19 who have had children or are Average household size (modelled ILO estimate, \%) currently pregnant)

(2019)

\begin{tabular}{|c|c|c|}
\hline $42 \%$ & NA & NA \\
\hline $50 \%$ & NA & NA \\
\hline $41 \%$ & NA & NA \\
\hline $52 \%$ & $3 \%$ & 2002 \\
\hline $26 \%$ & NA & NA \\
\hline $40 \%$ & $7 \%$ & 2017 \\
\hline $35 \%$ & NA & NA \\
\hline $38 \%$ & $2 \%$ & 2017 \\
\hline $27 \%$ & $9 \%$ & 2017 \\
\hline $33 \%$ & $11 \%$ & 1987 \\
\hline $26 \%$ & $28 \%$ & 2018 \\
\hline $32 \%$ & NA & NA \\
\hline $10 \%$ & $8 \%$ & 2016 \\
\hline $78 \%$ & $17 \%$ & 2016 \\
\hline $20 \%$ & $5 \%$ & 1987 \\
\hline $67 \%$ & $12 \%$ & 2014 \\
\hline $62 \%$ & $17 \%$ & 2005 \\
\hline $40 \%$ & $6 \%$ & 2016 \\
\hline $36 \%$ & $12 \%$ & 2018 \\
\hline $38 \%$ & $7 \%$ & 2016 \\
\hline $21 \%$ & $12 \%$ & 2015 \\
\hline $18 \%$ & $8 \%$ & 2018 \\
\hline
\end{tabular}

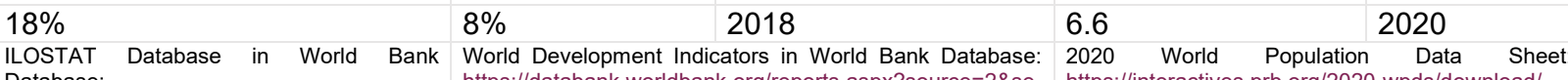

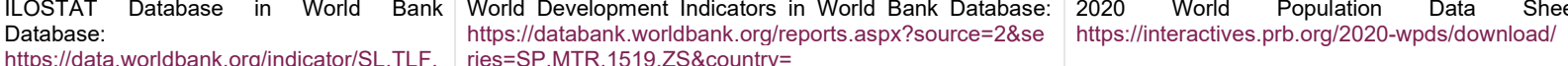
ACTI.1524.FE.ZS

$\begin{array}{ll}\text { NA } & \text { NA } \\ 2.4 & 2020 \\ 3.3 & 2020 \\ 3.9 & 2020 \\ 4.8 & 2020 \\ 4 & 2020 \\ 4.2 & 2020 \\ 5.3 & 2020 \\ 4.2 & 2020 \\ \text { NA } & \text { NA } \\ 4.3 & 2020 \\ 4.2 & 2020 \\ 4.6 & 2020 \\ 4.2 & 2020 \\ 3.9 & 2020 \\ 4.6 & 2020 \\ 5.3 & 2015 \\ 4.2 & 2020 \\ 5 & 2020 \\ 5.3 & 2020 \\ 8 & 2020 \\ 6.6 & 2020 \\ 2020 & \text { World }\end{array}$




\section{Annexe 2}

\section{Government policies and plans relating to gender equality in education}

\begin{tabular}{|c|c|}
\hline Afghanistan & $\begin{array}{l}\text { Gender and education specific plans/policies/legislation }{ }^{16} \\
\text { Action plan to prevent gender-based violence and support children (date unknown). } \\
\text { National Education Strategic Plan (2017-2021): } \\
\text { - There is a focus on addressing the shortage of female teachers in schools. } \\
\text { - Commits to developing strategies and equitable solutions to integrate disadvantaged groups in the national system. } \\
\text { Draft Girls' Education Policy (2017): } \\
\text { - Includes efforts to specifically improve the implementation of WASH infrastructure in schools. } \\
\text { Community Based Education Policy and Guidelines (2018): } \\
\text { - Focuses on improving girls' education participation in rural areas. } \\
\text { National Action Plan to Eliminate Early and Child Marriage (2017). } \\
\text { Part of the Regional Action Plan to End Child Marriage (South Asia Initiative to End Violence Against Children). } \\
\text { International conventions }{ }^{17} \\
\text { - State party to CEDAW with no reservations. } \\
\text { - State party to CADE. } \\
\text { - State party to ICESCR. }\end{array}$ \\
\hline
\end{tabular}

16 These plans/policies/legislations were found through scoping of each country's Ministry of Education website where these were available in English, and a rapid search of other sources such as the Global Partnership for Education website (https://www.globalpartnership.org). As this was a rapid scoping exercise, it is acknowledged that all relevant policies/programmes may not have been found and included.

17 See https://www.right-to-education.org/sites/right-to-education.org/files/resource-attachments/RTE_Country_commitments_gender_equality_education_2018.pdf 


\begin{tabular}{|c|c|}
\hline & $\begin{array}{l}\text { Constitutional status of the right to education } \frac{18}{2} \\
\text { Directive principle/aspirational right to education. }\end{array}$ \\
\hline Bangladesh & 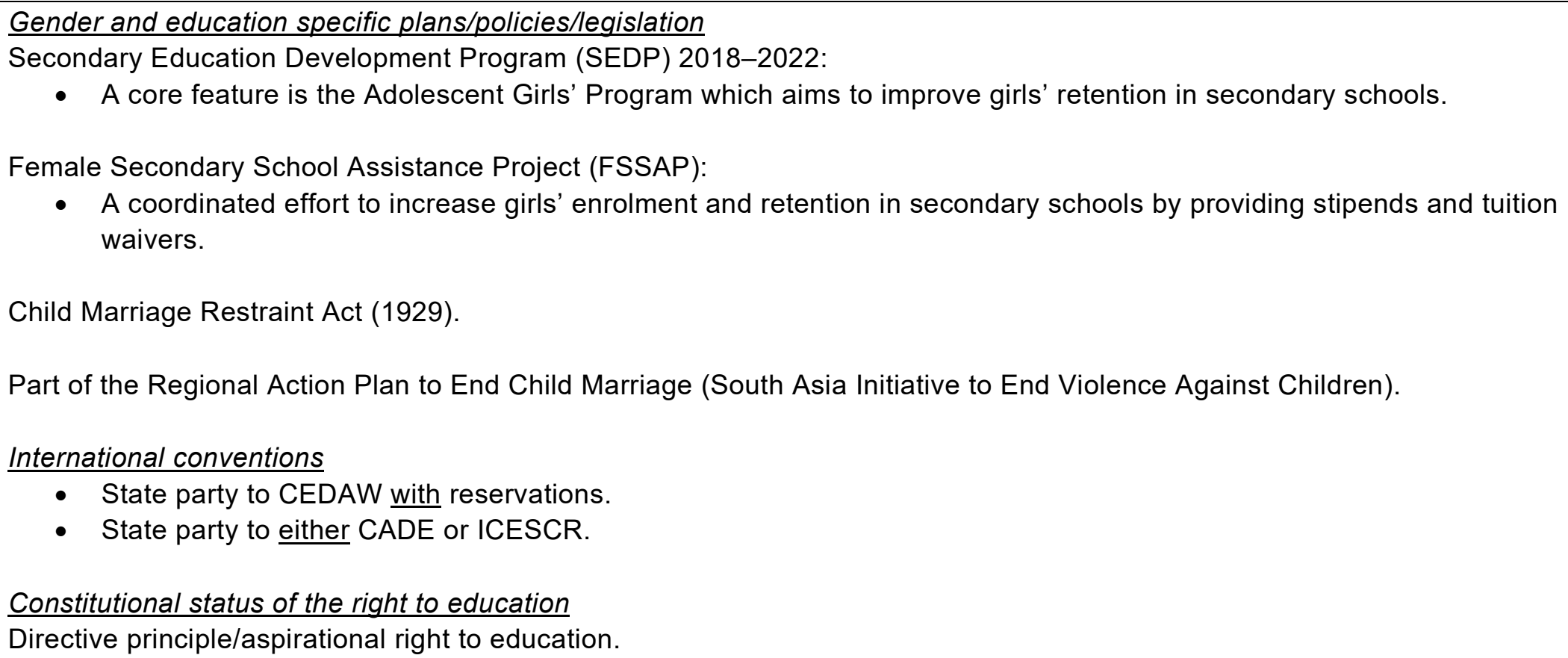 \\
\hline Bhutan & $\begin{array}{l}\text { Gender and education specific plans/policies/legislation } \\
\text { The Bhutan Education Blueprint (2014-2024): } \\
\text { - Emphasises that education without equity is a risk to economic and social disparities. } \\
\text { - It has given priority to girls' education, and specifically girls' educational outcomes and life transitions. } \\
\text { Part of the Regional Action Plan to End Child Marriage (South Asia Initiative to End Violence Against Children). }\end{array}$ \\
\hline
\end{tabular}

${ }^{18}$ See https://www.right-to-education.org/sites/right-to-education.org/files/resource-attachments/RTE_Accountability_from_a_human_rights_perspective_2017_en.pdf 


\begin{tabular}{|c|c|}
\hline & $\begin{array}{l}\frac{\text { International conventions }}{\bullet \quad \text { State party to CEDAW with no reservations. }} \\
\frac{\text { Constitutional status of the right to education }}{\text { Directive principle/aspirational right to education. }}\end{array}$ \\
\hline Cambodia & $\begin{array}{l}\text { Gender and education specific plans/policies/legis/ation } \\
\text { National Education for All programme (2000-2015): } \\
\text { - Focused on expanding education opportunities for poor communities and girls. } \\
\text { Education Strategic Plan (2019-2023): } \\
\text { - A key priority is to strengthen gender equality and promote gender-responsive, inclusive learning environments. } \\
\text { Provincial Action Plans to Prevent Child Marriage and Teenage Pregnancies. } \\
\text { International conventions } \\
\text { - State party to CEDAW with no reservations. } \\
\text { Constitutional status of the right to education } \\
\text { Justiciable right to education. }\end{array}$ \\
\hline China & $\begin{array}{l}\text { Gender and education specific plans/policies/legislation } \\
\text { Compulsory Education Law of the People's Republic of China (1986). } \\
\text { International conventions } \\
\text { - State party to CEDAW with no reservations. } \\
\text { - State party to CADE. } \\
\text { Constitutional status of the right to education }\end{array}$ \\
\hline
\end{tabular}




\begin{tabular}{|c|c|}
\hline & Directive principle/aspirational right to education. \\
\hline Fiji & 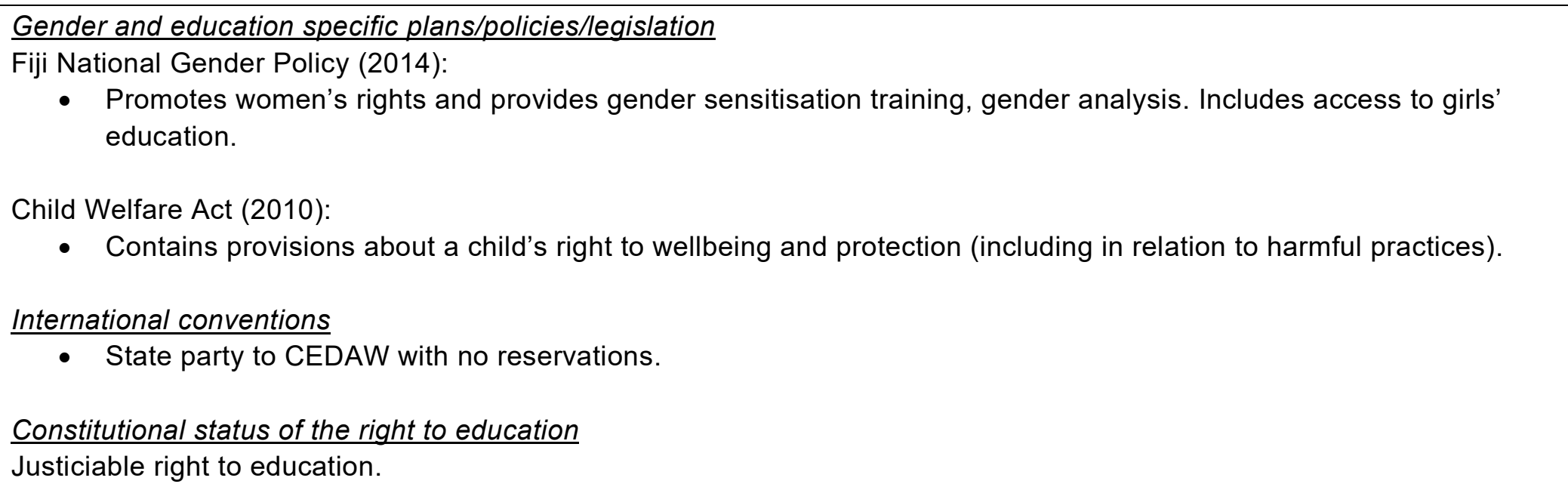 \\
\hline India & $\begin{array}{l}\text { Gender and education specific plans/policies/legislation } \\
\text { Right to Education Act ( } 2009 \text { ): } \\
\text { - Mandated that it is the right of every child to obtain a minimum amount of education. } \\
\text { Formula Funding (Savra Shiksha Abhiyan programme): } \\
\text { - To ensure that the most disadvantaged are not left behind. } \\
\text { Part of the Regional Action Plan to End Child Marriage (South Asia Initiative to End Violence Against Children). } \\
\text { Beti bachao, beti padhao (Save daughters, educate daughters) initiative by the Ministry of Women and Child Development, } \\
\text { the Ministry of Health and Family Welfare, and the Ministry of Human Resources. } \\
\text { International conventions: } \\
\text { - State party to CEDAW with reservations. } \\
\text { - State party to either CADE or ICESCR. }\end{array}$ \\
\hline
\end{tabular}




\begin{tabular}{|c|c|}
\hline & $\begin{array}{l}\text { Constitutional status of the right to education } \\
\text { Justiciable right to education. }\end{array}$ \\
\hline Indonesia & $\begin{array}{l}\text { Gender and education specific plans/policies/legislation } \\
\text { The Law on National Education (No. 20/2003) and Constitution Amendment III: } \\
\text { - Emphasises that all Indonesian citizens have the right to education. } \\
\text { [Other plans were present but not available in English] } \\
\text { International conventions } \\
\text { - State party to CEDAW with no reservations. } \\
\text { - State party to CADE. } \\
\text { Constitutional status of the right to education } \\
\text { Justiciable right to education. }\end{array}$ \\
\hline Japan & $\begin{array}{l}\frac{\text { Gender and education specific plans/policies/legislation }}{\text { [Plans/policies were present but not available in English] }} \\
\frac{\text { International conventions }}{\text { - State party to CEDAW with no reservations. }} \\
\text { - State party to either CADE or ICESCR. } \\
\text { Constitutional status of the right to education } \\
\text { Justiciable right to education. }\end{array}$ \\
\hline Lao PDR & $\begin{array}{l}\text { Gender and education specific plans/policies/legislation: } \\
\text { Education Sector Development Plan (2016-2020): } \\
\quad \text { - Gender parity is integrated throughout. } \\
\text { International conventions }\end{array}$ \\
\hline
\end{tabular}




\begin{tabular}{|c|c|}
\hline & $\begin{array}{l}\text { - State party to CEDAW with no reservations. } \\
\text { - State party to either CADE or ICESCR. } \\
\text { Constitutional status of the right to education } \\
\text { Directive principle/aspirational right to education. }\end{array}$ \\
\hline Malaysia & $\begin{array}{l}\text { Gender and education specific plans/policies/legislation } \\
\text { Eleventh Malaysia Plan (2016-2020): } \\
\text { - Focus on increasing female labour force participation } \\
\text { Malaysia Education Blueprint 2015-2025 (Higher Education): } \\
\text { - Reference to gender equality in numerous aspects of the plan. } \\
\frac{\text { International conventions }}{\text { - State party to CEDAW with reservations. }} \\
\frac{\text { Constitutional status of the right to education }}{\text { No right to education. }}\end{array}$ \\
\hline Maldives & $\begin{array}{l}\text { Gender and education specific plans/policies/legislation } \\
\text { Education Sector Plan (2019-2023): } \\
\text { - Explicitly states addressing the gender gap in education as a key concern. } \\
\text { National Gender Policy (2016-2021). } \\
\text { Part of the Regional Action Plan to End Child Marriage (South Asia Initiative to End Violence Against Children). } \\
\text { International conventions } \\
\text { Constitutional status of the right to education }\end{array}$ \\
\hline
\end{tabular}




\begin{tabular}{|c|c|}
\hline & Justiciable right to education. \\
\hline Myanmar & $\begin{array}{l}\text { Gender and education specific plans/policies/legislation } \\
\text { Education Sector Plan (2016-2021): } \\
\text { - Very limited mention of gender/girls' education specifically. } \\
\frac{\text { International conventions }}{\bullet \quad \text { State party to CEDAW with no reservations. }} \\
\frac{\text { Constitutional status of the right to education }}{\text { Justiciable right to education. }}\end{array}$ \\
\hline Nepal & $\begin{array}{l}\text { Gender and education specific plans/policies/legislation } \\
\text { Nepal School Sector Development Plan (2016-2023): } \\
\text { - Strategies to address gender disparities are included throughout. } \\
\text { Part of the Regional Action Plan to End Child Marriage (South Asia Initiative to End Violence Against Children). } \\
\text { International conventions } \\
\text { - State party to CEDAW with no reservations. } \\
\text { Constitutional status of the right to education } \\
\text { Justiciable right to education. }\end{array}$ \\
\hline Pakistan & $\begin{array}{l}\text { Gender and education specific plans/policies/legislation: } \\
\text { - Education sector plans per province: Sindh, Balochistan, Punjab. } \\
\text { - Equity is a cross-cutting theme, including gender equality. } \\
\text { Formula Funding (National Finance Commission Award programme): } \\
\text { - To ensure that the most disadvantaged are not left behind. }\end{array}$ \\
\hline
\end{tabular}




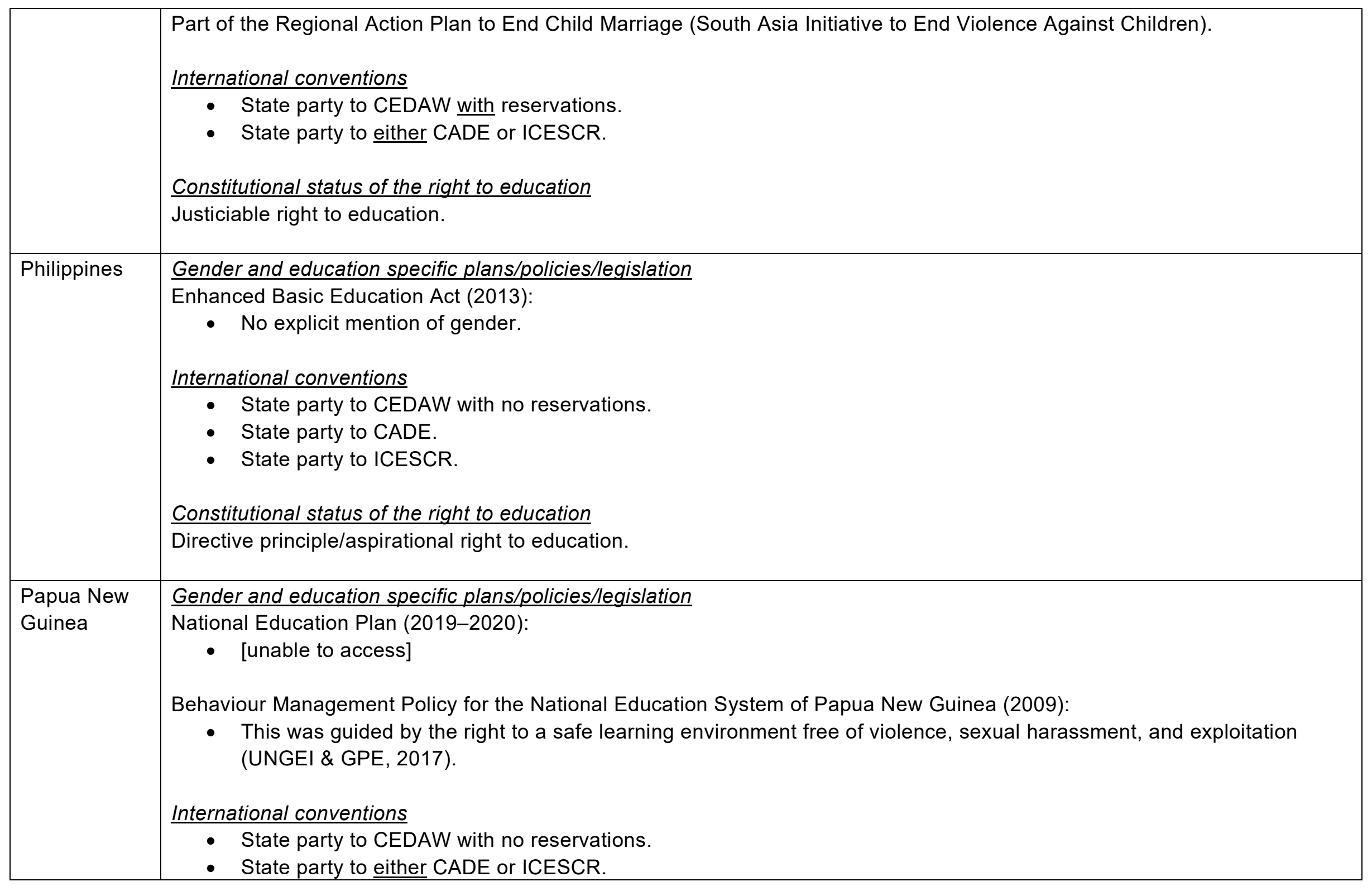




\begin{tabular}{|c|c|}
\hline & $\frac{\text { Constitutional status of the right to education }}{\text { No right to education. }}$ \\
\hline Singapore & $\begin{array}{l}\text { Gender and education specific plans/policies/legislation } \\
\text { Numerous plans and policies, multiple references to gender although no gender-specific policies were found. } \\
\frac{\text { International conventions }}{\bullet \quad \text { State party to CEDAW with reservations. }} \\
\frac{\text { Constitutional status of the right to education }}{\text { No right to education. }}\end{array}$ \\
\hline Sri Lanka & $\begin{array}{l}\text { Gender and education specific plans/policies/legislation } \\
\text { National Policy on Preschool Education (2019): } \\
\text { - Limited references to gender. } \\
\text { National Policy on Technical and Vocational Education (2018): } \\
\text { - No reference to gender. } \\
\text { Formula Funding (Education Quality Inputs programme): } \\
\text { - To ensure that the most disadvantaged are not left behind. } \\
\text { Part of the Regional Action Plan to End Child Marriage (South Asia Initiative to End Violence Against Children). } \\
\text { International conventions } \\
\text { - State party to CEDAW with no reservations. } \\
\text { - State party to CADE. } \\
\text { Constitutional status of the right to education } \\
\text { Directive principle/aspirational right to education. }\end{array}$ \\
\hline
\end{tabular}




\begin{tabular}{|c|c|}
\hline Taiwan & $\begin{array}{l}\text { Gender and education specific plans/policies/legis/ation } \\
\text { Multiple policies available on the MoE's website - none explicitly related to gender, but many with references to gender. } \\
\frac{\text { International conventions }}{\bullet \quad \text { Unknown. }} \\
\frac{\text { Constitutional status of the right to education }}{\text { Unknown. }}\end{array}$ \\
\hline Thailand & $\begin{array}{l}\frac{\text { Gender and education specific plans/policies/legislation }}{\text { [Plans/policies were present, but difficult to access] }} \\
\text { International conventions } \\
\text { - State party to CEDAW with no reservations. } \\
\text { Constitutional status of the right to education } \\
\text { Justiciable right to education. }\end{array}$ \\
\hline Timor-Leste & $\begin{array}{l}\text { Gender and education specific plans/policies/legislation } \\
\text { Education Sector Plan (2011-2030): } \\
\text { - General education goals include gender equality, but gender parity is more often referenced throughout the document. } \\
\text { International conventions } \\
\text { - State party to CEDAW with no reservations. } \\
\text { Constitutional status of the right to education } \\
\text { Justiciable right to education. }\end{array}$ \\
\hline Viet Nam & Gender and education specific plans/policies/legislation \\
\hline
\end{tabular}




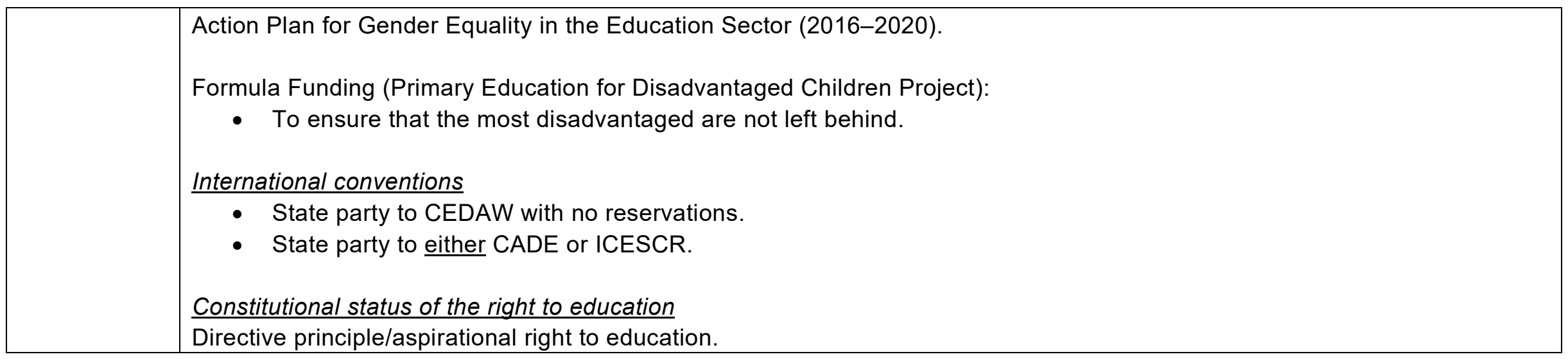

